Portland State University

PDXScholar

Spring 6-7-2019

\title{
Examining the Development and Classroom Dynamics of Student Disaffection Over Multiple Time Periods: Short-term Episodes and Long-term Trajectories
}

Emily Anne Saxton

Portland State University

Follow this and additional works at: https://pdxscholar.library.pdx.edu/open_access_etds

Part of the Educational Psychology Commons

Let us know how access to this document benefits you.

\section{Recommended Citation}

Saxton, Emily Anne, "Examining the Development and Classroom Dynamics of Student Disaffection Over Multiple Time Periods: Short-term Episodes and Long-term Trajectories" (2019). Dissertations and Theses. Paper 5006.

https://doi.org/10.15760/etd.6882

This Dissertation is brought to you for free and open access. It has been accepted for inclusion in Dissertations and Theses by an authorized administrator of PDXScholar. Please contact us if we can make this document more accessible: pdxscholar@pdx.edu. 
Examining the Development and Classroom Dynamics of Student Disaffection Over Multiple Time Periods: Short-term Episodes and Long-term Trajectories

by

Emily Anne Saxton

A dissertation submitted in partial fulfillment of the requirements for the degree of

Doctor of Philosophy

in

Applied Psychology

Dissertation Committee:

Ellen Skinner, Chair

Karlyn Adams-Wiggins

Dara Shifrer

Joel Steele

Portland State University

2019 
Abstract i

\begin{abstract}
Student disaffection, a pervasive problem in middle school classrooms, is costly not only for disaffected students themselves (e.g., declines in GPA, high school drop out) but also for their teachers (e.g., stress-related health outcomes). Despite its importance, however, open questions remain regarding both the development of disaffection during early adolescence and the classroom dynamics that underlie changes in disaffection. This dissertation includes two free-standing manuscripts that explore these open questions regarding the development and classroom dynamics of disaffection. Each focuses on different developmental time scales and employs different methodological approaches to examine these important, but unanswered questions.

Drawing from a database of classroom observation videos, study one is a multiple case study focusing on four classrooms, which were selected based on school-level socioeconomic status and student-reported disaffection. This study was designed to explore 1) how disaffection is first initiated, 2) how it develops across single class periods, 3) how teachers generally respond to student disaffection, and 4) whether different kinds of teacher responses reduce or amplify disaffection. Student disaffection and teacher responses to disaffection were observationally coded and analyzed resulting in the following findings. First, students were initially most frequently socially off task during individual work time or relatively passive whole group time. Second, six patterns of how disaffection changed over the observed class periods were found with each pattern representing distinct student experiences and varying degrees in severity of disaffection. Third, while teacher's overall responses to disaffection could be classified as
\end{abstract}


generally supportive (involvement and autonomy support) or defensive (withdrawal and controlling behavior), the teachers were not strictly adherent to one response style. Finally, five kinds of teacher responses to disaffection (supportive, quick fix, no response, mixed, and defensive) were found, each with varying degrees of effectiveness at resolving disaffection.

Drawing from a 5-year longitudinal cohort-sequential dataset, study two is designed to describe the normative trajectories of disaffection across the early adolescent years and then to also examine the classroom dynamics that underlie these developmental changes in disaffection. Surveys of student's experiences of disaffection and perceptions of their relationships with their science teachers and teacher's views of student disaffection were collected twice per school year and subsequently analyzed. Latent growth curve models examined the development of disaffection finding both behavioral and emotional forms to have gradually increasing linear trajectories across the early adolescent years. Additionally, both initial levels in fall of $6^{\text {th }}$ grade and rates of change significantly differed between students. Regarding the classroom dynamics of disaffection, the supported model suggests that teacher views of disaffection directly and indirectly through student-teacher relationships predict concurrent student experiences of disaffection and that earlier student experiences of disaffection predict changes in teacher views of disaffection across the school year.

Taken together, the studies in this dissertation contribute to our growing understanding of how disaffection develops both across single middle school class periods (study 1) and across early adolescence (study 2). Additionally, these studies are 


\begin{abstract}
iii
among the first to investigate the classroom dynamics that may explain why disaffection develops over these multiple time frames. Implications of each study and the collective findings of this dissertation are considered in the respective discussion sections in
\end{abstract} Chapter 3, 4, and 5. 


\section{Table of Contents}

\begin{tabular}{|c|c|c|}
\hline Chapter & Chapter Title/Subtitle & Page \\
\hline & Abstract & $\mathrm{i}$ \\
\hline & List of Tables & vi \\
\hline & List of Figures & vii \\
\hline 1 & Introduction & 1 \\
\hline \multirow[t]{16}{*}{2} & Literature Review & 10 \\
\hline & How is Student Disaffection Defined and Measured? & 11 \\
\hline & $\begin{array}{l}\text { The multidimensional phenomenon of student } \\
\text { disaffection. }\end{array}$ & 11 \\
\hline & Measurement of disaffection. & 16 \\
\hline & $\begin{array}{l}\text { What is known about the Consequences, Development, and } \\
\text { Dynamics of disaffection? }\end{array}$ & 30 \\
\hline & Consequences of disaffection & 30 \\
\hline & Consequences for students & 30 \\
\hline & Consequences for teachers & 34 \\
\hline & Development of Disaffection in Adolescence & 34 \\
\hline & $\begin{array}{l}\text { Development of disaffection within single school } \\
\text { years. }\end{array}$ & 35 \\
\hline & Development of disaffection across multiple years. & 36 \\
\hline & $\begin{array}{l}\text { Interindividual differences in the development of } \\
\text { disaffection. }\end{array}$ & 40 \\
\hline & $\begin{array}{l}\text { Classroom Dynamics of Disaffection: the role of student- } \\
\text { teacher relationships }\end{array}$ & 41 \\
\hline & $\begin{array}{l}\text { How does a student's relationship with their teacher } \\
\text { impact their disaffection? }\end{array}$ & 41 \\
\hline & $\begin{array}{l}\text { How does a student's disaffection influence their } \\
\text { relationships with their teachers? }\end{array}$ & 45 \\
\hline & Summary & 46 \\
\hline
\end{tabular}


Purpose

Study Aims and Research Questions 54

Research Design and Methods $\quad 55$

Design and Procedure $\quad 55$

Sample: Selection of cases 56

Data Sources $\quad 57$

Analysis Plan $\quad 58$

$\begin{array}{ll}\text { Findings } & 66\end{array}$

$\begin{array}{ll}\text { Discussion } & 98\end{array}$

$\begin{array}{ll}\text { Purpose } & 114\end{array}$

Study Aims and Research Questions $\quad 126$

$\begin{array}{ll}\text { Research Design and Methods } & 127\end{array}$

$\begin{array}{ll}\text { Participants } & 127\end{array}$

$\begin{array}{ll}\text { Design and Procedure } & 128\end{array}$

$\begin{array}{ll}\text { Measures } & 129\end{array}$

Analysis Plan 131

Results 132

Discussion 142

$\begin{array}{lll}5 & \text { Discussion } & 156\end{array}$

$\begin{array}{ll}\text { Strengths } & 156\end{array}$

Limitations $\quad 159$

Overarching Implications 161

$\begin{array}{ll}\text { References } & 167\end{array}$

Appendix A: Study 1 - Item by Construct Tables 184

Appendix B: Study 2 Item by Construct Tables 185 


\section{List of Tables}

Table Title Page

$2.1 \quad$ Different Behavioral and Emotional Forms of Student Disaffection 13

$2.2 \quad$ Student-Report Measures of Disaffection 18

2.3 Teacher-Report Measures of Disaffection 21

2.4 Summary of Correlations between Different Operationalization's of 33 Disaffection and Metrics of Academic Performance

2.5 Summary of Findings for Changes in Disaffection Within the Same 36 School Year

2.6 Summary of Findings for Changes in Disaffection Across the 39 Adolescent Years

2.7 Summary of Correlations between Student-reported Disaffection and Student-teacher Relationships

3.1 Observation Codes for Teacher Autonomy Support and Control 61

3.2 Observation Codes for Teacher Involvement and Withdrawal 63

3.3 Observation Codes for Teacher Proactive and Reactive Classroom 64 Management

3.4 Observation Codes for Student Disaffection 65

3.5 Teacher Responses to Disaffected Students 83

4.1 The Data Collection Design of the Study 129

4.2 Descriptive Statistics (Means, Standard Deviations, and Range) and 134 Internal Consistencies (Alpha, $\alpha$ and Omega, $\omega$ ) for all Scales at Each Measurement Wave

4.3 Correlations Between Student Experience of Disaffection (SR),

Teacher Views of Disaffection (TR), and Student-teacher Relationships (SR) Scales

4.4 Measurement Invariance of the Behavioral and Emotional Disaffection (SR) Scales

4.5 Behavioral and Emotional Disaffection: Comparisons of Unconditional Latent Growth Model Fit

4.6 Model Estimates for Unconditional Linear Latent Growth Curve Models 


\section{List of Figures}

Figure Title Page

1.1 Multiple time-scales represented in the two studies of this dissertation

3.1 Hypothesized model of the dynamics of student disaffection: defensive and supportive cycles of teacher interpretation and responses to signs of student disaffection

3.2 Final model of the classroom dynamics of disaffection 105

4.1 The classroom dynamics model of disaffection $\quad 122$

4.2 Student's predicted and observed behavioral (BD) and emotional (ED) disaffection trajectories from fall of $6^{\text {th }}$ grade to spring of $8^{\text {th }}$ grade

4.3 Latent structural model depicting the classroom dynamics of disaffection 
Introduction 1

\section{Chapter 1: Introduction}

Disaffection is, unfortunately, a commonplace experience for many adolescent students. Although there are times when students' experiences of disaffection are fleeting, parents and educators fear that persistent, prolonged disaffection acts as a marker of more severe declines in motivation that will eventually undercut learning and achievement and lead students to dislike school, skip classes, and ultimately drop out. School administrators also worry about student disaffection, not only because of its serious implications for students, but also because of its implications for their teaching staff: Some forms of disaffection (e.g., disruptive behavior, misbehavior) are ranked high by teachers as job-related stressors (Kyriacou, 2001). If teachers are unable to effectively reverse disaffection, these stressors may wear on teachers over time and lead to burnout (Chang, 2009). Disaffection is, therefore, costly for both students and their teachers.

Given the importance of student disaffection to many educational stakeholders, it is surprising how little research addresses it explicitly. There are two primary reasons why research to date has largely overlooked disaffection: 1) prior research has emphasized adaptive motivational constructs (i.e., engagement) at the expense of maladaptive constructs (i.e., disaffection), and 2) when disaffection is examined, it is typically investigated under many different names, which widely disperses studies across areas concerned with very different topics (e.g., student motivation, academic emotions, teacher classroom management strategies). On the one hand, the last few decades of motivational and educational research have focused more strongly on the construct of engagement, to the relative neglect of the study of disaffection. This emphasis on 
engagement may stem from assumptions researchers hold about how engagement and disaffection are connected; which, in turn, have implications for how engagement and disaffection are operationalized. One possible assumption is that high levels of disaffection are equivalent to low levels of engagement; this assumption could lead researchers to measure engagement alone without seeing a need for any explicit assessment of disaffection (e.g., Jang, Reeve, \& Deci, 2010; Martin \& Rimm-Kaufman, 2015; Poorthuis et al., 2015; Ream \& Rumberger, 2008). Other researchers may assume that engagement and disaffection belong on a single continuum (Reschly \& Christenson, 2012), which may explain why a number of studies include disaffection in their operationalization of engagement by reverse coding disaffection items and including them in composite engagement scores (e.g., Archambault, Janosz, Morizot, \& Pagani, 2009; Lee \& Reeve, 2012). Regardless, these common practices make it impossible to isolate the construct of disaffection in study findings - either because it is missing or because it is combined with engagement. As a result, the now substantial literature on student engagement contributes relatively few findings that add to our understanding of disaffection.

On the other hand, there is also a lack of consistent terminology associated with the broad phenomenon of disaffection. Research on disaffection is found under a variety of labels and is broadly distributed across the motivational and educational literatures. While each of these lines of research is valuable in its own right, it is only when they are drawn together and synthesized that a clear picture of the phenomenon of disaffection comes into view. To accomplish just that, disaffection is used as an umbrella term in this 
dissertation to combine relevant findings on student disengagement, disruptive behavior, misbehavior, defiance, and academic emotions such as boredom, anxiety, and frustration.

Once the literature is refocused through a broad "disaffection lens", the consequences of disaffection are much easier to discern. In the short-term, disaffection interferes with students' academic functioning including their final grades or GPAs (Gonzalez, Garrido, Castro, \& Rodríguez, 2015; Gonzalez \& Paoloni, 2014; King, 2015), academic coping (Skinner, Pitzer, \& Steele, 2016), and educational aspirations (Green, Martin, \& Marsh, 2007). In the long term, some forms of disaffection (i.e., misbehavior) in middle school increase the likelihood of high school drop out (Balfanz, Herzog, \& Mac Iver, 2007; Rumberger \& Lim, 2008). Long-term prospects are dim for high school dropouts who have lower incomes, fewer job opportunities, greater substance use, and a greater likelihood of involvement in some forms of crime (Henry, Knight, \& Thornberry, 2012).

Student disaffection is also costly for teachers. Chang (2009) notes that student disaffection is among the principal factors contributing to teacher burnout, which in turn has negative outcomes for the individual teacher (e.g., negative physiological stressrelated health outcomes and lower job satisfaction) as well as the teaching profession as a whole (e.g., increased absenteeism and ultimately teacher turnover) (Chang, 2009; Maslach, Schaufeli, \& Leiter, 2001). Kyriacou (2001) casts burnout as an outcome of teachers' ineffective coping with stress over time, implying that the ways in which teachers respond to student disaffection may help determine how costly disaffection is for both teachers and their students. 
Because of its potential consequences for both students and teachers, it is important for virtually every participant and stakeholder in school systems that we understand more about how disaffection develops and what classroom dynamics amplify or reverse it. Unfortunately, however, research on both of these topics is thin. Most quantitative studies of disaffection rely heavily on correlational (e.g., Guevenc, 2015) and cross-sectional (e.g., Green, Martin, \& Marsh, 2007) study designs, which do not answer open questions regarding either development or dynamics. Additionally, quite a few longitudinal studies include disaffection as an outcome (e.g., Gonzalez \& Paoloni, 2014) or predictor (e.g., Peklaj, Kalin, Pecjak, Zuljan, \& Levpuscek, 2012), but these studies stop short of modeling changes in disaffection; again, precluding the examination of questions regarding the development and dynamics of disaffection.

Regarding its development, particularly during the early adolescent years, only a small number of studies have examined changes in disaffection within single years (e.g., Skinner, Furrer, Marchand, \& Kindermann, 2008) or across multiple school years (e.g., Martin, Way, Bobis, \& Anderson, 2015). Fewer still have shed light on whether individual students differ in how their disaffection develops over the early adolescent years (e.g., Ahmed van der Werf, Kuyper, and Minnaert, 2013). Furthermore, few of these studies employ modeling frameworks, such as latent growth curve models, that allow for the simultaneous modeling of average disaffection trajectories as well as individual differences in those trajectories (Singer \& Willett, 2003; McArdle \& Grimm, 2010). 
Regarding the classroom dynamics of disaffection, some research has pointed to everyday classroom life as a key explanatory factor for the development of disaffection (Martin et al., 2015; Riley \& Docking, 2004). Within the walls of the classroom, social interactions, such as those that happen every day between students and teachers (Bronfenbrenner \& Morris, 1998), are thought to be a primary driver of the development of disaffection. Research to date has demonstrated bivariate links between student disaffection and student-teacher relationships (e.g., Galand \& Hospel, 2013; Guvenc, 2015); however, no studies to date have examined how these phenomena interact dynamically over time.

\section{Dissertation Overview}

To address these gaps, both studies in this dissertation focus jointly on the development and classroom dynamics of disaffection during early adolescence. Study one is a multiple-case study that first selected cases based, in part, on students' report of their own disaffection; then moment-to-moment interactions surrounding episodes of disaffection were observed and qualitatively coded. The first goal of this study was to investigate how disaffection is initially sparked as well as how it develops across single class periods. A second goal was to examine the interactions between students and teachers that surround these episodes of disaffection to uncover the classroom dynamics that amplify or reverse disaffection.

Similarly, study two had two overarching goals focused on the development of disaffection across the early adolescent years and the classroom dynamics of disaffection within single school years. First, this study sought to add to our growing knowledge of 
how disaffection develops over the early adolescent years by using growth curve modeling to chart normative trajectories of disaffection. At the same time, this study sought to extend what is known about the development of disaffection by modeling differences between students' growth trajectories. Secondly, this study examined the classroom dynamics of disaffection with a series of structural models that tested for both concurrent and reciprocal effects between student disaffection, both as experienced by students and as viewed by teachers, and student-teacher relationships.

Overall, four unifying themes draw together the proposed studies in this dissertation. First, as a result of the serious and negative implications of disaffection for both student academic success and teacher well-being, this dissertation assumes that the study of disaffection on its own, and not as part of engagement, is important and worthwhile. Second, in this dissertation, disaffection is conceptualized as a multidimensional, state-like construct, based on the assumption that student disaffection in classroom settings can take on a variety of forms and fluctuate over time. For instance, students can experience feelings of boredom in school, which may lead to inattentive behaviors, or, alternatively, students may experience emotions of frustration accompanied by disruptive behavior. These various behavioral and emotional forms of disaffection fluctuate over time such that an adolescent may experience occasional bouts of boredom and inattention throughout the school year, anxiety before a big exam, frustration about the lack of relevance of a particular topic to their life outside of school, and a strong aversion to a particular type of classroom activity (e.g., group work). This multidimensional, state-like conceptualization of disaffection carries with it the 
assumption that there is no such thing as a consistently, permanently, and irrevocably disaffected student; instead, disaffection is conceptualized as an ever-changing set of behaviors and emotions that are, in part, dependent on features of the learning environment, chief among them relationships with teachers. The assumption that disaffection is plastic or malleable, which can be contrasted with notions of disaffection as a persistent trait, provides a conceptualization that invites questions about how and why it changes, that is, about the development and dynamics of disaffection.

The third theme emphasizes the importance of including different perspectives (students, teachers, observers) in the study of disaffection. Different approaches to measuring disaffection are associated with unique strengths and limitations and, ideally, these need to be carefully balanced with the use of multiple informants (Pekrun \& Buhner, 2014). However, a particular limitation of prior work on disaffection is its overreliance on single reporters of disaffection. Thus far there has been a heavy reliance on student or teacher report of disaffection either through interviews or surveys from one, but not both reporters. Additionally, despite calls for researchers to draw from observational data to add an additional third-party perspective to our understanding of disaffection (Skilling, Bobis, Martin, Anderson, \& Way, 2016), little research has employed observational techniques. To address these limitations, the studies in this dissertation were intentionally designed to draw from more than one perspective on disaffection through the use of multiple measurement approaches. The first study used student-report of disaffection to help select cases for the multiple case study, and then drew from third-party observations of disaffection to answer its research questions. The 
second study modeled relations between student disaffection, as reported by both students and their teachers, and student-teacher relationships.

The final unifying theme relates to the importance of studying phenomenon at multiple time scales. Many developmentalists acknowledge that development occurs at multiple time scales (Gerstorf, Hoppmann, and Ram, 2014; Yoshikawa, Weisner, Kahil, \& Way, 2008), which implies that in order to fully understand the development of any given phenomenon it is essential to study it across multiple spans of time. The studies in this dissertation examine open questions regarding the development of disaffection across different developmental time scales, including micro-time (study 1: episodes of disaffection within a single class period), meso-time (study 2: within year changes in disaffection), and macro-time (study 2: trajectories of disaffection across the early adolescent years) (Figure 1.1). In doing so, this dissertation seeks to employ what Gerstorf, Hoppmann, and Ram (2014) refer to as a "highly useful toolbox that can help us better understand the intricate nature of human development" (p. 76), in this case the development of disaffection.

This proposal is organized into four subsequent chapters focused on the larger relevant literature, two separate studies, and a concluding discussion. Chapter 2 begins with a map of the study of disaffection (including its definition and measurement), and then summarizes what is known about disaffection, including its consequences, development during adolescence, and the classroom dynamics that underlie disaffection. Chapters 3 and 4 are intended to function as separate manuscripts describing each study's rationale, research questions, methods, and proposed analyses. Chapter 3 is a multiple 
case study of the classroom dynamics of disaffection, which focuses on an in-depth examination of class periods that were marked by episodes of student disaffection. Chapter 4 is a longitudinal study designed to investigate the normative trajectories of disaffection across the early adolescent years and to explore the classroom dynamics that may explain why disaffection develops across the school year. Finally, Chapter 5 considers the strengths and limitations of the two studies and discusses the implications of the collective study for educators, researchers, and interventionist.

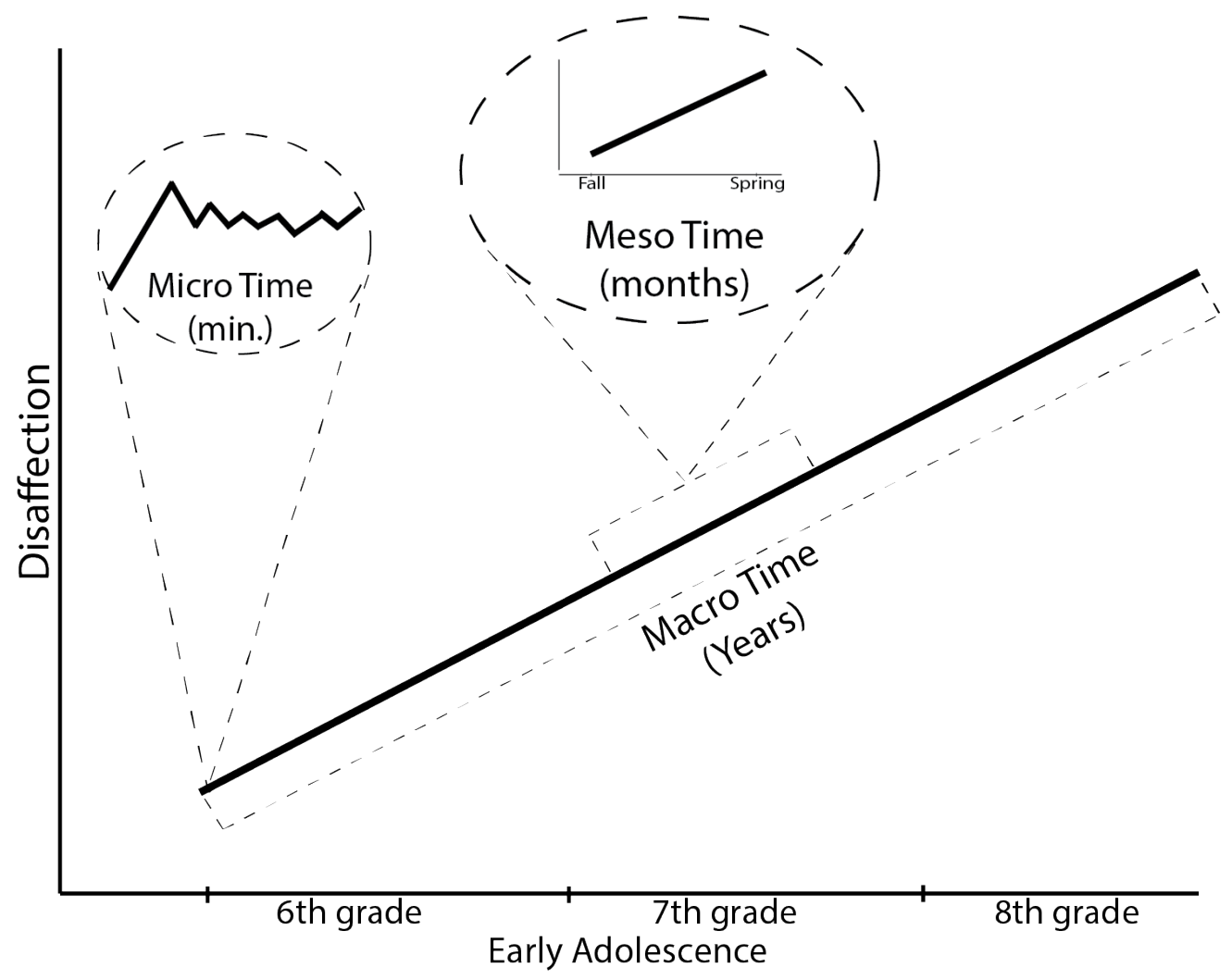

Figure 1.1. The multiple time-scales represented in the two studies of this dissertation: study one investigates the development of disaffection in micro-time (single class periods) and study two addresses both meso-time (changes in disaffection within single school years) and macro-time (disaffection trajectories across the early adolescent years). Figure based loosely on Gerstorf, Hoppmann, \& Ram, 2014. 


\section{Chapter 2: Literature Review}

When many parents and teachers think of the time that early adolescents spend in school, all too often disaffection with academic endeavors is seen as an unfortunately common experience. Although to date no studies have documented the prevalence of overall disaffection at school, a handful of experience sampling studies provide some information about one particular form of disaffection, namely boredom: suggesting that adolescent students report experiencing boredom a striking amount of their time in school (range 32\%-58\%; Larson \& Richards, 1991; Nett, Goetz, \& Hall, 2011). Given that boredom represents only one of many forms of disaffection, these statistics alone likely underestimate the frequency with which students experience the broader phenomenon of disaffection, but, at a minimum, it may serve as a conservative estimate, suggesting that students on average experience disaffection approximately one third of their time in school.

This prevalence of disaffection carries with it not only serious implications for students, but also a high likelihood that disaffection is a frequent, ongoing stressor for teachers (Kyriacou, 2001). As a result, disaffection has important consequences for both students and their teachers. Consequences for students include short-term declines in academic performance and functioning and lower long-term prospects in terms of grade retention and high school graduation. Consequences for teachers relate to higher job stress with its associated negative physiological symptoms and lower job satisfaction. Whereas the importance and costs of disaffection are fairly well understood, two areas about which little is currently known are the development of disaffection across early 
adolescence and the classroom dynamics that explain why disaffection develops across time. This dissertation aims to address these gaps in our knowledge about student disaffection.

The following literature review is organized into two main sections. The first section is designed to give a lay of the land regarding the study of disaffection including how it is defined, why the term disaffection is adopted over other competing terms, and how disaffection is typically measured. The second section seeks to summarize what is known about disaffection including its consequences for students and teachers, its development in early adolescence, and the classroom dynamics that may help explain its development.

\section{How is Student Disaffection Defined and Measured?}

The multidimensional phenomenon of student disaffection. Taken broadly, disaffection is a behavioral and emotional state that arises when a student's motivation to take part in an activity begins to flag. Outside of school, disaffection with noncompulsory activities, such as playing video games, is likely to be expressed simply as withdrawal, avoidance, giving up, and disinterest. The endeavor of schooling, however, is compulsory for K-12 students (Jackson, 1980); as a result, when students' motivation flags, they do not have the option of physically withdrawing or avoiding academics entirely (Skinner, Kindermann, \& Furrer, 2009). This opens the door to other disaffected behaviors and emotions such as feigning participation, doing the minimum, and aversion. Additionally, learning activities and curricula may, at times, be monotonous, unchallenging, and perceived as irrelevant to students' lives, which can initiate different 
forms of disaffection such as boredom, disinterest, and inattention (Daschmann, Goetz, \& Stupnisky, 2011; Nardi \& Steward, 2003; Vogel-Walcutt, Fiorella, Carper, \& Schatz, 2012).

A complete conceptualization of academic disaffection in early adolescence must expand even further to accommodate what is known about adolescent development. For instance, early adolescence is a time when peers become increasingly important (Eccles, 1999; Eccles et al., 1993), as such, social aspects of school, such as interactions with peers, may be more interesting to adolescents than academic endeavors; these competing interests may result in yet another form of disaffection including disinterest and off task behavior (e.g., chatting with peers; passing notes) (Ravet, 2007). Additionally, early adolescence is a time when autonomy gains heightened importance, which suggests that middle school students are likely to be particularly sensitive to classroom environments that may appear controlling or coercive (Eccles, 1999). A controlling classroom environment is likely to initiate disaffection that takes the form of resistance, disruption, frustration, and boredom (Jang, Kim, \& Reeve, 2012; Toshalis, 2015; Vogel-Walcutt et al., 2012). As a result of all these characteristics of middle school learning environments and adolescent students themselves, disaffection with academics is best understood as a multidimensional phenomenon that can take a variety of forms including behavioral and emotional expressions of declining motivation (Table 2.1). 
Table 2.1

\begin{tabular}{|c|c|c|c|}
\hline \multicolumn{4}{|c|}{ Student Disaffection } \\
\hline \multicolumn{2}{|c|}{ Behavioral Disaffection } & \multicolumn{2}{|c|}{ Emotional Disaffection } \\
\hline Adopted Term & Equivalent terms & $\begin{array}{l}\text { Adopted } \\
\text { Term }\end{array}$ & $\begin{array}{l}\text { Equivalent } \\
\text { terms }\end{array}$ \\
\hline Withdrawal & $\begin{array}{l}\text { Disengagement, } \\
\text { giving up, } \\
\text { passivity, } \\
\text { avoidance }\end{array}$ & Boredom & $\begin{array}{l}\text { Disinterest, } \\
\text { low arousal }\end{array}$ \\
\hline Inattention & $\begin{array}{l}\text { Unfocused, } \\
\text { distraction }\end{array}$ & Frustration & Anger \\
\hline Disruption & $\begin{array}{l}\text { Refusal, resistance, } \\
\text { opposition, } \\
\text { defiance }\end{array}$ & Anxiety & $\begin{array}{l}\text { Worry, } \\
\text { nervousness, } \\
\text { apprehension }\end{array}$ \\
\hline Off task behavior & Misbehavior & Apathy & \\
\hline Low effort & $\begin{array}{l}\text { Going through the } \\
\text { motions, doing } \\
\text { minimum, } \\
\text { ritualistic } \\
\text { participation }\end{array}$ & Aversion & \\
\hline Feigning participa & & Sadness & \\
\hline
\end{tabular}

Disaffection as an organizing construct. Perhaps because of its

multidimensionality, the broader phenomenon of disaffection is currently referred to by many names in both school settings and the research literature. Terms that are frequently used include disaffection, disengagement, withdrawal, disruptive behavior, misbehavior, anxiety, and boredom (Table 2.1). In this dissertation, the term disaffection is preferred because it can be used as a construct that draws together and organizes the many forms that disaffection can take in schools. This is particularly important for complex multidimensional phenomenon like disaffection because such an umbrella term can aid 
researchers in leveraging all that is known about the broader phenomenon of disaffection while simultaneously making it more easily comprehensible to teachers.

There are two main reasons why other competing terms were deemed less suitable to function as an organizing construct: 1) some alternative terms are considered too general because they already have meanings that are broader than disaffection, and 2) some alternative terms are considered too specific because they focus on only one aspect of the multidimensional phenomenon of disaffection. First, some alternative terms for disaffection are used in other streams of literature to denote related, but not precisely the same phenomenon. As a result, when these terms are used they do not distinctively demarcate disaffection. Disengagement, which is among the most frequently used terms, is a prime example of this issue with overly general terminology. Disengagement (or sometimes 'school disengagement') is also used in the drop out literature to refer to the long, gradual process of 'detaching from school' prior to actually dropping out (Balfanz, Herzog, \& Mac Iver, 2007). This phenomenon is typically operationalized using an index of warning signs for school dropout that are all drawn from school records, such as low standardized test scores, poor attendance, suspensions, and grade retention (e.g., Henry, Knight, \& Thornberry, 2012). These indices are clearly distinct from the behaviors and emotions that typically characterize disaffection in the classroom. Although one could plausibly posit a relationship between components of disaffection (inattention, withdrawal, disruption) and the metrics of school disengagement, perhaps hypothesizing that these disaffected behaviors are antecedents to school disengagement, these are not 
equivalent phenomenon. Therefore, the use of the term disengagement in place of disaffection could lead to confusion as to the target construct of theoretical interest.

A second reason that many alternative names for disaffection are not ideal is that some of these terms are too specific and so only represent one of many forms disaffection can take in classroom settings. For example, the term disruptive behavior is frequently used, particularly in education research on classroom management (e.g., Shim, Cho, \& Wang, 2013). However, disruptive behavior in the classroom (alternatively called resistance, refusal, or opposition) is only one form of behavior that falls under the larger, more complex phenomenon of disaffection. The use of this term as an organizing construct would exclude other common forms of disaffected behavior including giving up, inattention, and low effort investment and, as a result, does not capture the larger phenomenon of interest.

Due to the limitations of other common terms, disaffection is adopted as the preferred organizational construct to represent the broader phenomenon of interest in this dissertation. The term disaffection is preferable because it incorporates the research findings from the disparate but related constructs in a way that facilitates synthesis and is approachable not only for researchers, but also for teachers and school administrators, who do not have time to stay up-to-date on the myriad of constructs that fall underneath the larger idea of disaffection. Thus, the use of the term disaffection may help unify the study of its overlapping components, and so bring it the conceptual and empirical attention it deserves. 
Measurement of disaffection. With such a large variety of terms and different dimensions of disaffection, it is perhaps not surprising that an equally large variety of measurement tools are used to study disaffection. The following sections first summarize both different measures (student-report surveys, teacher-report surveys, observations) of disaffection, then discuss the strengths and weaknesses of the different measurement approaches, and finally based on this analysis makes recommendations for the measurement of disaffection.

Student-report (SR) of disaffection. There are three primary types of studentreport measures of disaffection: traditional surveys, shorter real time assessments, and interviews.

Traditional survey approach. Student-report surveys of disaffection that have been published to date can be categorized as comprehensive; broad and multidimensional; broad, but unidimensional; one-sided, but multidimensional; or onesided and unidimensional (Table 2.2). To begin, no published surveys were located that could be categorized as comprehensively representing all the forms of disaffection, but there are surveys that fit into each of the other categories. Broad and multidimensional surveys are those designed to cover both behavioral and emotional disaffection with multiple forms of disaffected behaviors and emotions represented in the items of the survey’s sub-scales. The Engagement versus Disaffection with Learning Scale - SR is categorized as a broad and multidimensional survey because it covers the broad conceptual space of disaffection including multiple behavioral (low effort, distraction, feigning participation) and emotional (boredom, anxiety, frustration) forms (Skinner, 
Kindermann, \& Furrer 2009). Other surveys, which for the sake of this review are categorized as broad, but unidimensional, also cover both behavioral and emotional disaffection, but with a relatively narrow scope. For instance, the Student Motivation and Engagement scale (Martin, 2011) includes behavioral disaffection (only withdrawal) and emotional disaffection (only anxiety) sub-scales. Similarly, the Effective Participation Scale (Guvenc, 2015) includes sub-scales that tap behavioral disaffection (only feigning participation) and emotional disaffection (only worry). Another category of survey are those that are one-sided, meaning only behavioral or emotional disaffection is measured, but multidimensional. An example of this type of survey is the Academic Emotions Questionnaire (Pekrun, Goetz, Frenzel, Barchfeld, \& Perry, 2011), which assesses multiple forms of emotional disaffection (boredom, anxiety, anger). Finally, several published surveys can be categorized as one-sided and unidimensional; these surveys predominately stem from the many distinct lines of research (e.g., boredom, resistance/disruption) that are folded under the broader construct of disaffection for the purposes of this dissertation. The Oppositional Defiance Scale (Vansteenkiste, Soenens, Van Petegem, \& Duriez, 2014) is an example of a one-sided and unidimensional survey that only attends to one form of behavioral disaffection, disruptive behavior. 


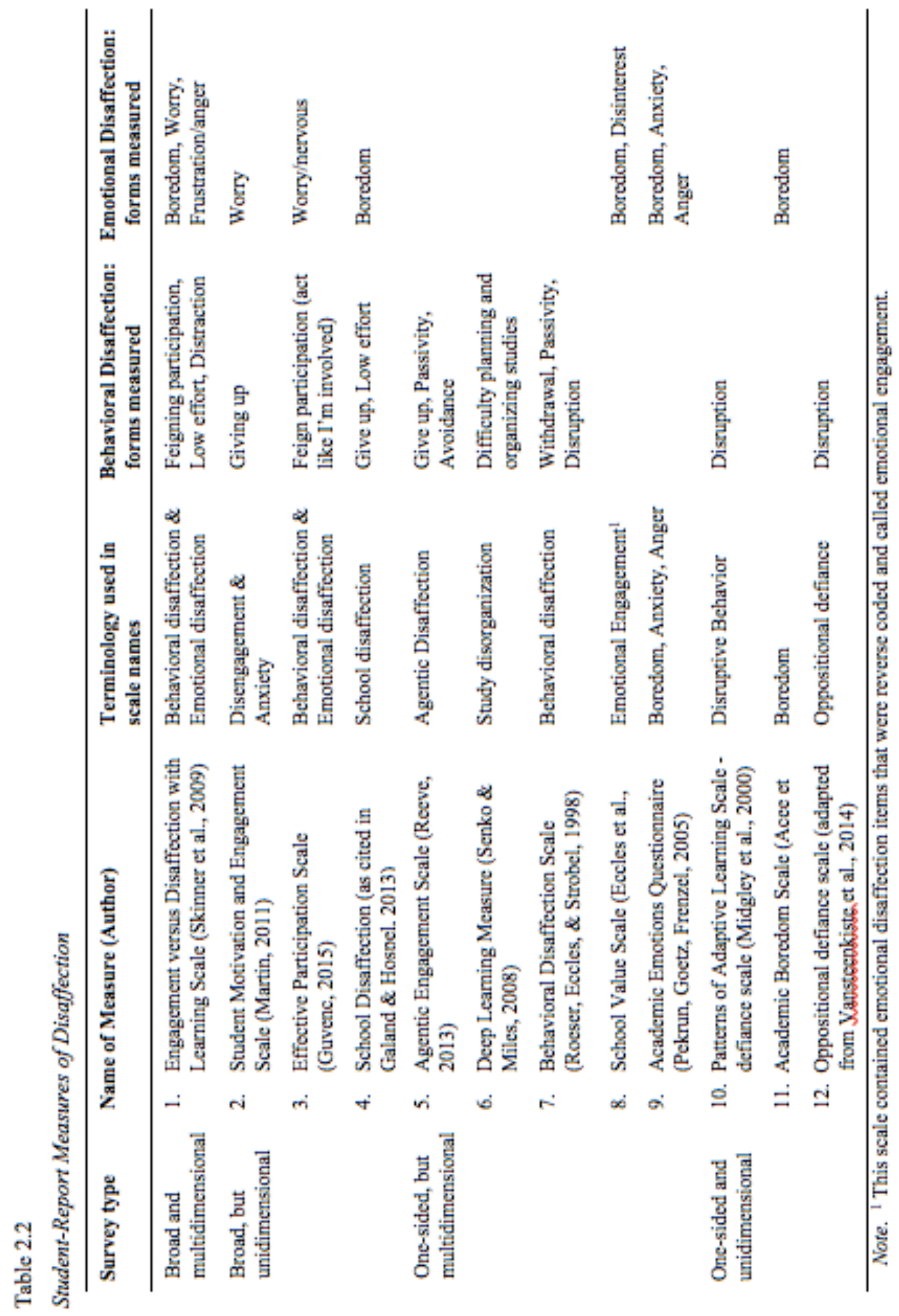


Real-time assessments. Another form of subjective, student-report measures are real-time assessments of disaffection; these measures are typically characterized by very short or single item scales to accommodate the high frequency of measurement points used in experience sampling or real-time study designs. Among the small subset of studies employing real-time assessments, these disaffection measures can be categorized as either broad, but unidimensional or one-sided, but multidimensional. An example of a broad, but unidimensional measure stems from a study of student motivation in real time; in this study, a short form of the Student Motivation and Engagement scale (with single items tapping withdrawal and anxiety) was administered to students with the aid of mobile devices (Martin et al., 2015). Two other studies used real time assessments that can be classified as one-sided, but multidimensional. In an experience sampling study by Larson and Richards (1991), single items were also used, but in this case only emotional disaffection was represented and students were asked to place themselves on a continuum of emotions (e.g., boredom - - - excited; angry - - - friendly). In other studies, students are presented with emoticons representing multiple emotional forms of disaffection (boredom, anger, anxiety) and are then asked to select up to three emotions they are currently feeling (Tulis \& Fulmer, 2013; Tulis \& Ainley, 2011).

Student Interviews. The majority of interviews that seek to gain insight into student disaffection tend to be retrospective and semi-structured, and many are coupled with the use of classroom observations. For instance, Nardi and Steward (2003) conducted semi-structured interviews of students in groups of one to four using specific disaffection incidents from recent classroom observations as context for the interviews. 
Taking a slightly different approach, another study paired semi-structured interviews with Likert style questions to facilitate discussions of disaffection with students (Brown \& Fletcher, 2002). Unfortunately, most research studies that interview students about disaffection do not provide enough detail in their methods sections to determine if interview protocols are designed to assess disaffection in a comprehensive manner and thus these interview protocols cannot be categorized in the same way as other disaffection measures. The results of some studies, however, seem to imply that interviews have the potential to measure the scope and dimensionality disaffection; for example, Ravet's (2007) discussion of the results of student interviews covers multiple behavioral and emotional forms of disaffection.

Teacher-report (TR) of disaffection. Although relatively less common than student-report of disaffection, there is also variety among the small set of existing measures of disaffection that rely on teacher-reports (Table 2.3). Among these measures, there were again no published surveys that could be categorized as comprehensive in their coverage of all forms of behavioral and emotional disaffection. However, one published survey, the Engagement versus Disaffection with Learning Scale - TR (Skinner, Kindermann, \& Furrer, 2009), can be categorized as broad and multidimensional because it measures multiple forms of both behavioral (BD) and emotional (ED) disaffection. Another survey, entitled the SNAP-IV (Swanson et al., 2012), is a broad, but unidimensional survey, which includes both a defiance (BD) and anger (ED) scale. Yet another survey, the Teachers Rating Scale - Short Form (Connor, 1997), taps student behaviors of resistance and inattention, but no emotional forms of 
Literature Review $\quad 21$

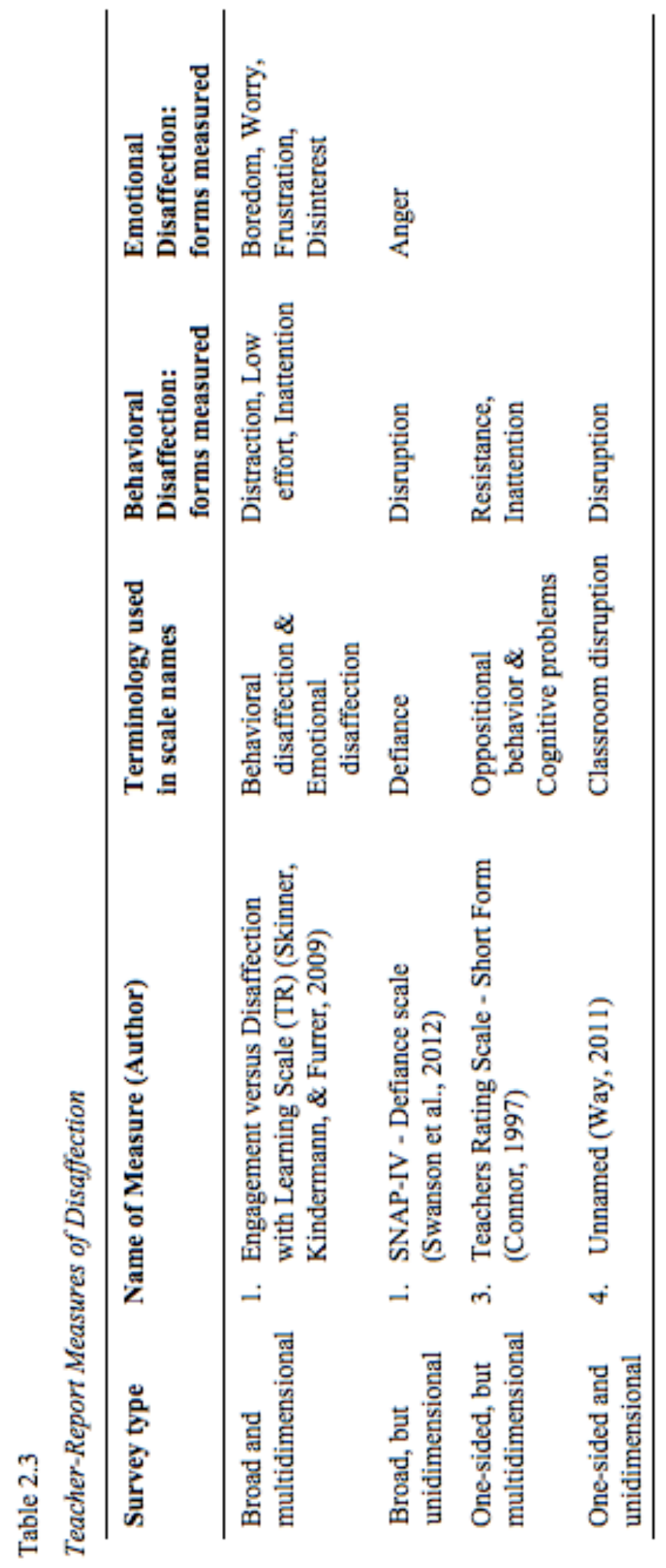


disaffection and, as such, is a one-sided, but multidimensional survey. Finally, one single survey item (i.e., "How often is the student disruptive in class?") serves as an example of a teacher report measure that is one-sided and unidimensional because it only taps disruptive behavior (Way, 2011).

Third-party observation of disaffection. Moving away from measures that rely on either the student or teacher perspective, another perspective that measures can tap is that of third-party observers. Although studies that measure disaffection with observations are often based in real classrooms, this is not always the case. An example of classroombased observations of disaffection can be drawn from a study that focused on specific students across a varying number of occasions (range: 2 - 25) for a set amount of time (2 hours in total). In this study, three codes out of a larger coding scheme aligned with behavioral aspects of disaffection including disruption, off task behavior, and inattention (Skinner, Kindermann, \& Furrer, 2009); this observational coding scheme would best be categorized as a one-sided, but multidimensional measure because of its focus on multiple disaffected behaviors. Other studies seek to leverage technology in their use of observations and, therefore, tend to take place outside of the classroom in lab-based settings. For instance, in studying a computer-based learning environment in a lab setting, emotional disaffection (boredom, frustration) was assessed for 30 second intervals every 5 minutes by coding facial expressions and behavior (i.e., responding slowly to computer prompts) (Craig, Graesser, Sullins, \& Gholson, 2004); this coding scheme could be classified as one-sided, but multidimensional measure. Other researchers used computers to code facial expressions, body posture, and conversational cues related to emotional 
forms of disaffection (Vogel-Walcutt, Fiorella, Carper, \& Schatz, 2012), which again qualifies as a one-sided, but multidimensional measure.

\section{Strengths and limitations of different measurement approaches. All}

psychological measures have strengths and limitations, and measures of disaffection are no exception. Each of the above types of measures of disaffection (student-report, teacher-report, observations) rely on a distinct perspective on student disaffection in the classroom and each of these perspectives contributes something unique and valuable while simultaneously having distinct drawbacks. These strengths and weaknesses are briefly reviewed and in light of them, a case is made for the value of including multiple perspectives in the study of disaffection.

Student-reports of disaffection. The limitations of measures of disaffection that rely of student reporters include misattribution, under-reporting, and social desirability bias. Misattribution in the self-report of disaffection refers to the inaccurate reporting of an emotion or behavior because of confusion with another emotion or behavior. For example, a student may be experiencing frustration or anger at school, but in their survey response that emotion may be mislabeled as something else, perhaps a more familiar emotion, like boredom (Vogel-Walcutt, Fiorella, Carper, \& Schatz, 2012). The problem of under-reporting relates to the possibility that some components of disaffection are unconscious (Fulmer \& Frijters, 2009). If students are unaware that they are enacting a particular disaffected behavior, for example, this may prevent them from accurately reporting those behaviors (Fulmer \& Frijters, 2009). One final limitation of student-report measures of disaffection is social desirability bias. Although Chan (2009) challenges the 
assumption that social desirability bias is a ubiquitous problem for all self-report measures, he also cautions that for some constructs respondents may have a plausible reason to manage impressions in their answers. In the case of disaffection, which is clearly a maladaptive motivational phenomenon, it is possible that social desirability bias is relevant to student-report of disaffection. Disaffection researchers must ask themselves, for instance, how likely a student is to admit they are being disruptive in class?

Fortunately, behavior and emotions in school do not generally top the list of topics (e.g., racism, drug use, sexual habits, etc.) that are highly sensitivity to social desirability bias. Nevertheless, careful phrasing of questions to minimize both social desirability bias and misattribution, as well as, careful design of the survey administration setting to ensure confidentiality are advisable to minimize possible distortions that can result from these limitations (Pekrun \& Buhner, 2014).

All three of these potential issues can result in an underestimation of levels of disaffection when student-report measures are used, so why are these the most common measures of disaffection? Despite these limitations, student-report measures of disaffection also have substantial strengths including their practicality (e.g., easy, inexpensive administration) (Fulmer \& Frijters, 2009; Pekrun \& Buhner, 2014; VogelWalcutt, Fiorella, Carper, \& Schatz, 2012) and the nuanced, insider perspective students bring to their report of their own disaffection. Regarding the particular strengths of the student perspective for reporting emotional disaffection, Pekrun \& Buhner (2014) write, "For a nuanced description of emotional feelings and thoughts, self-report is indispensable" (p. 565). Additionally, some forms of emotional disaffection, particularly 
those emotions that are considered passive or deactivating emotions (e.g., boredom), may be harder for teachers and third-party observers to accurately assess if students are not exhibiting open signs of or intentionally concealing these forms of disaffection (Skinner, Kindermann, \& Furrer, 2009). Thus, the student perspective is unique in its access to the internal workings of disaffection, which makes students an extremely valuable data source on disaffection.

Teacher-reports (TR) of disaffection. Measures of disaffection that rely on teacher reports can also be biased by misattribution, respondent fatigue, and teacher assumptions about the stability of student disaffection. In the case of the teacher perspective, misattribution could occur when a teacher misunderstands or overlooks signs of disaffection, which could lead to either under or overestimation of disaffection. An example of misattribution that could lead to overestimation would be if a teacher misinterpreted a tired student's behavior and demeanor as that of a bored student. Conversely, if a teacher failed to notice a student's boredom, perhaps because other students in the classroom are being disruptive, then that teacher would underestimate that particular student's disaffection. Respondent fatigue in teacher reports of disaffection stems from the combination of class size and the number of items in many disaffection surveys. All of the above reviewed teacher-report measures require teachers to report on individual students' disaffection and all but one TR survey had multiple scales with multiple items, therefore, these surveys require participating teachers to fill out lengthy surveys for multiple students. Given that many middle school teachers have multiple class periods and large class sizes, this type of survey could result in respondent fatigue, 
which could take the form of giving similar responses for all students by perhaps unintentionally regressing towards the average student's disaffection or towards the neutral Likert response. If this fatigue happens, teacher report data will be inaccurate for at least some students and information regarding variations in student disaffection would be lost or reduced. Finally, if teachers hold assumptions that student disaffection is traitlike and therefore stable, rather than state-like, this assumption may lead teachers to base their reports, not on recent levels of disaffection, but rather on their general, stagnant beliefs about particular student's disaffection. The implication, then, would be that teacher-report of disaffection would be less accurate and less representative of current states or less reflective of changes over time.

Despite these limitations, there are also strengths associated with teacher-report of disaffection. Beyond the affordability of teacher-reports (Reisenzein, Junge, Studtmann, \& Huber, 2014), another strength relates to teachers' knowledge of students, which stems from the amount of time teachers have spent with their students and their deeper knowledge of students' background, home life, and prior behavior. As a result of this knowledge of students, teachers may be more sensitive to signs of disaffection than third party observers and may be able to distinguish subtle signs of disaffection more accurately than third party observers. Another strength relates to teachers' general expertise in observing student actions; most teachers have years of experience informally assessing a variety of aspects of their students' behavior and learning. As such, teachers may be exceptionally adept at spotting signs of student disaffection (i.e., off-task behavior such as passing notes). Finally, teachers are intricately involved in what happens 
inside the walls of their classrooms so their perceptions of student disaffection likely matter for the development of disaffection (Reisenzein, Junge, Studtmann, \& Huber, 2014). This means that, if researchers are interested in prediction or intervention, teachers' views of disaffection matter because they have bearing on how teachers respond to student disaffection and whether disaffection is resolved or amplified.

Third-party observations of disaffection. Finally, observations of disaffection are also associated with strengths and weaknesses. In terms of strengths, observations are often context-specific, real time, and made by trained, third party raters. The contextspecificity of observations makes these measures better suited to capture the full complexity of motivational constructs, like disaffection (Fulmer \& Frijters, 2009). Additionally, observations occur in real time and can make it possible to capture moment-to-moment fluctuations in disaffection. In contrast, both student-report measures and teacher-report measures at best tap disaffection on a typical day or over a recent period of time (i.e., over the last month) so only observations and real-time assessments (SR) of disaffection allow researchers to investigate changes in disaffection across micro developmental time. Additionally, third-party observers can be trained and reliability across raters can be empirically investigated and monitored, so trained observers may be able to more consistently rate disaffection than teachers, who are inherently basing their reports on their own unstandardized interpretations of students' actions.

Some challenges associated with observational measures include issues with generalizability, Hawthorne effect, and lack of contextual knowledge. Questions regarding generalizability address whether a particular observation of disaffection is more 
broadly representative to other occasions (Fulmer \& Frijters, 2009). For example, how representative is today's observation of a particular student's disaffection to other class periods or days? If third-party observations of disaffection have low generalizability, more observation occasions may be needed in order for the findings stemming from these measures to be useful. Additionally, as outsiders to the observed classroom, there are also valid questions of whether third-party observers have the necessary background knowledge (e.g., history of interactions that today's social interactions are built on) to detect nuances of disaffection. In this respect, students and teacher have a stronger knowledge base and unique perspective over external raters of disaffection in observing and reporting on disaffection. One final limitation of observations is related to the Hawthorne effect; given that the presence of observers is readily apparent during classroom observations, students clearly know they are being observed. As a result, researchers need to be cognizant of the possibility that their presence impacts student actions during classroom observations. The Hawthorne effect can be reduced by planning multiple observations to habituate students to the presence of observers and, when appropriate and permitted by ethical standards, obscuring the true purpose of observations so that students aren't hyper aware of particular behaviors and emotions that may be of interest to the researchers.

Conclusions about measures of disaffection. Clearly from the above review of measures of disaffection, each type of measure has multiple strengths and limitations and, as a result, no one measure is clearly preferred over another. In their review of the measurement of student motivation, Fulmer and Frijters (2009) conclude that the full 
complexity of motivational constructs, like disaffection, cannot be captured with a single measurement approach and that "multiple perspectives, and the interaction between these perspectives must be utilized" (p. 240). To balance the strengths and limitations of these various measures, the ideal measurement of disaffection would entail multiple, broad and multidimensional measures. The use of multiple measures of disaffection allows for the different perspectives of disaffection (students, teachers, and observers) to complement one another and enrich our understanding of disaffection by carefully balancing the limitations of any one measure with the strengths of another (Fulmer \& Frijters, 2009; Pekrun \& Buhner, 2014; Vogel-Walcutt, Fiorella, Carper, \& Schatz, 2012). The preference for broad and multidimensional measures of student disaffection relates to the high likelihood that student experiences of disaffection are multi-faceted. For instance, any given student is unlikely to experience only one form of disaffection so a measure that is not broad and multidimensional may fail to capture a complete picture of a particular students' disaffection. Additionally, there can be variation in different students' experiences of disaffection in response to the same learning activity (e.g., one student may experience boredom, another frustration, and still another may experience no disaffection, but rather be interested). Therefore, only broad and multidimensional measures of disaffection can adequately capture the complexity of disaffection within and between students.

The multidimensional nature of disaffection and the plurality in terminology and measures surrounding the study of disaffection has the potential of creating significant challenges for synthesizing research findings on the broader phenomenon of disaffection. 
This challenge, however, is overcome when disaffection is used as an organizing construct and all alternative terms and lines of research are drawn together under the umbrella of disaffection.

What is known about the Consequences, Development, and Dynamics of Disaffection?

\section{Consequences of disaffection}

Adopting disaffection as an organizing construct makes it possible to synthesize findings from different lines of research and, in doing so, to create a more coherent picture of the consequences of disaffection. The costly consequences of student disaffection do not stop with poor outcomes for students (low academic performance and poor long-term prospects), but also extend to negative outcomes for the teachers (high job stress and low job satisfaction) of disaffected students.

Consequences for students. Disaffection is detrimental for students' academic success because it blocks learning and diminishes academic performance. For adolescent students, both teacher-reported and student-reported disaffection has been consistently and negatively associated with various metrics of academic performance (i.e., final grade, GPA); the strength of these correlations, however, appears to depend in part on what forms of disaffection are measured and who reports on student disaffection (Table 2.4). Associations between student disaffection and academic performance also remained significant when some studies tested more complex models, which accounted for other variables. 
Regarding behavioral disaffection specifically, several short-term longitudinal studies have demonstrated that behavioral disaffection predicts poorer subsequent academic performance. For instance, teacher report (TR) of behavioral disaffection in April predicted lower final grades for adolescents in June, in a path model controlling for autonomy and engagement (TR) (Gonzalez \& Paoloni, 2014). Additionally, in a structural model including engagement (TR), perceived control, and anxiety (SR), behavioral disaffection (TR) negatively predicted $9^{\text {th }}$ and $10^{\text {th }}$ graders average final grades (Gonzalez, Garrido, Castro, \& Rodríguez, 2015). Finally, student-reported behavioral disaffection negatively predicted average final grade in a structural model, which controlled for engagement (SR), perceived control, and perceived task value (Gonzalez, Paoloni, Donolo, \& Rinaudo, 2015). Taken together, this collection of studies suggests that behavioral disaffection inhibits academic performance during the same school year, likely because many forms of behavioral disaffection (e.g., inattention, low effort) act as barriers to learning.

Research findings also suggest that high levels of emotional disaffection predict lower levels of academic performance (Pekrun, 2017). Although a number of studies have demonstrated negative associations between emotional disaffection and academic performance (Table 2.4), other studies have moved past simple associations or unidirectional predictions to examine how emotional disaffection and academic performance dynamically relate over time. For instance, a recent 5-year longitudinal study found reciprocal relations between emotional disaffection (boredom, anxiety, and anger) and academic performance (both grades and achievement test scores) across $5^{\text {th }}$ to 
$9^{\text {th }}$ grade, such that increases of boredom, for example, predicted decreases in grades (Pekrun, Lichtenfeld, Marsh, Murayama, \& Goetz, 2017). Using conditional growth curve modeling, Ahmed van der Werf, Kuyper, and Minnaert (2013) found that increases in $7^{\text {th }}$ graders' emotional disaffection (both boredom and anxiety) across the school year predicted concurrent decreases in academic performance (math grades) (Ahmed, van der Werf, Kuyper, \& Minnaert, 2013). Regardless of whether the time scale of interest is within a single school year or across the adolescent years, these studies suggest both that emotional disaffection interferes with academic performance and that struggles with grades may also worsen future experiences of emotional disaffection.

In terms of the long-term prospects, student disaffection has been linked to a number of outcomes that reflect poorly on a student's chances of finishing high school. Although there are many pathways to high school drop out (Dupéré et al., 2015; Balfanz, Herzog, \& Mac Iver, 2007), at least one of these pathways is linked to disaffection. Past research demonstrates that problems with some forms of behavioral disaffection (particularly misbehavior) in middle school increase the likelihood of dropping out during high school (Balfanz, Herzog, \& Mac Iver, 2007; Juvonen, Le, Kaganoff, Augustine, \& Constant, 2004; Rumberger \& Lim, 2008). Additionally, some forms of emotional disaffection have also been implicated in decisions to drop out. For instance, a retrospective study showed that almost half of the dropouts interviewed cited experiences of emotional disaffection (namely boredom) in school as a contributing factor to their decision to drop out of high school (Bridgeland, 2010). Furthermore, because of their concurrent struggles with academic performance many disaffected students may have a 
collection of 'predisposing' and 'precipitating' antecedents for drop out (Dupéré et al., 2015).

Table 2.4

Summary of Correlations Between Different Operationalizations of Disaffection and Metrics of Academic Performance

\section{Behavioral Disaffection}

\begin{tabular}{llll} 
Reporter & $\begin{array}{l}\text { Feigning } \\
\text { participation \& } \\
\text { inattention }\end{array}$ & $\begin{array}{l}\text { Low effort and } \\
\text { inattention }\end{array}$ & Disruptive behaviors \\
\hline $\mathrm{SR}$ & $-.42(1)$ & & $-.10(2)$ \\
$\mathrm{TR}$ & & $-.53(3) ;$ & \\
& & $-.36(4)$ & \\
& & Average: -.445 & \\
\hline
\end{tabular}

\section{$\underline{\text { Emotional Disaffection }}$}

\begin{tabular}{llll} 
& Boredom & Anxiety & Frustration \\
\hline SR & T1: -.24, & $-.44(3) ;$ & Grade 5: -.30, \\
T2: -.16, & T1: -.31, & Grade 6: -.30, \\
T3: $-.26(5) ;$ & T2: -.30, & Grade 7: -.34, \\
Grade 5: -.37, & T3: $-.19(5) ;$ & Grade 8: -.36, \\
Grade 6: -.37, & Grade 5: -.37, & Grade 9: $-.42(6)$ \\
Grade 7: -.39, & Grade 6: -.38, & Grade 5: $-.17(7)$ \\
Grade $8:-.39$, & Grade 7: -.37, & \\
Grade 9: $-.45(6)$ & Grade $8:-.37$, & \\
& & Grade 9: $-.40(6)$ & Average: -.344 \\
\hline
\end{tabular}

\section{Combined (both behavioral and emotional disaffection)}

SR T1: -.339 ;

T2: $-.376(8)$;

$-.23(9)$

Average: -.315

TR $\quad-.39(8)$

Note. SR = Student-report; TR = teacher- report; $1=$ Gonzalez et al.,, 2015; 2 = Peklaj, Kalin, Pecjak, Zuljan, \& Levpuscek, 2012; 3 = Gonzalez et al., 2015; 4 = Gonzalez \& Paoloni, 2014; 5 = Ahmed, van der Werf, Kuyper, \& Minnaert, 2013; 6 = Pekrun, Lichtenfeld, Marsh, Murayama, \& Goetz, 2017; $7=$ Boekaerts, 1993; 8 = King, 2015; $9=$ Skinner, Pitzer, \& Steele, 2016 
Consequences for teachers. The teaching profession is considered a stressful, emotionally taxing career (Chang, 2009; Kyriacou, 2001; Nizielski, Hallum, Schutz, \& Lopes, 2013; Markow, Macia, \& Lee, 2013). There are, of course, many sources of stress in teachers' professional lives, but chief among them is student disaffection, particularly misbehavior or disruptive behavior (Kyriacou, 2001). Teachers themselves report experiencing frustration and anger when students misbehave or put forth low effort in their classrooms; thus effort is required on the part of teachers to regulate their own negative emotions in response to disaffected behaviors (Sutton, 2004). If left unresolved, student disaffection can contribute to chronic, high levels of teacher stress over time, which has been linked to teacher burnout (Chang, 2009). Teacher burnout is associated with negative outcomes for the teacher in terms of negative physiological stress-related health outcomes, declines in effectiveness of teaching, decreased job satisfaction and work motivation, and a reduction in job commitment (Betoret, 2006; Chang, 2009; Maslach et al., 2001). The costs of burnout also extend beyond the individual teacher to the teaching profession including increased absenteeism, greater intention to leave the job, and ultimately teacher turnover (Chang, 2009; Maslach et al., 2001).

\section{Development of Disaffection in Adolescence}

Although prior research has established that disaffection is costly for students and their teachers, research to date has not definitively answered questions regarding how disaffection develops across grades, particularly middle school grades. Motivational researchers describe general declines in motivation the longer students progress in school, with conspicuously sharp declines across the transition to middle school (Wigfield, 
Byrnes, \& Eccles, 2006; Wigfield et al., 2015). However, most prior research has emphasized constructs such as engagement at the expense of disaffection. As a result, relatively few studies have tested whether these general predictions regarding the development of motivation also hold for the development of disaffection. Findings from the small collection of studies that explicitly address the development of disaffection are summarized below by focusing first on within year changes, then on changes across adolescence, and finally on interindividual differences in these changes.

Development of disaffection within single school years. Only three past studies have explicitly examined changes in disaffection within single school years during adolescence (Table 2.5). One study, focusing on behavioral disaffection, found significant differences between fall and spring in a sample that included $6^{\text {th }}$ and $7^{\text {th }}$ grade middle school students, suggesting that behavioral disaffection increased across the school year (Skinner, Furrer, Marchand, \& Kindermann, 2008). Evidence regarding within year changes in emotional disaffection are more mixed, appearing to depend on which forms of emotional disaffection are measured. Skinner and colleagues (2008) found that emotional disaffection, both when treated holistically and when three components (boredom, anxiety, frustration) were tested individually, was higher in spring than earlier in fall. Consistent with the findings that boredom increases across the school year, Ahmed and colleagues (2013), using growth curve modeling, also found that boredom increased across three waves during the $7^{\text {th }}$ grade school year. In contrast to these two findings, however, Larson and Richards (1992) found no differences in levels of boredom across three measurement waves, suggesting that boredom was stable across 
the school year. Regarding anxiety, Ahmed and colleagues (2013) found contradictory evidence to the Skinner et al. (2008) findings, when their growth curve model indicated that $7^{\text {th }}$ graders levels of anxiety were relatively stable across the school year.

Table 2.5

Summary of Findings for Changes in Disaffection within the Same School Year

Within Year

Statistical Grade

Analysis Level

Finding

\section{Behavioral Disaffection}

Skinner et al., $2008 \quad$ T-test $\quad$ 4th - 7th $\quad$ BD (holistic)

grade $\quad$ Spring $>$ Fall, $t=-2.44^{*}$

\section{Emotional Disaffection}

Skinner et al., 2008

T-test

4th -7 th

ED (holistic):

Spring $>$ Fall $t=-4.47^{* *}$

Boredom:

Spring $>$ Fall, $t=-4.92 * * *$

Anxiety:

Spring $>$ Fall, $t=-2.82 * *$

Frustration:

Spring $>$ Fall, $t=-2.47^{*}$

Ahmed et al., 2013 Multilevel 7th

growth curve

Boredom:

models

mean growth rate $\theta_{\mathrm{s}}=.21^{* *}$

Anxiety:

mean growth rate $\theta_{\mathrm{s}}=.02 \mathrm{~ns}$

Larson \& Richards, MANOVA 5th -8 th Boredom:

1991

$n s, F$ test statistic not

provided

Note. ${ }^{*} p<.05 ; * * p<.01 ; * * * p<.001$

Development of disaffection across multiple years. Three studies provide

mixed evidence for changes in disaffection across years, with findings seemingly 
dependent on what forms of disaffection (behavioral or emotional) are measured (Table 2.6). Studies that measure behavioral disaffection generally suggest that this form of disaffection increases across the transition to middle school and then further increases across the middle school years (Martin, Way, Bobis, \& Anderson, 2015; Skinner et al., 2008). Skinner and colleagues (2008) found grade-level differences that suggest behavioral disaffection (low effort, distraction, feigning participation) significantly increased across the transition to middle school $\left(5^{\text {th }}\right.$ to $6^{\text {th }}$ grade $)$ and continued to increase into $7^{\text {th }}$ grade. Using multilevel modeling and a longitudinal design that tracked students across 1 year, Martin and colleagues (2015) found increases in disaffection (withdrawal) across the transition to middle school $\left(6^{\text {th }}\right.$ to $7^{\text {th }}$ grade in this sample) and then again across $7^{\text {th }}$ to $8^{\text {th }}$ grade. Finally, in a sample of $7^{\text {th }}$ through $9^{\text {th }}$ grade students followed across a one year period from spring to spring, significant increases in average reported disaffection (withdrawal) were found, however, these increases became nonsignificant after Bonferroni adjustment (Plenty \& Heubeck, 2013). Overall, most existing evidence points to trends of behavioral disaffection increasing across the middle school years.

Based on three studies to date, emotional disaffection also appears to increase across the middle school transition, however, in contrast to behavioral disaffection, it then appears to remain relatively stable across the middle school grades. Grade-level differences suggest a significant increase across the transition to middle school $\left(5^{\text {th }}\right.$ to $6^{\text {th }}$ grade) with levels of emotional disaffection (boredom, anxiety, frustration) remaining 
relatively stable from $6^{\text {th }}$ to $7^{\text {th }}$ grade (Skinner, Furrer, Marchand, \& Kindermann, 2008). Plenty \& Heubeck (2013) also found no significant change in average levels of emotional disaffection (anxiety) from $7^{\text {th }}$ to $8^{\text {th }}$ or $8^{\text {th }}$ to $9^{\text {th }}$ grades. Finally, Larson $\&$ Richards (1991) similarly found, in examining grade-level difference, that boredom and anger appeared to remain relatively stable across the middle school years (both increased, but the increases were not statistically significant). So while the student experience of emotional disaffection may rise to higher levels after transitioning to middle school, evidence to date points to it then remaining stable across the middle school grades. 
Table 2.6

Summary of Findings for Changes in Disaffection Across the Adolescent Years

Across Years

$\begin{array}{cccc}\text { Statistical } & \text { Grade } & \\ \text { Study } & \text { Analysis } & \text { Level } & \text { Finding }\end{array}$

\section{$\underline{\text { Behavioral Disaffection }}$}

Engels et al., 2017 Growth curve 7th-11th BD (holistic):

models mean growth rate $\theta_{\mathrm{s}}=.09 * * *$

Martin, Way, Bobis, Multilevel 6th - 8th Withdrawal:

$\&$ Anderson, 2015 modeling $\quad 7^{\text {th }}>6^{\text {th }} ; \mathrm{B}=.27, p<.01$

Withdrawal:

$8^{\text {th }}>6^{\text {th }} ; \mathrm{B}=.40, p<.001$

Plenty \& Heubeck, RM-ANOVA 7th - 9th Withdrawal:

2013

$\mathrm{Y} 2>\mathrm{Y} 1$;

$F=5.48, n s$ after Bonferroni

adjustment

Skinner et al., 2008 MANOVA 4th - 7th BD (holistic):

$$
\begin{aligned}
& 5^{\text {th }}>7^{\text {th }} \\
& 6^{\text {th }}>7^{\text {th }} \\
& F=9.63 * * *
\end{aligned}
$$

\section{$\underline{\text { Emotional Disaffection }}$}

Engels et al., 2017 Growth curve 7th - 11th models

Larson \& Richards, MANOVA 5th - 9th 1991

Skinner et al., 2008 MANOVA 4th - 7th
ED (holistic):

mean growth rate $\theta_{\mathrm{s}}=.02, n s$

Boredom:

$F(4,371)=1.28, p=.274$

Anger:

$7^{\text {th }}>6^{\text {th }}$ (middle school transition);

$F(4,371)=2.20, p=.068$

ED (holistic):

$6^{\text {th }}>5^{\text {th }} ; 6^{\text {th }} \& 7^{\text {th }} n s ; F=16.92 * * *$

Boredom:

$6^{\text {th }}>5^{\text {th }} ; 6^{\text {th }} \& 7^{\text {th }} n s ; F=28.36^{* * *}$

Anxiety:

$6^{\text {th }}>5^{\text {th }} ; 6^{\text {th }} \& 7^{\text {th }} n s ; F=3.70^{*}$

Frustration:

$6^{\text {th }}>5^{\text {th }} ; 6^{\text {th }} \& 7^{\text {th }} n s ; F=13.45^{* * *}$

Note. ${ }^{*} p<.05 ; * * p<.01 ; * * * p<.001$ 
Interindividual differences in the development of disaffection. Few studies to date explicitly examine whether there are substantial differences in individual students' trajectories of disaffection within the school year or across early adolescence. Regarding differences between students' emotional disaffection within the same school year, Ahmed et al. (2013) found evidence for significant differences in students' initial levels of both anxiety and boredom in fall of $7^{\text {th }}$ grade, as well as, small, but significant variation in the rate of change for anxiety, but not for boredom. Across grade levels, one study indirectly points to a likelihood of individual differences in changes in emotional disaffection (anxiety), finding that $9.2 \%$ of students experienced a 'noteworthy' increase (i.e., $\geq 2$ points on a 7 point Likert scale) in emotional disaffection while another $7.9 \%$ of students reported a 'noteworthy' decrease (Plenty \& Heubeck, 2013). This same study contributes the only indication to date that students may also differ in their behavioral disaffection (withdrawal) trajectories, finding that $11.2 \%$ of students experienced a 'noteworthy' increase while another $7.1 \%$ of students experienced a 'noteworthy' decrease (Plenty \& Heubeck, 2013).

Taken together, these findings suggest that both forms of disaffection are likely amplified by the transition to middle school and that behavioral disaffection may then normatively continue to increase across the early adolescent years. There may also be significant differences between students' disaffection trajectories. Given the preliminary nature of these findings, however, more research into the development of disaffection during early adolescence is needed. 


\section{Classroom Dynamics of Disaffection: the role of student-teacher relationships}

When seeking to understand why disaffection develops in classroom settings, there are a variety of processes to potentially consider; chief among these processes are social interactions (Bronfenbrenner \& Morris, 1998). In addition to other social partners (i.e., peers and parents), a handful of past studies suggest that a student's relationship with their teacher plays a unique and important role in explaining why disaffection develops during early adolescence (Galand \& Hospel, 2013; King, 2015). A complete understanding of the role of student-teacher relationships in the development of disaffection requires the joint consideration of 1) how these relationships both instigate disaffection and influence its change over time and 2) how student disaffection may shape student-teacher relationships. In other words, how do student disaffection and student-teacher relationships dynamically interact to mutually influence each other over time?

\section{How does a student's relationship with their teacher impact their}

disaffection? The majority of studies that examine the effect of student-teacher relationships on disaffection conceptualize these relationships holistically and as a continuum. As such, positive relationships are often characterized by involvement, structure, and autonomy support while negative relationships are characterized by the

opposite, namely, withdrawal, chaos, and controlling behavior on the part of teachers. A handful of these studies provide some evidence that positive student-teacher relationships, when considered holistically, may lead to lower levels of disaffection (Table 2.7). Two correlational studies indicate that high quality student-teacher 
relationships are negatively associated with disaffection (behavioral and emotional combined) (Galand \& Hospel, 2013; Guvenc, 2015); these associations remain significant when more complex models accounting for additional variables are tested. For instance, high quality student-teacher relationships were significantly and negatively associated with $7^{\text {th }}$ and $8^{\text {th }}$ grade students' self-reported (SR) disaffection in a regression that controlled for peer victimization and other forms of social support from parents and peers (Galand \& Hospel, 2013). Similarly, positive student-teacher relationships predicted lower levels of $9^{\text {th }}$ grade student's disaffection (SR) in a structural equation model, which accounted for autonomy and engagement (Guvenc, 2015). Additionally, a short-term longitudinal study found that student-teacher relationships in fall predicted decreases in both behavioral and emotional disaffection from fall to spring of the same school year, although the prediction was stronger for behavioral disaffection (Skinner, Furrer, Marchand, \& Kindermann, 2008). While holistic studies are useful in demonstrating that student-teacher relationships matter for student disaffection, they do not provide actionable information for educators and interventionists. Additionally, for the developmental stage of adolescence, there are good reasons stemming from stage environment fit theory to posit that some components of student-teacher relationships are more important to disaffection than others. 
Table 2.7

\begin{tabular}{|c|c|c|c|}
\hline & \multicolumn{3}{|c|}{ Student-reported disaffection } \\
\hline & BD \& ED combined & BD & ED \\
\hline $\begin{array}{l}\text { Student-teacher } \\
\text { relationship } \\
\text { (holistic) }\end{array}$ & $-.43(1)$ & $\begin{array}{l}\text { Fall: }-.44, \\
\text { Spring: }-.50(5)\end{array}$ & $\begin{array}{l}\text { Fall: -.52, } \\
\text { Spring: -.51 (5) }\end{array}$ \\
\hline $\begin{array}{l}\text { Involvement vs. } \\
\text { withdrawal }\end{array}$ & $\begin{array}{l}\text { Combined: } \\
-.40(2)\end{array}$ & & \\
\hline $\begin{array}{l}\text { Autonomy support } \\
\text { (AS) vs. } \\
\text { controlling } \\
\text { behavior (CB) }\end{array}$ & $\begin{array}{l}\text { Combined: } \\
-.52(2) \\
\text { AS only: } \\
\text { T1 -.44, T2 -.42, } \\
\text { T3 -.51 (4) } \\
\text { CB only: } \\
\text { T1 .55, T2 .66, } \\
\text { T3 .66 (4) }\end{array}$ & $\begin{array}{l}\text { Combined: } \\
\Phi \\
\text { AS only: } \\
-.15(3) \\
\text { CB only: } \\
.56(3)\end{array}$ & \\
\hline
\end{tabular}

Note. $\mathrm{SR}=$ Student-report; TR $=$ teacher- report; $1=$ Galand \& Hospel, 2013; $2=$ Guvenc, 2014; 3 = Haerens, Aelterman, Vansteenkiste, Soenens, \& Van Petegem, 2015; 4 = Jang, Kim, \& Reeve, 2016; 5 = Skinner, Furrer, Marchand, \& Kindermann, 2008

Prioritizing two components of student-teacher relationships: involvement vs. withdrawal and autonomy support vs. controlling behavior. Based on stage-environment fit theory and findings of several research studies, the most salient aspects of studentteacher relationships for student disaffection appear to be involvement (warm, caring) vs. withdrawal (distant, cold) and autonomy support (choice, relevance) vs. controlling behavior (coercion, use of extrinsic motivational strategies). Adolescence is a time when relationships with peers and non-parent adults become increasingly important; unfortunately, at the same time, students experience a transition to secondary school structures which are larger and more departmentalized leading to higher teacher-tostudent ratios and classroom environments that are perceived as less warm and caring 
(Eccles, 1999; Eccles et al., 1993; Mac Iver, Young, \& Washburn, 2001). Thus stageenvironment fit theory suggests that there is a mismatch between early adolescents' growing needs for close relationship with teachers and their new middle school environment. Indeed, a cross-sectional study of $6^{\text {th }}, 8^{\text {th }}$, and $10^{\text {th }}$ grade emotionally disaffected (bored) students, found that student views of involvement (specifically, attunement and dependability) were worse among older students than younger students suggesting that this component of student-teacher relationships may decline across the adolescent years (Riley \& Docking, 2004). Research findings further suggest that this mismatch may have bearing on student disaffection. Correlational evidence supports the link between warm, caring relationship with teachers (involvement) and lower levels of disaffection (Guvenc, 2015). Interviews with disaffected secondary students themselves, however, revealed a strong trend of these students perceiving their teachers as neglectful, cold, or distant (withdrawal) (Lumby, 2012). Together, these studies suggest that although disaffected students would benefit from student-teacher relationships characterized by involvement, instead these students too often perceive their teacher as withdrawn from them. None of these studies, however, examined how the involvement vs. withdrawal component of student-teacher relationships influences changes in disaffection over time.

Early adolescence is also a time when autonomy gains heightened importance, which suggests that middle school students are likely to be particularly sensitive to classroom environments that may appear controlling or coercive (Eccles, 1999). Confirming this expectation, Riley and Docking (2004) found that student views of 
autonomy support (specifically, respect and lack of coercion) were worse among older students than younger students, suggesting that students perceive their teachers' autonomy support to decline through adolescence ( $6^{\text {th }}$ to $10^{\text {th }}$ grade). This is concerning because lower perceptions of autonomy support are associated with higher levels of disaffection (SR) (Guvenc, 2015; Jang, Kim, \& Reeve, 2016). Consistent with these findings, student perceptions of controlling behavior were found to directly predict behavioral disaffection (resistance) in a larger SEM model, which controlled for autonomy supportive teaching among other things (Haerenn, Aelterman, Vansteenkiste, Soenens, \& Van Petegem, 2015). Finally, although less frequently mentioned in interviews than involvement vs. withdrawal, some disaffected students indicated in interviews that they perceived their learning environments as coercive (Lumby, 2012). Again, these findings suggest that autonomy supportive relationships with teachers would be beneficial in reducing student experiences of disaffection, but that at least some disaffected students perceive their relationships with teachers as controlling rather than autonomy supportive.

\section{How does a student's disaffection influence their relationships with their}

teachers? Given that emotional forms of disaffection (i.e., boredom, anxiety, frustration) are unpleasant for students and that behavioral forms of disaffection (i.e., off task behavior, inattention, disruption) are stressful for teachers, it seems highly likely that student disaffection would shape, and most likely strain, student-teacher relationships. Confirming this expectation, a short-term longitudinal study demonstrated that higher levels of student disaffection at the beginning of the semester predicted student-teacher 
relationships that were characterized by both lower autonomy support and higher teacher control eight weeks later; this same trend held from mid-semester to the end of the semester (Jang et al., 2016). Despite its intuitive appeal, however, this directional effect has received much less empirical attention than the effect of student-teacher relationships on disaffection.

\section{Summary.}

Disaffection is a complex multi-dimensional phenomenon, the study of which is spread across different terminology, fields of research, and measurement approaches. When drawn together and synthesized, however, the disparate strands of disaffection research paint a clear picture that student disaffection has important and negative consequences for students, teachers, and school administrators. As a result of its importance to multiple stakeholders in school systems, a greater understanding of both the development of disaffection and the classroom dynamics that instigate its development is needed. 


\section{Chapter 3: Study 1}

Classroom Dynamics of Student Disaffection: A Multiple Case Study of Single Class Periods.

\section{Purpose}

The phenomenon of "student disaffection" is called by many disparate names in both teacher lounges and research publications (such as disengagement, disruptive behavior, misbehavior, anxiety, resistance, or boredom). Student disaffection captures a problem in middle school classrooms, the pervasiveness of which is brought into sharper focus when disaffection is used as an umbrella term to gather together research findings on this broader set of terms. The costly implications of disaffection for not only disaffected students themselves but also for their teachers is clear from prior research, which also suggests that disaffection may be an especially pressing problem in schools that serve high needs populations (i.e. lower socioeconomic status) (Martin, Anderson, Bobis, Way, \& Vellar, 2012; Martin, Way, Bobis, \& Anderson, 2015). However, the classroom dynamics that underlie student disaffection and explain how it unfolds over the course of single classroom periods are not yet well understood.

This study explores one theoretically plausible explanation of these classroom dynamics. Suppose, hypothetically, that a student in a local middle school classroom begins to experience disaffection and expresses it, behaviorally (i.e., off task behavior, inattention, disruptive behavior) and/or emotionally (i.e., boredom, anxiety, frustration). In order to respond to that student's disaffection, teachers must first see and draw interpretations regarding the meaning of that student's actions. Teachers can interpret signs of student disaffection as either threatening or as challenging but valuable 
information that some aspect of the classroom context is not meeting the student's needs. These different interpretations are likely to result in divergent teacher responses to the student's disaffection, which then initiate cycles that can either amplify or reduce student disaffection. By looking inside the walls of middle school classrooms, this multiple case study investigates the dynamics of disaffection as they unfold within single class periods.

\section{Costs of Student Disaffection}

Costs for the student. Disaffection exacts short and long-term costs from students themselves. In the short-term, disaffection interferes with academic functioning. For instance, several short-term longitudinal studies have demonstrated that students with higher disaffection earlier in the school year have lower final grades or GPAs (Gonzalez, Garrido, Castro, \& Rodríguez, 2015; Gonzalez \& Paoloni, 2014; Gonzalez, Paoloni, Donolo, \& Rinaudo, 2015; King, 2015). Students with higher levels of disaffection also reported academic coping profiles that were characterized by the use of more maladaptive, rather than adaptive coping strategies (Skinner, Pitzer, \& Steele, 2016). Finally, higher levels of student disaffection were associated with lower educational aspirations in Science, Mathematics, and English (Green, Martin, \& Marsh, 2007).

In the long term, research suggests that more mild forms of misbehavior in middle school, such as those that align with the definition of disaffection, increase the likelihood of high school drop out (Balfanz, Herzog, \& Mac Iver, 2007; Juvonen, Le, Kaganoff, Augustine, \& Constant, 2004; Rumberger \& Lim, 2008). Further, students who experience the difficulties with academic performance outlined above are also at risk for dropping out of high school, which suggests that many disaffected students may have a 
collection of 'predisposing' and 'precipitating' antecedents that contribute to drop out (Dupéré et al., 2015). For students who ultimately drop out of high school, their longterm prospects are dim including lower income, fewer job opportunities, greater health problems including alcohol and substance use, and a greater likelihood of involvement in some forms of crime (Freudenberg \& Ruglis, 2007; Henry, Knight, \& Thornberry, 2012; Stark \& Noel, 2015). Clearly, disaffected students are vulnerable in both the short-term and long-term.

Costs for teachers. Student disaffection is also costly from the teacher perspective. More so than ever, teaching is a stressful and emotionally demanding profession (Chang, 2009; Kyriacou, 2001; Nizielski, Hallum, Schutz, \& Lopes, 2013; Markow, Macia, \& Lee, 2013) with research further demonstrating that teachers who work in high need environments report even higher levels of job-related stress (Richards, 2012). While there are many potential sources of stress in teachers' professional lives, one classroom-based stressor that teachers often cite as being especially taxing is disaffection, specifically disruptive behavior or misbehavior (Kyriacou, 2001). Chronic, high levels of teacher stress can lead to burnout, which is characterized by emotional exhaustion, depersonalization, and a lack of personal accomplishment (Maslach, Schaufeli, \& Leiter, 2001). In a review of the teacher burnout literature, Chang (2009) classifies student disaffection (specifically disruptive behavior) as among the principal factors contributing to teacher burnout. Student disaffection may also be a greater stressor in high needs school settings because lower school-level SES is predictive of higher levels of disaffection even when student-level factors and classroom-level factors are 
controlled for (Martin, Anderson, Bobis, Way, \& Vellar, 2012; Martin, Way, Bobis, \& Anderson, 2015). The negative outcomes associated with teacher burnout include costs to the teaching profession (e.g., increased absenteeism, intentions to leave the job, and ultimately teacher turnover) as well as costs to the individual teacher (e.g., negative physiological stress-related health outcomes, declines in teaching effectiveness, decreased job satisfaction, and a reduction in job commitment) (Chang, 2009; Maslach et al., 2001). Kyriacou (2001) casts burnout as an outcome of teachers' ineffective coping with stress over time, implying that the ways in which teachers respond or cope with student disaffection may have bearing on how costly disaffection is for both teachers and their students.

\section{Teacher Interpretations of and Responses to Student Disaffection}

Drawing from Resistance Theory, Toshalis (2015) contends that teachers can either view student disaffection (specifically, student resistance or disruptive behaviors), as a threat or as a diagnostic resource (Figure 3.1). These differential teacher interpretations of student disaffection may lead to different teacher responses instigating either defensive or supportive cycles, which are associated with different outcomes for students' subsequent disaffection and teachers' experiences of stress.

Viewing student disaffection as a threat. There are many reasons why teachers may view disaffection as a threat. First among them, student disaffection may make teachers feel disrespected or disliked by their students (Skinner \& Belmont, 1993). Second, student disaffection may cause teachers to doubt their competence, or feel helpless in addressing the problem of disaffection (Skilling, Bobis, Martin, Anderson, \& 
Way, 2016; Skinner \& Belmont, 1993). Third, if teachers view themselves as classroom authority figures, disaffected students are likely to be viewed as challenging that authority; thus student disaffection is threatening to the classroom power balance that teachers work hard to establish (Reeve, 2009; Toshalis, 2015). For these reasons, student disaffection may threaten teachers' needs to feel liked by their students, competent in their teaching, and in charge of their classrooms.

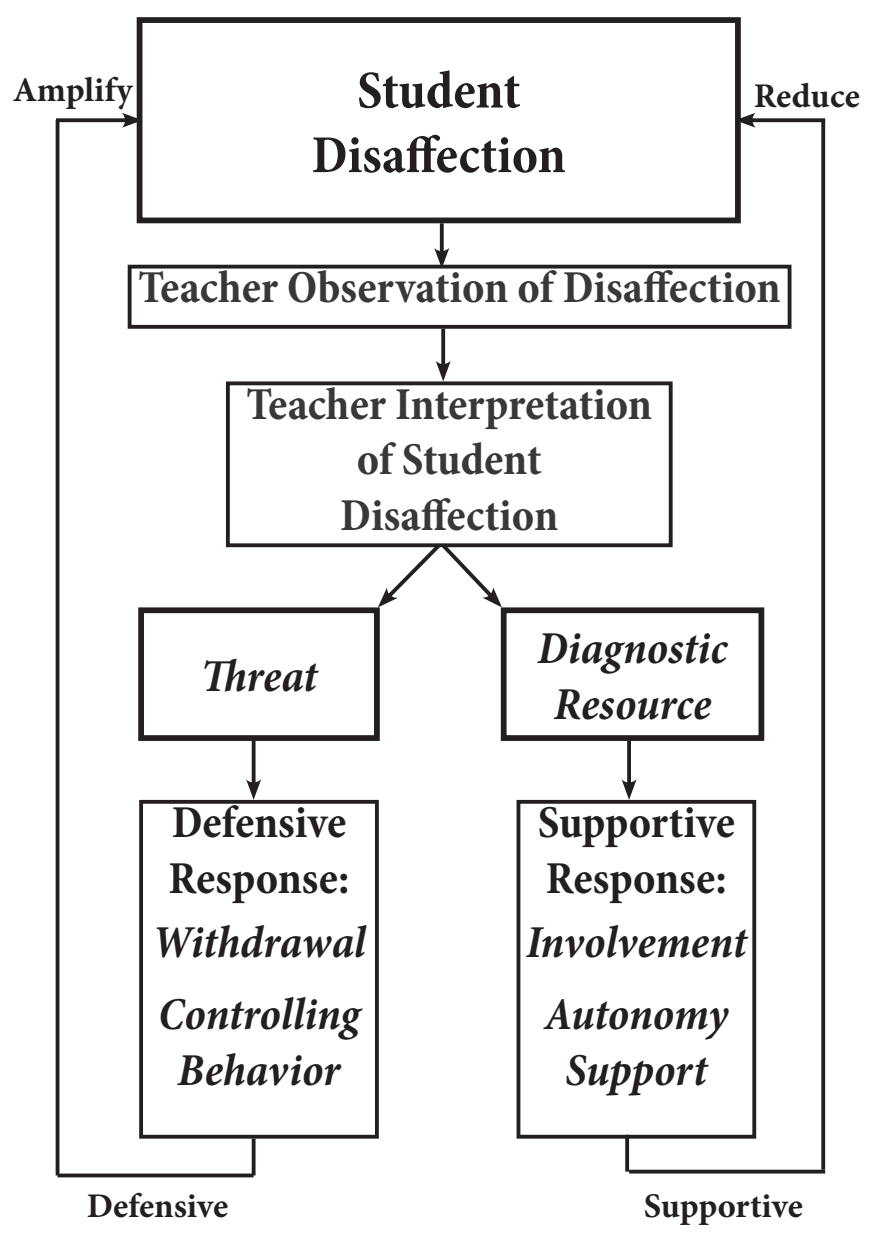

Figure 3.1. Hypothesized model of the dynamics of student disaffection: defensive and supportive cycles of teacher interpretation and responses to signs of student disaffection. 
Regardless of the reasons why teachers interpret student disaffection as a threat, two common teacher responses to disaffection that result from this interpretation are withdrawal from students and/or increases in control or power exertion (Lumby, 2012; Skilling et al., 2016; Toshalis, 2015; Reeve, 2009). Preliminary evidence that student disaffection can lead to teacher withdrawal stems from interviews with secondary students whose teachers perceived them as disaffected. These interviews, in which students reported perceptions of their teachers as "unaware or indifferent" to them, provide some evidence that teachers may react to signs of disaffection by withdrawing from students (Lumby, 2012, p. 271). Teachers themselves provide some indication that student disaffection is, at times, met with controlling responses. When interviewed about the teaching practices they used to promote engagement, some middle school teachers reported using controlling teaching styles (e.g., demerits or sanctions) to address behaviors that are prototypical of disaffection (e.g., off task behavior, low effort) (Skilling et al., 2016). According to Reeve (2009), “...students can push a teacher’s buttons to invoke a reactionary motivating style, and poor motivation, poor engagement, inattentiveness, and disruptive behaviors represent four such buttons that lower the threshold of an emergent controlling style." (p. 166). These teacher reactions to student disaffection, whether characterized by withdrawal or controlling behavior, represent a defensive response that is unlikely to address the underlying reasons for student disaffection. Thus, this defensive cycle is likely to further amplify student experiences of disaffection (as depicted on the left side of Figure 3.1). 
Viewing student disaffection as a diagnostic resource. Perhaps

counterintuitively, teachers can view disaffection as a diagnostic resource, a valuable signal that the learning context is not meeting the needs of their students or is perceived as boring, cold, unfair, or controlling (Lumby, 2012; Nardi \& Steward, 2003; Toshalis, 2015). If teachers view disaffection as a resource, they are more likely to respond in productive ways by strengthening student-teacher relationships (via involvement and autonomy support). There is evidence for the potential of teacher support (involvement and autonomy support) to counteract disaffection. For instance, students who reported experiencing higher levels of teacher support (treated holistically) in fall of the school year also showed greater decreases in disaffection (behavioral and emotional) across the school year (Skinner, Furrer, Marchand, \& Kindermann, 2008). Additionally, a correlational study found that higher teacher support (again, treated holistically) was associated with lower levels of disaffection (Guvenc, 2015).

Despite the potential for teacher support to reduce student disaffection, however, we currently have few tangible examples in the research literature of teachers who view disaffection as a diagnostic resource and so harness that information to respond in supportive ways that reverse disaffection. One exception is a single case drawn from a larger multiple case study in which Ravet (2007) describes a $6^{\text {th }}$ grade teacher who reported investing in establishing 'warm, trusting, and respectful relationships' (involvement) with her disaffected students. Ravet (2007) then goes on to note that this teacher's three disengaged students also reported positive relationships with their teacher and that they were "the only [students] in the study who made progress across the 
research period in terms of reduced disengagement" (p. 346). This example serves as preliminary evidence in support of this type of supportive cycle. Therefore, positive teacher responses are expected to reduce student disaffection (as depicted on the right side of Figure 3.1).

Current evidence regarding how teachers respond to student disaffection is largely limited to surveys or interviews with teachers and their disaffected students; however, observation-based studies could add value to this area of research by shifting the perspective from one of retrospective self-report to a contemporaneous third-party perspective (Skilling et al., 2016). This study aims to contribute to our understanding by using classroom observations of the interactions that surround episodes of student disaffection.

\section{Study Aims and Research Questions}

The purpose of this study was to describe the dynamics of student experiences of disaffection and teacher responses to disaffection by examining moment-to-moment interactions between middle school teachers and their students. This multiple case study focused on a library of classroom observation videos of teacher's self-designated most stressful class periods. First, case selection focused on finding classrooms that were potential 'hot-spots' for incidents of disaffection; these hot-spots were defined as classrooms that had predisposing factors (including students' own reports of disaffection and schools serving low socioeconomic status (SES) populations) because these factors increased the likelihood of disaffection occurring during the observed class periods. Next, the selected cases were qualitatively coded to describe the moment-to-moment 
interactions that unfold within these classrooms. The following research questions framed this study: (1) What kinds of classroom events initially spark student disaffection during the observed class periods?, (2) How does student disaffection unfold over the course of single class periods?, (3) How do teachers respond to signs of student disaffection?, and (4) How do episodes of disaffection evolve differentially (whether amplified or reduced) when met with teacher involvement and autonomy support versus withdrawal and controlling behavior?

\section{Research Design and Methods}

\section{Design and Procedure}

This study is nested within a larger wait list-control randomized control trial designed to investigate the efficacy of a mindfulness-based stress reduction program for teachers. All cases for this multiple case study were drawn from the baseline data collection for this larger study. Middle school teachers were recruited from a large urban school district ( 48,000 students, 39-46\% economically disadvantaged, 16\% English learners) through district wide emails to principals and flyers delivered to schools across the district. If teachers expressed interest in participation in the project, recruitment phone calls informed teachers of the details of the program and research; teacher consent was obtained at the first individual meeting with teachers.

Target 'most stressful' class. Teachers were asked to designate the class period

they currently found most stressful and this class became the target class for the research study with all data collection conducted in that class. All students in that particular class 
were invited to participate and parental consent and student assent was obtained. Teacher surveys, student surveys, and classroom observations were collected in Fall of 2014 or 2015 depending on which of two project cohorts the participating teachers were enrolled in.

Sample: selection of cases. Purposive sampling methods were used to select cases to include in this multiple case study (Hesse-Biber \& Leavy, 2011; Stake, 2006). In order to obtain a stratified purposive sample of cases that allowed for the intensive study of class periods that were marked by episodes of disaffection, two criteria were used: student-report surveys of disaffection and school-level socioeconomic status (SES). First, student-report surveys of disaffection were used to identify classrooms where students themselves reported experiences of disaffection. These student reports were key to narrowing down cases where the target phenomenon of this study, student disaffection, was present. Second, schools with low SES were prioritized for case selection because prior research has demonstrated that lower school-level SES predicts higher levels of disaffection while controlling for a variety of related variables including previous disaffection, student-level factors, and classroom-level factors (Martin, Anderson, Bobis, Way, \& Vellar, 2012; Martin, Way, Bobis, \& Anderson, 2015). Thresholds were used as cut offs for finding potential cases as follows: student disaffection ( $\geq$ average of three on the five-point Likert scale) and school-level SES (> 55\% economically disadvantaged). Combined together, these data sources allowed for the identification of a subset of 23 cases where there was a high likelihood of moments of student disaffection being captured in the videoed observations. All 23 cases were screened, however, the majority 
of these cases were excluded from the study because of issues with video or audio quality $(n=8)$, the class seemed largely engaged $(n=7)$, or the teacher assigned an activity (e.g., showing a movie or individual work with no teacher check ins) that did not involve many teacher-student interactions $(n=4)$. Thus, four cases were identified for inclusion in the study. All teachers in the four selected cases were Caucasian with a range of teaching experience (2-15 years). By design, the selection criteria for this study ensured that all teachers were teaching in a high needs environment with school-level SES ranging from $65-90 \%$ economically disadvantaged student populations and at least one student reporting disaffection at levels of 3.0 or above on the student survey.

\section{Data Sources}

Multiple data sources were used in this study including: surveys (both studentreport and teacher-report), videoed observations of classroom periods, and publicly available school-level demographic data. Each data source is briefly described below, including item examples as appropriate (see Appendix A for full list of items).

Case selection variables. As detailed above, the following data sources were used to identify cases.

Student disaffection (student-report). Seven items comprise the student disaffection scale, which used a 5-point Likert response scale: Not true at all (1), A little bit true (2), Somewhat true (3), Fairly true (4), Totally true (5). These items were drawn from Skinner, Kindermann, and Furrer's (2009) Classroom Engagement measure. Three items in this scale tap aspects of emotional disaffection including boredom, worry, and frustration (e.g., "The work in this class frustrates me.") and another four items represent 
aspects of behavioral disaffection including lack of effort and inattention (e.g., "When I'm in class, I think about other things."). Reliabilities for this scale were good $(\alpha=.76)$.

School-level SES data. Publicly available school-level SES data (\% economically disadvantaged) was collected from the Oregon Department of Education.

\section{Main study variables.}

Classroom Observations (videoed). Full classroom periods were video recorded using a camera, which included a microphone lanyard with Bluetooth technology that enabled the camera to track teachers as they moved around the classroom. Videos for the selected cases were coded with the coding scheme described below.

\section{Analysis Plan}

The data analysis in this study proceeded in four overall phases: data exploration, video coding, individual case interpretation, and cross-case analysis (Hesse-Biber \& Leavy, 2011; Stake, 2006; Yin, 2003). The data exploration phase included initial review of all possible cases in the larger dataset. First, videos from all classrooms that met the previously described selection criteria were reviewed. Cases were then further selected from the subset of classrooms meeting these criteria if the interactions between the teacher and disaffected student(s) were adequately captured on the video. This process of narrowing down cases resulted in the selection of 4 cases, which aligns with recommendations regarding the minimum number of cases that should be included in multiple case studies (Stake, 2006).

The video coding phase began with the training of a team of coders (composed of the first and third and fourth authors) to apply the coding scheme to classroom 
observation videos that were not part of the multiple case study. Discrepancies were discussed and consensus on code use was reached during these trainings. Additionally, the coding scheme was iteratively refined during the training period. Next, coding pairs (first author and one other coder) used the updated coding scheme to code $50 \%$ of the video for each case. Interrater reliability (IRR) was evaluated using Cohen's kappa coefficient for both disaffection codes $(K=.78 / .92)$ and teacher response codes $(K=$ $.74 / .74)$, indicating good interrater agreement. After evaluating IRR, the first author reviewed all discrepancies and reconciled codes where possible. Memos were written during the code reconciliation process and reviewed by the first author prior to the coding of the remainder of each case video. Final code summaries were then created for each completed video.

Upon completion of the data exploration and coding phases, individual case interpretation commenced with a review of all data and generation of a comprehensive descriptive summary of each case. The first author then carried out cross-case analysis, which was an iterative and reductive process (Stake, 2006). First, for each research question, individual case descriptions were read and coded for their relevance to research question-based themes, findings for each case were summarized, and specific excerpts were noted in support of the initial case-specific findings. Second, findings across all cases were aggregated, reviewed, and used to develop tentative assertions that applied to the larger set of cases. Finally, tentative assertions were drafted and discussed by the first and second author and considerations were made regarding the total number of 
assertions, any refinements needed to specific assertions, and the ordering of assertions for the final manuscript. Detailed memos were kept throughout all stages of the analysis.

Coding procedures. Observation codes were iteratively developed using both inductive methods and deductive methods. The deductive codes were drawn from prior research on characteristics of student-teacher relationships (involvement vs. withdrawal and autonomy support vs. controlling behavior) (Allen et al., 2013; Noddings, 2012; Pianta, Hamre, \& Allen, 2012; Reeve, 2009; Reeve \& Jang, 2006; Reeve, Jang, Carrell, Jeon, \& Barch, 2004; Skinner \& Belmont, 1993; Skinner \& Wellborn, 1997; Wallace \& Sung, 2016; Wallace, Sung, \& Williams, 2014; Wentzel, 2009) and student disaffection (Coan \& Gottman, 2007; Craig, Graesser, Sullins, \& Gholson, 2004; Kerr, Zigmond, Schaeffer, \& Brown, 1986; Reisenzein, Junge, Studtmann, \& Huber, 2014; Skinner, Kindermann, \& Furrer 2009; Toshalis, 2015Vogel-Walcutt, Fiorela, Carper, \& Schatz, 2012). Inductive codes were based on unanticipated behaviors that are observed directly in the cases (e.g., Redirection of behavior). The final coding schemes are detailed in Table 3.1-3.4. 
Chapter 361

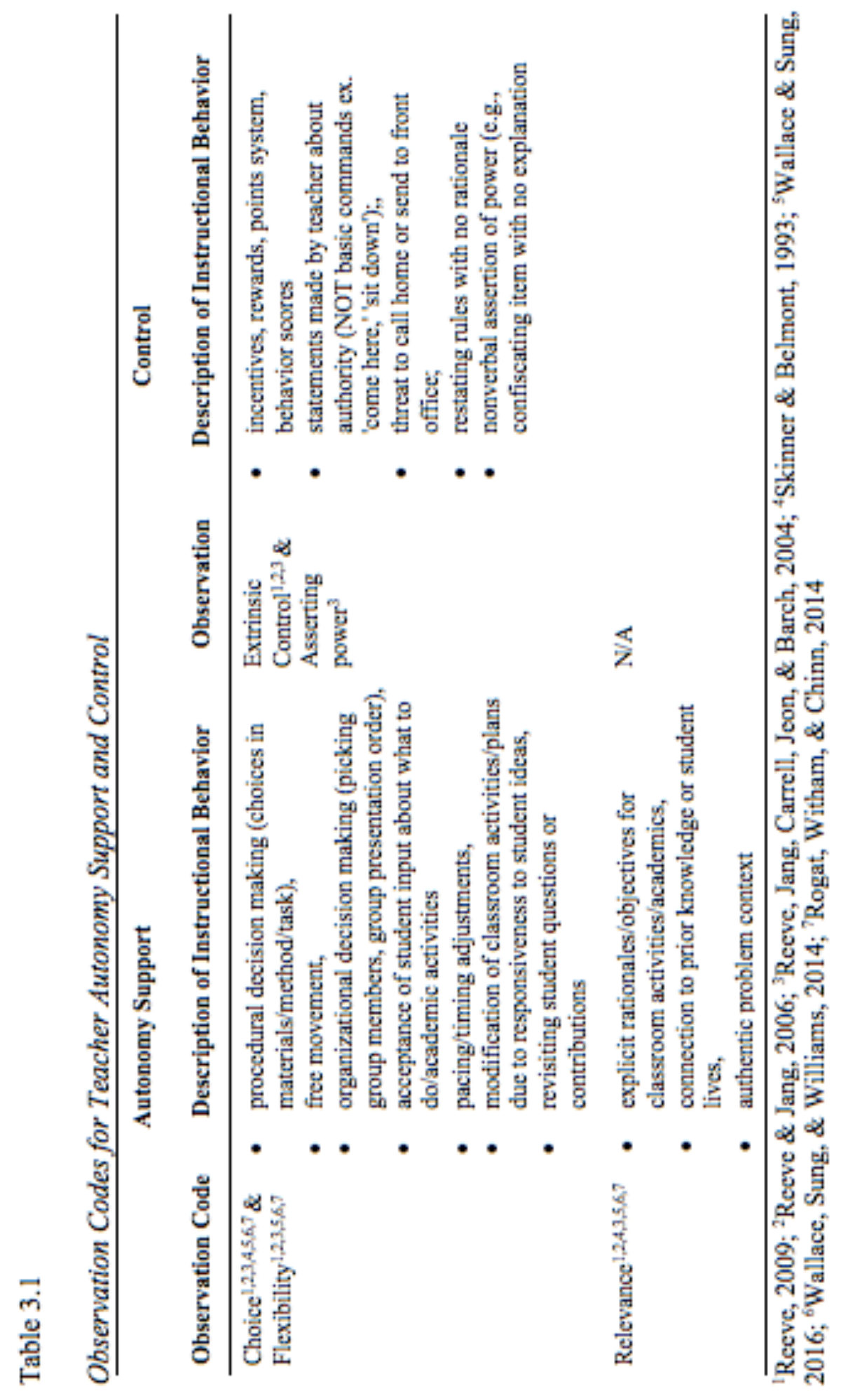




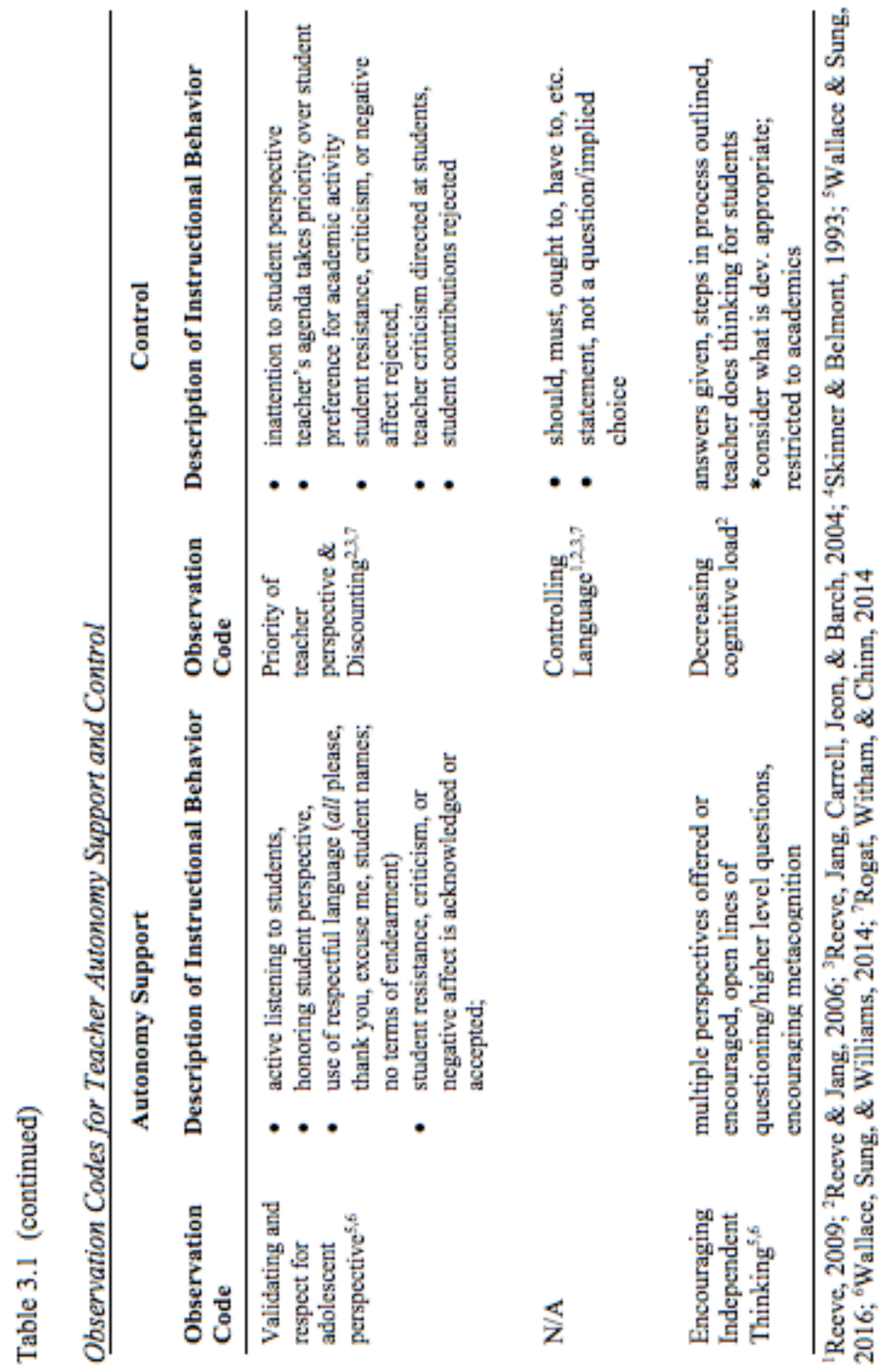




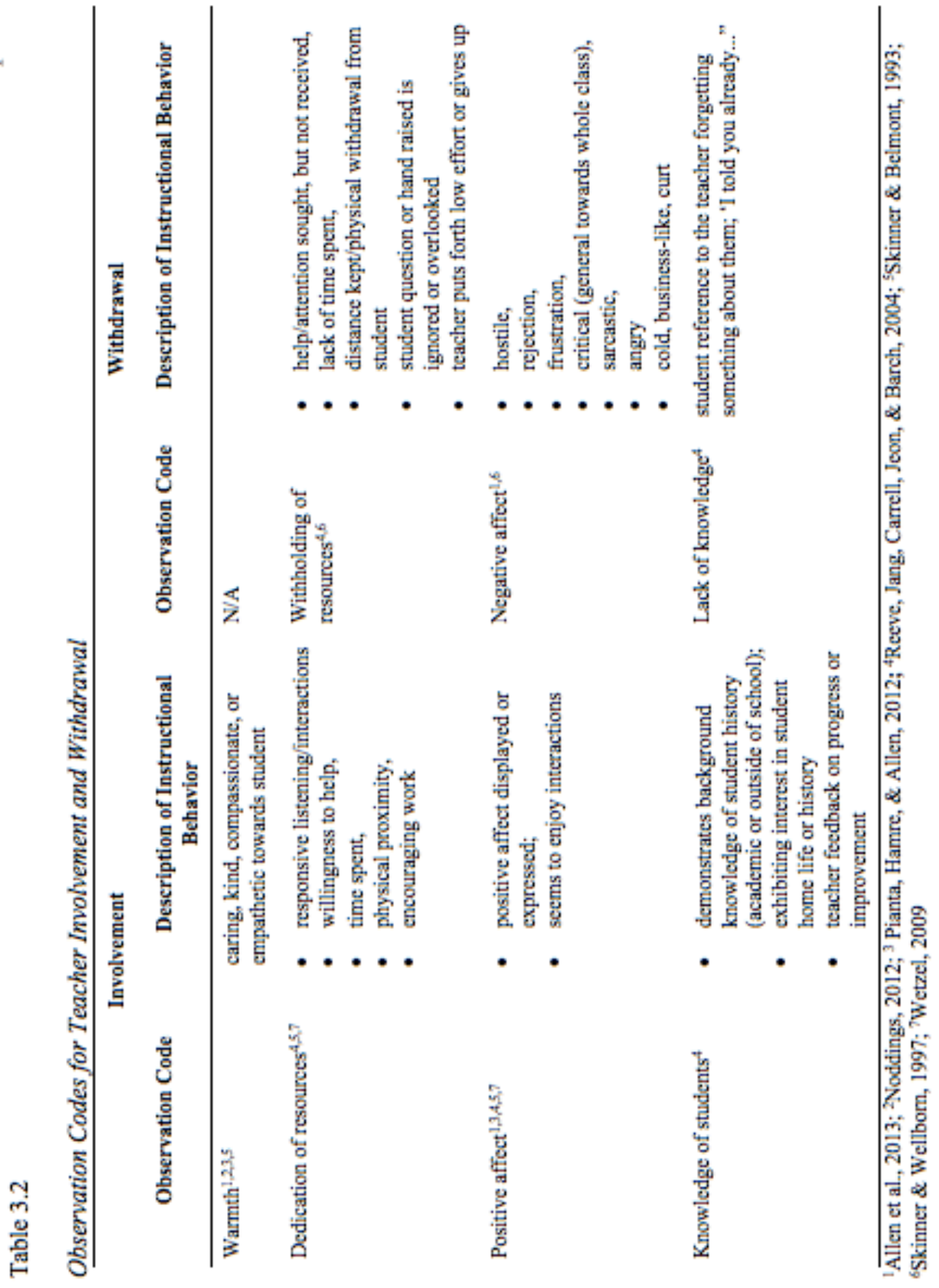


Chapter $3 \quad 64$
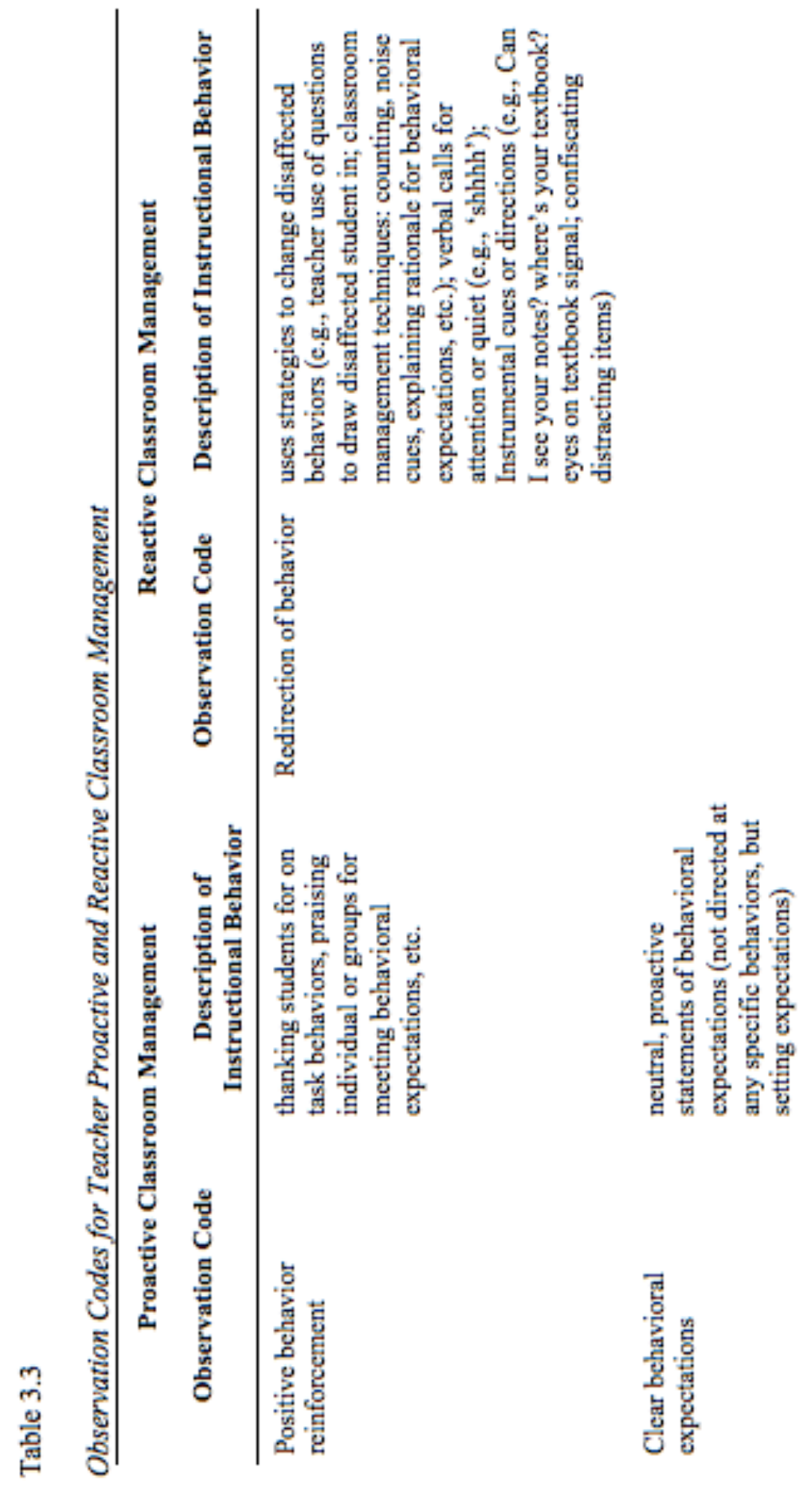


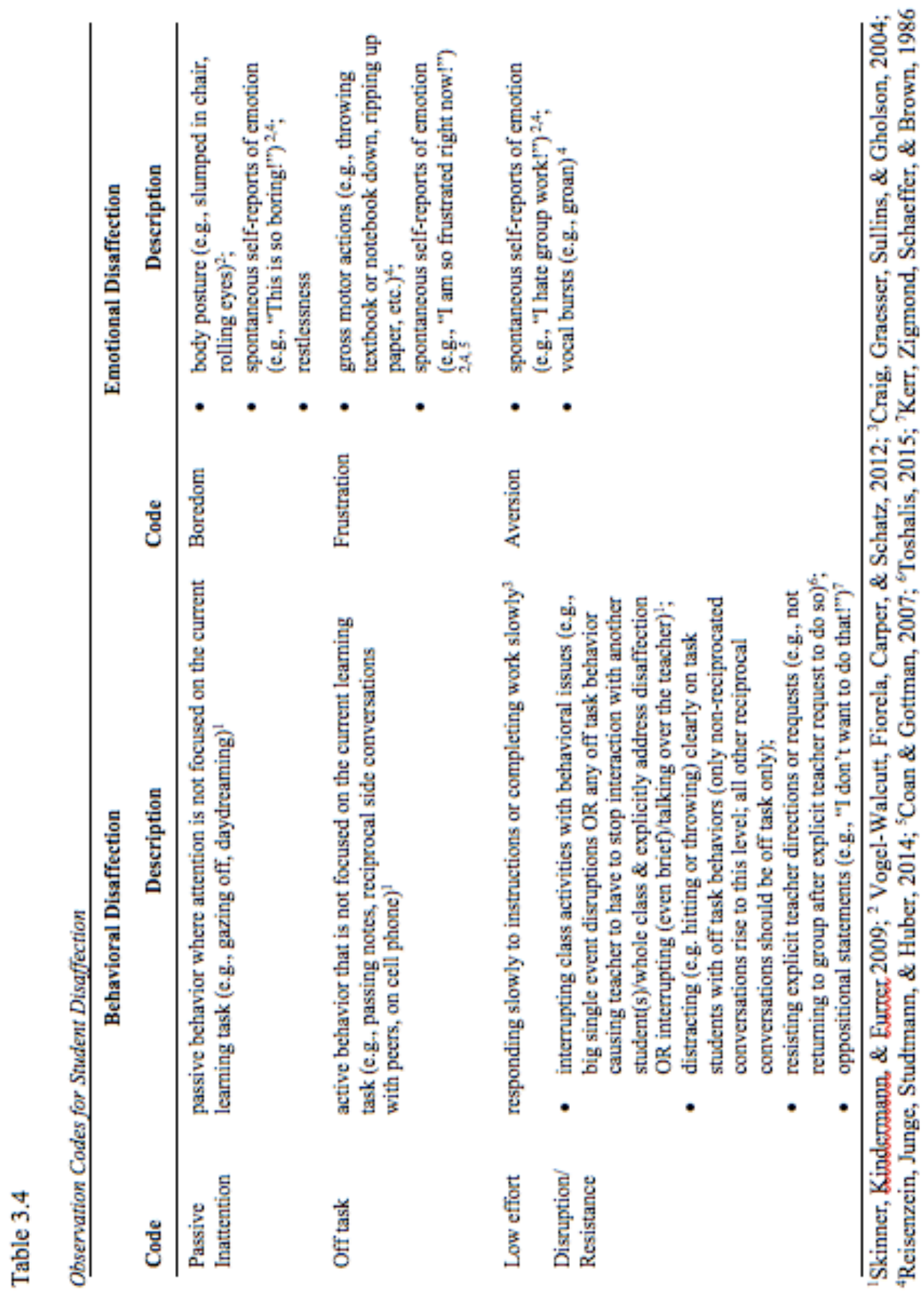




\section{Findings}

The following sections first introduce the four cases (or classrooms) that compose this multiple case study and then present findings for its four research questions: (1) What kinds of classroom events initially spark student disaffection during the observed class periods?, (2) How does student disaffection unfold over the course of single class periods?, (3) How do teachers respond to signs of student disaffection?, and (4) How do episodes of disaffection evolve differentially (whether amplified or reduced) when met with teacher involvement and autonomy support versus withdrawal and controlling behavior?

\section{Description of Classroom Cases}

Ms. Everett's ${ }^{1}$ Classroom. With a smile on her face and a positive demeanor, Ms. Everett, who had 15 years teaching experience and was teaching in a school with a $65 \%$ economically disadvantaged student population, described the mid-November day her class was observed with the proclamation: "Welcome to a Monday on a full week, after wacky weather, and no heat [in the school earlier that morning]!" On this particular day, five students (28\% of students present that day) in Ms. Everett's class exhibited signs of disaffection with varying degrees of severity. Ms. Everett and her $8^{\text {th }}$ grade math students began their class with a warm up activity, which was focused on multiple representations of mathematical patterns. At the end of the individual work time, Ms. Everett led a debrief of the warm up activity and then introduced the main activity of the

\footnotetext{
${ }^{1}$ All names used are psuedonyms.
} 
day called the "tile patterns team challenge." In this activity, student groups were tasked with making a poster showing every way they could represent the given pattern (shown on the assignment as a series of figures). During the introduction of this activity, Ms. Everett and her students reviewed the different mathematical representations the class had previously used: coordinate plane graph, table with $\mathrm{x}$ and y values, figures (0-5 and 20th), and 'rule' (i.e. equation). The bulk of the remaining class period was then spent on this small group activity. Ms. Everett spent her time moving between groups checking on their progress, answering questions, engaging in some social talk, and redirecting disaffection - all with mutually reciprocated smiles and laughter. The class concluded with a brief whole group activity where all students rotated around looking at the completed posters and copying down the rule from each poster. Finally, as the class concluded, Ms. Everett assigned homework.

Ms. Hamley's Classroom. With 2 years teaching experience, Ms. Hamley was teaching in a school that had a student population that was $81 \%$ economically disadvantaged. During this particular class in late November, Ms. Hamley and her $7^{\text {th }}$ grade mathematics students were focused on order of operations, specifically parentheses and exponents. At some point during this class period, six of Ms. Hamley's students ( $27 \%$ of students present) displayed signs of disaffection. The class began with an individual warm up activity that involved solving order of operations problems. After 7 minutes of individual work time had passed, Ms. Hamley began a whole class debrief of the warm up problems by accepting volunteers to talk her through each solution while she modeled how to show each step of the problem solving on the white board. Next, Ms. 
Hamley asked students to pull out a worksheet she had previously handed out, and patiently dedicated several minutes to helping students find their handouts or giving new handouts as needed. Then students were asked to again work individually to solve these new problems with Ms. Hamley emphasizing that students should practice showing their work as was just modeled in the warm up debrief. As students worked, Ms. Hamley moved around the classroom checking on students, but then, upon noticing one too many struggling students, she changed course and called the whole class back together. Once these problems were worked out as a whole class, Ms. Hamley then introduced a new activity while explaining the role of order of operations in these new problems ".. order of operations helps you take a situation or story and be able to write it into an equation and have people solve it the way you want them to solve it." Students then individually worked to convert the new story problem into an equation, after which Ms. Hamley led a whole class review of the solution. This process was then repeated for two additional problems. The class ended with Ms. Hamley handing out the students' next math packet assignment and allowing some individual work time on these packets.

Ms. Stillman's Classroom. Ms. Stillman, who had 12 years teaching experience, was teaching in a school that did not report the current school-level SES, however, the whole student population was offered free and reduced lunch during the study year; the year prior, $89 \%$ of students in this school were economically disadvantaged. On this early November day, Ms. Stillman and her $6^{\text {th }}$ grade science students were in the midst of concluding one science inquiry project and beginning another. During this class period, eight of Ms. Stillman's students (53\% of students present) showed signs of disaffection 
with varying degrees of severity. To conclude their substrate temperature change experiment, Ms. Stillman first gave her students one minute on the timer (a frequently used tool in this class) to complete their data tables, then she selected two groups to present their data tables and conclusions by rolling a die, and finally she gave two additional minutes for groups to finalize their conclusions. Next, the class moved onto their second investigation, which was focused on comparing daily and monthly weather data. Building on some prior individual work, Ms. Stillman gave students 2 minutes to share their data in their small groups and then moved to a whole class activity of finalizing the weather data "so that we all agree as a class." As enacted, however, this process consisted largely of Ms. Stillman instructing students to use her data instead of their own data, if they disagreed. Next, Ms. Stillman attempted to launch an activity of finding last week's precipitation data, but students briefly watched her struggle to find a website with the data before she gave up and moved on to a review of what the class has done thus far in their investigation. As she had many times before in this class, Ms. Stillman paused mid-sentence during the review to announce another deduction of table points from groups that were talking. Next, Ms. Stillman began another whole class activity of making an 'analysis of day weather' data table, which she scaffolded based on her past observation of students poor table making skills: "Now what I learned the last time you guys were required to make a data table all by yourselves is that you guys don't have a lot of practice in this and that didn't go so hot, so I'm not going to do it for you, but I'm also not going to make you do it yourselves, so let's do it together." Ms. Stillman then asked a series of questions aimed at deciding how many columns were needed in 
this new table with the mix of answers from students indicating she was correct that students may not have had success completing this task independently. Together the class finished mapping out the basic structure of the table and the first column, which was entitled data labels (i.e. temperature, precipitation, wind direction, etc.) and then Ms. Stillman stopped the lesson. This class ended with a raffle, which was "owed" from last week's class points.

Ms. Zacks' Classroom. With 8 years of teaching experience, Ms. Zacks was teaching in a school with a $90 \%$ economically disadvantaged student population. We joined Ms. Zacks and her 7th grade social studies students on the Monday after Thanksgiving in the middle of an instructional unit on medieval Europe. On this particular day, 11 of Ms. Zacks' students (58\% of students present) displayed signs of disaffection at some point during the class period. The class began with a warm up activity involving a map analysis worksheet for a map entitled 'European trade from 1200 to 1360 .' Approximately 8 minutes into the class, Ms. Zacks pulled her class together for a debriefing discussion of the warm up map posing questions such as "What is one thing you see in the map?" and "What do you think this map is trying to tell us?" Next, Ms. Zacks asked her students to take out their vocabulary sheets to continue their previous work on the unit's vocabulary. Based on confusion locating students' vocabulary sheets and a general lack of progress, Ms. Zacks announced "OK, I'm seeing people aren't really getting as far as I'd like you to get, so, shhh, instead of breaking up into our little working groups, OK (holding her fist, which was a silent, ineffective gesture for attention) we're going to have to go back to working as a class." This 
announcement was met with a collective groan from students indicating an overall aversion to the whole class structure. The next $\sim 30$ min of the class were focused on the vocabulary worksheet during which Ms. Zacks called on various students to give her the definition of the concept, occasionally posing questions about the concept (e.g. regarding commerce, “Did anyone go shopping this weekend?"), and frequently stopping to deal with disaffected students. Towards the end of class, despite two remaining vocabulary words, Ms. Zacks concluded the activity to move into a whole group sharing time called 'good weekend/bad weekend.' Between the general chaos of the classroom and an interruption from a member of the front office staff, however, Ms. Zacks never successfully began this sharing activity and the class period ended with an apology from her: "I'm sorry I didn't get to hear your good weekend/bad weekend" and her dismissal of the students by name.

\section{Research question 1: What kinds of classroom events initially spark student disaffection during the observed class periods?}

Each student's first instance of disaffection was identified, and both the specific type of disaffection and the concurrent type of classroom activity were noted. When these incidents were analyzed within and between cases, several patterns emerged. Initial student disaffection took many forms including, in order of their prevalence, socially off task behavior (68\%), passive inattention (16\%), solitary off task behavior $(12 \%)$, and much more rarely boredom or resistance ( $4 \%$ each). Across all classroom cases, the majority of disaffected students were initially socially off task, but this kind of disaffection occurred during a variety of classroom activities or events such as individual 
work time, whole class time, and less commonly small group time. Students most frequently experienced initial socially off task disaffection during individual work time and whole class time that required students to be relatively passive classroom participants.

Initial socially off task disaffection was observed most frequently (47\%) during individual work time. Often, these initial moments of disaffection occurred during the warm up activities that three of the four teachers in this study used to start their classes. For instance, during the warm up activity in Ms. Zack's class, John, rather than working on his map analysis, first talked and laughed with another student at his table, then shifted his attention and began to talk with another pair of girls sitting nearby, and finally got up moving out of his assigned seat to sit with these students and continue their conversation. Similarly, John's classmates Yasmine, Arla and Patricia; Ms. Hamley’s students Shannon, Noah, and Alyssa; and Freddie in Ms. Everett's class were all socially preoccupied when they were supposed to be working on their respective warm up activities. Initial socially off task disaffection was not equally present during all warm up activities in these three classes, however, suggesting that it is not the use of individual warm up activities that is sparking these initial moments of disaffection. Instead, it maybe some quality of the implementation of the warm up that leads to student disaffection, such as the developmental appropriateness of the task, the way the task is introduced, or the clarity of norms set for behavior during the individual warm up work time.

The second most common type of classroom activity (35\%) during which students were initially socially off task involved whole class time that required students to be 
relatively passive classroom participants. Frequently, the passive whole class activity involved the provision of teacher instructions. For example, while Ms. Everett was introducing and giving instructions for the tile patterns team challenge, Jensen was first nodding and making faces at another student across the class and then he initiated a sideconversation with Katrina, who was sitting next to him. Similarly, Byron was turned around in his seat talking to Carmen instead of listening to Ms. Stillman who was giving instructions to the class. Clearly, social aspects of the classroom are a predominant competing interest in middle school, therefore, if classroom activities, such as individual or whole group time, are structured in ways that do not sufficiently draw student interests, these classroom activities will lack sufficient appeal to override the temptation to socialize with peers. Thus, students may be at increased risk of experiencing socially driven disaffection and, likewise, teachers may have more disaffected students to contend with during these types of activities.

\section{Research question 2: How does student disaffection unfold over the course of single class periods?}

In depth individual descriptions of students behaviors and emotions during the observed class periods were analyzed with particular attention to how individual student's disaffection ebbed and flowed throughout the class period. Across all cases, six distinct patterns of how student disaffection unfolded could be discerned. Definitions and examples to illustrate each pattern are provided below. 
Fleeting disaffection: "I have my moments." Overall, six students (24\%) across three of the four classroom cases exhibited a pattern of disaffection during the observed class period that was infrequent (between 1-3 instances). Thus, disaffection was determined to be a fleeting experience for this group of students. Students in this group could experience fleeting disaffection at any point in the class, but this disaffection was most often observed at the beginning of the class implying some students had a hard time settling down upon arrival. For example, Shannon in Ms. Hamley's class was briefly talking to a student across the classroom (socially off task) before she settled in and began working on her warm up, but she was not disaffected during the remainder of the class. Similarly, Eddie in Ms. Stillman's class spent time either staring off into space or with his head down (boredom and passive inattention) during the first 10 minutes of class and was very briefly looking around the classroom at other students (off task) later in the class, but otherwise he remained engaged in the remaining classroom activities.

\section{Oscillates between disaffection and engagement: "I'm easily distracted."}

Across all four cases, six students' (24\%) disaffection showed a pattern that was marked by frequent moments of both disaffection and engagement suggesting that it was difficult for these students to stay engaged in classroom activities, perhaps because they were frequently distracted by social or other aspects of the classroom. For example, Freddie in Ms. Everett's class experienced three types of disaffection throughout the class period including times when he was staring out the window (passive inattention), laughing and talking with other members of his group (socially off task), and dancing on his own off to the side of his group (solitary off task), but he also had moments where he engaged in the 
tile patterns team challenge by discussing the project with a fellow group member, and by drawing on and cutting out figures for the poster. Noah's disaffection in Ms. Hamley's class also fits this pattern: his pace in working on the warm up was initially slow (low effort), he frequently was drawn into side conversations with Jaxson who sat behind him (socially off task), and, at one point, his conversation with yet another student across the class caused the teacher to stop her lesson to redirect his behavior (disruption). However, in between these moments of disaffection Noah experienced moments of engagement. For example, he took notes during the debrief of the warm up problems and he interacted with Ms. Hamley while solving a problem.

\section{Concurrent socially off task disaffection with engagement: "I'm a multi-}

tasker in this class." Two pairs of students $(16 \%)$ in two different classroom cases

experienced socially off task disaffection that was concurrent with low-level engagement. For example, Yasmine and Arla consistently talked with each other and, at times, other classmates throughout the majority of Ms. Zacks' class, but they were also simultaneously working on their vocabulary worksheets. When Ms. Zacks called on Arla to share the definition of the next vocabulary word, Arla was prepared to immediately stop her ongoing side conversation with Yasmine, turn around, and read the definition off of her worksheet. Similarly, Byron and Tyler spent much of the class period in Ms. Stillman's class laughing and talking to each other, but they also seemed to keep up pace fairly well with copying down their data table. Byron even openly objected when Ms. Stillman awarded points to another group, but not his group, for being on task copying down the data table proclaiming: "What!? I've been writing!" 


\section{Oscillates between passive inattention and off task disaffection: "I can't get}

into this stuff; it just doesn't interest me." Across two of the four cases, three students' (12\%) disaffection exhibited a pattern that showed they experienced a variety of disaffection including moments of passive inattention and off task behavior, either social or solitary, that may stem from a lack of interest in the content or structure of the class. Jaxson in Ms. Hamley's class intermittently spent time slumped over in his chair and talking with other students, particularly with Noah who was seated behind him for most of the class. Out of the three students in this group, Jaxson's engagement was the rarest and it was primarily restricted to times when Ms. Hamley directly engaged him in solving the order of operations problems, but even then, his attention flagged and he again became off task before the problem was solved. Additionally, both Carmen from Ms. Stillman's class and Michael from Ms. Hamley's class spent time with raised hands or writing hall passes to request permission to leave the class for trips to the bathroom or their locker in what seemed like an effort to escape the class.

Socially off task with at least one instance of resistance: "I care enough to resist." Three students (12\%) in two classes experienced periodic socially off task disaffection, but their disaffection was notably marked by moments that rose to the level of resistance. These students also spent ample class time engaged in various classroom activities. Thus, when taken together, this pattern implies that these students cared enough about classroom activities and their interactions with their teacher to resist. The severity of observed resistance varied across students from Carter's brief objection to Ms. Everett's confiscation of a bottle of vitamin water from his classmate, to Patricia's 
implicit resistance to Ms. Zacks' repeated requests for her to move back to her seat, to Adele's open refusal to move back to her assigned seat which resulted in an extended argument where it was Ms. Zacks, not Adele, who ultimately relented and let Adele stay in her chosen seat with a fervent promise not to talk for the remainder of the class.

\section{High amounts of socially off task disaffection rising at times to the level of} disruption: "I'm just here for the socializing." Across two classroom cases, three students $(12 \%)$ exhibited perhaps the most severe pattern of disaffection, which was heavily marked with repeated instances of socially off task disaffection. These students' off task behavior at times rose to such a high level that they were also disruptive to the whole classroom environment, frequently causing the teacher to have to intervene. For example, Krystal, who was more often called Kay-Kay by her classmates and teacher, spent the majority of the class animatedly talking to various fellow students. Kay-Kay started the class sitting with a group of chatty girls who's conversation rose to such a disruptive volume that Ms. Zacks had to stop her lesson on multiple occasions early in the class to redirect their disaffected behaviors. Then Kay-Kay's socializing continued unabated even when Ms. Zacks moved her across the classroom to a new seat. Upon this move, she first found another female student to talk with and then when that student was moved away from her, Kay-Kay found her new tablemates just as suitable for conversation. The students exhibiting this pattern did, however, vary in terms of the amount of engagement they displayed during the class with two students rarely engaging while the other engaged more often in between moments of socializing.

\section{Research question 3: How do teachers respond to signs of student disaffection?}


All coded instances of teacher responses to disaffected students were used to examine how the four teachers in this study responded to student disaffection. Each teacher's overall response style to disaffected students is first described briefly and then findings regarding overall patterns are discussed.

Ms. Everett's response style. Ms. Everett's responses to her disaffected students revealed a highly involved style characterized by a positive demeanor that made it clear she was genuinely fond of her students. In terms of involved teacher behaviors, Ms. Everett most frequently responded to her disaffected students by dedicating resources (i.e., spending time, encouraging work, physical proximity in interactions). For example, upon yet again approaching her group of disaffected boys, Ms. Everett spent time checking in with the students while simultaneously encouraging their work: "Look at that, looks good...keep going, [figure] 4 and 5, then you need to describe figure 20 and make a graph and stuff; we're going to need more than 5 minutes." Ms. Everett was fairly low in both control and withdrawal, but these behaviors did appear occasionally. For instance, there were a few moments where Ms. Everett asserted power by confiscating items like hair gel or prioritized her perspective by rejecting Carter's request for his group to work outside in the hall. Albeit for good reason, given Carter's group was the most disaffected group of students in the class.

Ms. Hamley's response style. Ms. Hamley demonstrated both high autonomy support and involvement in her interactions with her disaffected students. For autonomy support (other than the respect code, which represents a low-level autonomy supportive response and was common for most teachers in the study), Ms. Hamley used 
choice/flexibility (i.e., flexible movement structure around the class) slightly more often, but also used a fairly equal mix of encouraging independent thinking (i.e., asking openended questions about order of operations - "what does 75 - 6 represent?," "why did we have to put that in parentheses?," and "if we didn't have the parentheses what would have happened?") and relevance (e.g., asking if the math they are doing is harder than what they did in previous grades). For involved teacher behaviors, Ms. Hamley used nearly equal amounts of dedication of resources (i.e., time spent with students either trying to help them find their handouts, patiently working with them as they figured out problems on the board, and encouraging their efforts) and positive affect (i.e., both in the form of frequent smiling and the occasional joke with reciprocated laughter or smiles). Ms. Hamley generally tolerated a fair amount of chatting and seemed to object most often when the noise level rose too high or she heard conversations that were not about math. Although much less common, some defensive behaviors were occasionally displayed by Ms. Hamley, for example, one particularly striking moment was when Noah and another off task student were publically singled out for their poor performance with Ms. Hamley using their poor grades as her rationale for why they "of all people" should not be talking, a form of discounting. Ms. Hamley also appeared to begin to lose her patience with Jaxson, who fell into the "I can't get into this stuff; it just doesn't interest me" pattern of disaffection toward the end of the class. Her responses to Jaxson became increasingly (though still mildly) defensive, including two instances each of controlling language and withholding of resources. 
Ms. Stillman's response style. Ms. Stillman's collective responses to the disaffected students in her class demonstrated high control and moderately high withdrawal. For controlling teacher behaviors, extrinsic control/asserting power was the most frequently observed behavior with the vast majority of these instances relating to her extensive use of a point system in her class (extrinsic control); however, she also confiscated items on a few occasions (asserting power). At times, students were given points and praised for their good behavior, but more frequently, Ms. Stillman called out "bad behavior" (or behavior that violated her expectations) by table or more rarely by individual and announced the subtraction of points. At other times, points were silently assigned as she seemed to keep score throughout the class. Additional evidence of controlling behavior was present when students were not allowed out of their seats without permission (demonstrating a lack of free movement) and free time once given was to be used as she wanted, not as students wanted (i.e., silent, in chairs, only looking out the window at the sky, not at other things that could be seen if students stood up). Ms. Stillman's responses that amount to withdrawal from disaffected students included negative affect (the most frequently used code), where irritation with either specific students or more frequently the class in general was evident, and withholding of resources (i.e., ignoring a raised hand or dismissing a student's attempt at a side conversation). Ms. Stillman's behavior was not, however, devoid of involvement. Although less frequent than withdrawal behaviors, she dedicated resources on several occasions (i.e., physical proximity and spending time with groups). Finally, Ms. Stillman seemed inconsistent, overall, in her responses to student disaffection. She had a low 
tolerance for student disaffection when noticed, but did not seem to respond to all disaffected students equally. Some disaffected students were met with frequent redirections and occasional confiscation of items and criticisms, while others seemed to fly under her radar and get away with fairly consistent off task behaviors. For example, the same infraction of using Ms. Stillman's tape went unnoted and uncorrected for Byron and Tyler, who were largely overlooked during the whole class; in contrast, Monique and Ann, who were frequently noticed, were met with confiscation of the tape and curt/rejecting treatment for a very similar infraction.

Ms. Zack's response style. Ms. Zack's responses to her 11 disaffected students, the most in any class included in this study, demonstrated a style that was high both in control and autonomy support. In terms of controlling behaviors, she most frequently used power assertion (i.e., threats to move seats or actually moving students to different seats). Ms. Zacks, however, rarely followed through on her threats to move student seats: she moved only two students to new seats, asked several to return to their assigned seats, and threatened, but never followed through on a new seat assignment for other students on numerous occasions. In fact, two students actually refused to move when Ms. Zacks asked them to do so. While controlling responses were most frequent, Ms. Zacks also demonstrated autonomy supportive responses when interacting with her disaffected students. She made multiple attempts to bring relevance to the unit by connecting vocabulary to student's lives. For example, on this school day, which was after the Thanksgiving break and Black Friday, she asked "Did anyone go shopping this weekend?" Her question elicited answers from many students with, for example, Arla 
excitedly waving her raised hand around yelling "Yes, I did!" Ms. Zacks then expanded "You participated in commerce if you went shopping. Shopping is a type of commerce if you are buying something." In general, Ms. Zacks seemed to simultaneously care about her students (as indicated by multiple attempts to link class concepts to their lives and her demonstrated knowledge of students) and lose her patience with their continual disaffection. She was understandably irritated at times with persistently disaffected students and actively tried to intervene on student disaffection, but she also seemed to tolerate a fairly high amount of chaos that the sheer number of disaffected students in this class created.

Overall findings regarding teacher responses to disaffection. Across all four cases, the most common response to signs of student disaffection was redirection (i.e., use of strategies, such as verbal calls for attention, instrumental cues, or directions, to change disaffected behaviors; range: 52.5-66.2\%). Although sometimes used as the sole strategy, redirection was often paired with other responses such as a low-level version of respect (i.e., use of names, please, thank you). Below is just one instance from each teacher, demonstrating the range of ways teachers used respectful redirection:

Ms. Everett: "So you need a table and a graph; Jensen and Freddie, someone can be working on the table and graph."

Ms. Hamley: "Warm up and the date. Get your notebook open, warm up and the date. Thank you, sir."

Ms. Stillman: "Carmen, what did Bobby just say?"

Ms. Zacks: "Ok, Kay-Kay, can you please sit in your seat? Thank you." 
Whether used with redirection or other kinds of teacher responses, this form of low-level respect was the second most common teacher response to disaffection, although it was used less consistently across the teachers (range: $36.3-63.6 \%$ ).

When considering the broader overall categories of responses (i.e., autonomy support, control, involvement, and withdrawal), the teachers in this study varied widely in their use of these strategies with their disaffected students (Table 3.5). For example, when considering control, Ms. Hamley used controlling language ("Jaxson, Jaxson, turn around

Table 3.5

Teacher Responses to Disaffected Students

\begin{tabular}{lcccccc}
\hline & Autonomy & & & & \multicolumn{2}{c}{$\begin{array}{c}\text { Classroom } \\
\text { Management }\end{array}$} \\
\cline { 5 - 7 } Teacher & Support* & Control & Involvement & Withdrawal & Proactive & Reactive \\
\hline Ms. Hamlerett & $16.4 \%$ & $23.6 \%$ & $38.2 \%$ & $3.6 \%$ & $1.8 \%$ & $65.5 \%$ \\
Ms. Stillman & $24.3 \%$ & $6.8 \%$ & $32.4 \%$ & $4.1 \%$ & $1.4 \%$ & $66.2 \%$ \\
Ms. Zacks & $4.0 \%$ & $44.9 \%$ & $14.5 \%$ & $18.8 \%$ & $17.4 \%$ & $58.0 \%$ \\
\hline
\end{tabular}

Note. $*$ The autonomy support code of respect was adjusted for the analysis of overall teacher responses to disaffection because the high use of low-level respect skewed the overall use of this broad strategy.

you are distracting other people; in your seat.") on only two occasions $(6.8 \%)$ in her

class; in contrast, Ms. Stillman extensively used a table point system in her class $(44.9 \%)$ both silently keeping tally and, at times, explicitly announcing the awarding or subtraction of points ("Darren, you're losing points for your class right now, or for your group."), which represents the use of extrinsic control as a strategy to respond to disaffected students. 
One final finding, which was also illustrated in the descriptions of each individual teacher's response style above, is that no teacher in this study responded to disaffected students in a way that revealed a style that was only supportive (autonomy support and involvement) or defensive (control and withdrawal). Predominantly supportive teachers, Ms. Everett and Ms. Hamley, had their defensive moments. For example, Ms. Everett lost her patience with Carter toward the end of class:

Carter approached Ms. Everett as she was trying to bring the class back together for the assignment of homework, showing her a paper and asking if she had already collected it. Ms. Everett responded initially with "No, not yet, I'm going to get everything later, but not yet; sit down if you have this." But when Carter did not sit down, she repeated in an irritated tone: "sit down if you have this." As he walked back to his seat, Carter shook his head indicating he too noted the irritation in her voice.

Ms. Hamley also seemed to lose her supportive demeanor toward the end of class with Jaxson, who was perhaps her most disaffected student. On at least two occasions, she responded to Jaxson in a defensive manner by withholding resources from him. At one point, for example, she put her hand up and backed away from him while ignoring a statement he had made to her. In contrast, the one predominantly defensive teacher in this study, Ms. Stillman, had her supportive moments. For instance, when Carmen indicated she might have trouble presenting to the class, presumably because of a sore throat, Ms. Stillman showed both flexibility and dedication of resources, when she allowed another group member, Ann, to join Carmen at the front of the class to present their data table and conclusion. Finally, Ms. Zacks showed a marked mix of supportive and defensive 
responses throughout the observed class period demonstrating that some teachers' styles do not fit neatly into one category as originally hypothesized.

\section{Research question 4: How do episodes of disaffection evolve differentially (whether amplified or reduced) when met with teacher involvement and autonomy support versus withdrawal and controlling behavior?}

Detailed descriptions of both individual student disaffection and teacher responses were coded and analyzed in sequence to examine the question of how episodes of disaffection evolve differently when met with different kinds of teacher responses. Teacher responses were categorized as supportive (i.e., the only codes applied to a particular response fell under either autonomy support or involvement), defensive (i.e., only control or withdrawal), mixed (i.e., a combination of supportive and defensive), or non-responsive for the purposes of this analysis. Due to the frequency of its use and the relatively neutral nature of the response, redirection with low-level respect was considered separately for this analysis.

Redirections. The most frequent type of response by teachers, namely redirection (often paired with low-level respect), resolved disaffection about half ( $48 \%)$ of the time. Instances of the redirection response that resulted in a resolution of disaffection often, but not always, involved an instrumental cue or direction such that the teacher's request was geared toward the task at hand. These redirections included calls for attention such as invitations to join the current class discussion (Ms. Stillman: "Monique, please join this conversation."), suggestions or questions about specific tasks (Ms. Everett: "So you need 
a table and a graph; Jensen and Freddie, someone can be working on the table and graph;” Ms. Hamley: "Shannon, your warm up's that way (pointing toward the board), not that way (pointing toward the other student Shannon had been talking to)."), or calls to specifically engage in some immediate interaction with the teacher (Ms. Hamley: "Jaxson, round us out. What's the answer to 4+8?"). Redirection responses that were less effective at resolving disaffection often involved vague commands (Ms. Stillman: "Ok, table groups 6 and 2, if I could get your focus up here.”), requests for changes in behavior (Ms. Everett: "Have a seat, Freddie.”), or implicit requests (Ms. Zacks gently and silently touching Yasmine's shoulder while she was talking to Arla). Finally, there was also evidence that the same response does not work equally well for all students in a given class, thus reinforcing the dynamic nature of these interactions. For instance, the following whole class redirection from Ms. Zacks,

"OK, you have about one more minute and then we are moving on. Some of you haven't gotten any words on the paper, that's a problem. Turn your voices off." yielded a resolution of disaffection for John and Patricia, but no change in the disaffected behavior of Kay-Kay.

Lack of response by the teacher. In contrast to these frequent redirections, there were also notable times when there was a lack of teacher response, that is, when teachers either did not notice or ignored disaffection. When teachers did not respond to disaffection, it largely went unresolved $(\sim 75 \%)$ in the short term, although there were occasions when no teacher response occurred and disaffection was resolved ( 25\%). Unresponsiveness on the part the teachers in this study was not linked to a particular form 
of disaffection: both socially off task and passively inattentive forms of disaffection were unnoticed or ignored at times. Eddie in Ms. Stillman's class and Michael in Ms. Hamley's class serve as just two examples of this unresponsiveness to passively inattentive students:

Towards the beginning of class, Eddie was sitting slumped in his chair for a bit, then he put his hood up and his head down (passive inattention and boredom). The camera briefly panned so that he was off screen, but the next time he was on camera ( $\sim 6.5$ min into class) his head was still down. He was then off camera again, but at $8.5 \mathrm{~min}$ his head was still down and stayed down until $\sim 10 \mathrm{~min}$. At no point in these 10 minutes did Ms. Stillman respond to Eddie's disaffection, which continued unabated.

While students were supposed to be converting a newly introduced word problem into an equation, Michael had his chin on his hand and elbow in his lap so that he was slumped in his chair and was staring off toward the classroom windows for at least 2 minutes. The camera panned off of him, but when back on camera he was still staring out the window. Two minutes later, Michael finally started to write something, but it turned out he was writing himself a pass to leave class. Ms. Hamley did not address Michael's inattention during this time and it continued until he opted to use one of his hall passes to exit the classroom altogether.

Examples of teachers not responding to socially off task disaffection are also apparent. For example, Sam in Ms. Everett's class and Adele, Yasmine, and Arla in Ms. Zacks' class all had times when teachers did not respond to their socially off task behavior and it continued:

Approximately 23 minutes into the class, Sean was up out of his seat with Jensen 
and Freddie. The boys were talking and clearly not working on their poster. A few minutes later, Sean was leaning against the heater with Freddie and shortly after that he joined Jensen who was talking to [off task] and distracting [disruption] an on-task group on the other side of the class.

At $\sim 17$ minutes into the class, Adele, Yasmine, and Arla were engaged in what appeared to be an interesting conversation with Yasmine leaning in close to Arla almost as if in a huddle. The conversation continued for the next 4 minutes while Ms. Zacks was teaching about the vocab word guild.

Neither Ms. Everett nor Ms. Zacks responded to the instance of disaffection described above and the students' disaffection carried on with no resolution.

Although less common, there were also times when the teachers in this study did not respond to clear signs of student disaffection, but it nevertheless resolved on its own. For instance, early in Ms. Everett's class, Freddie was talking, laughing, and making faces with the other students at his table while the class was supposed to be working individually on a warm-up activity. Ms. Everett did nothing to intervene, but after about a minute or two of this off task behavior, Freddie looked at the projector screen and began writing in his composition book. As students moved into a whole class discussion of the warm-up problem, his engagement also appeared to continue as he seemed to be attending to the discussion.

Exclusively supportive response. When teachers showed exclusively supportive responses, these interactions more often $(\sim 68 \%)$ resulted in a resolution of student disaffection ranging in duration from momentary to brief to more sustained. Some 
supportive responses seemed to only work in the moment, temporarily drawing students into an interaction with the teacher, but disaffection returned as soon as the teacher's efforts subsided. For example, in a supportive response that was both autonomy supportive (respect, encouraging independent thinking) and involved (dedication of resources, positive affect), Ms. Hamley successfully drew Michael out of his solitary off task disaffection while she was interacting with him, but the resolution was not sustained after their interaction ended. Ms. Hamley seemed to notice Michael's distraction with the pencil he'd been playing with in his lap:

Ms. Hamley: "Hey Michael, what's the first thing we do in this problem?" Michael: "umm, add...(inaudible)"

Ms. Hamley: "How come we don't square first?"

Michael (in an unsure tone): "because you have the parenthesis so you have to square both of them?"

Ms. Hamley: "Yeah, and also the order of operations, what comes first?" Michael: "Ummm..." pointing toward the projected problem, but pausing. Ms. Hamley then approached the side of the room and pointed toward a poster on the right wall of the classroom saying: "What's the first rule in order of operations?"

Other students who were closer to the poster also pointed to something specific on the poster seemingly trying to help Michael. During this time, Michael's attention briefly flagged again as he looked back down at his lap, but then he looked at the poster and said "Oh, um, (inaudible)"

Returning to the whiteboard at the front of the class, Ms. Hamley said: "Yeah, so we want to do everything in the parentheses first. So, you're right, $2+1$ is? (Michael answers), then if we square 3 what's that?" It seems like Michael started to answer incorrectly (likely multiplying by two 
instead), but Ms. Hamley pointed at him, smiling and nodding; she began to say "that's..."

Then Michael said: "oh, 9"

Ms. Hamley: "Perfect, perfect, perfect."

This concluded Ms. Hamley and Michael's interaction, and as she moved onto the next problem his attention almost immediately shifted back to the pencil in his lap (solitary off task).

Other supportive responses resulted in a resolution of disaffection that lasted beyond the actual interaction, though sometimes only briefly. For example, in an exclusively supportive response characterized by high-level respect, dedication of resources, positive affect, and redirection, Ms. Everett was successful at reengaging Freddie in his group's work:

Freddie was again disaffected as we see him in the midst of another brief moment of dancing off to the side of his group.

Ms. Everett: "Freddie, how are you helping your group?"

Freddie: "Well, I'm like the general"

Ms. Everett: "You're the organizer?"

Freddie: "And if they do something wrong I yell at them!"

Ms. Everett (laughing and smiling): "Well, why don't you praise them for doing something right?"

With this, Freddie seemed to reengage in the group activity and was seen fighting with Carter over who was going to write something on the poster immediately after this interaction. He remained engaged cutting out one of the group's figures for at least 3 
minutes, but then shortly after returned to his previous off task dancing.

Finally, although relatively rare, there were at least two instances of supportive responses that resulted in more sustained resolutions of disaffection. First, an interaction characterized by validation and positive affect in Ms. Zacks' class resulted in an end to Adele's socially off task disaffection for the remainder of the class.

Another student, Arla, first sought Ms. Zacks attention and then read a note from Adele to her (Adele is not supposed to be talking based on a previous agreement between her and Ms. Zacks):

Arla: "It says: Ask Ms. Zacks, that if she don't, if Adele doesn't talk for the rest of the day, [you will] call her parents and say that she does 'really, really, really, really good in class'."

Ms. Zacks: "I'd love to do that"

Arla: "But you can only say good things."

Ms. Zacks then approached Adele and said: "Sounds like a plan. Awesome. I love that incentive for me. I need positive phone calls."

Adele then worked for the rest of the class period with no further side conversation with her previous conversation partners, Arla and Yasmine. The second supportive response that resulted in a sustained resolution of disaffection occurred in Ms. Hamely's class:

Ms. Hamley paused her teaching and audibly sighed due to a generally unsatisfying amount of side chatter in her class.

Noah then asked Ms. Hamley: “can I move?...because he's bothering me"(pointing at Jaxson).

Ms. Hamley: "where... where can you sit that you're not going to be distracted? ...Do you want to sit back with Amanda's table?"

Noah nodded, collected his belongings and moved back to his new seat and was 
largely engaged for the remainder of the class period.

Ms. Hamely's response was characterized by both autonomy support, by validating Noah's request and giving him the choice to move, and involvement, by using her knowledge of her students in suggesting a new, less distracting seat.

Exclusively defensive response. Exclusively defensive responses resulted in unresolved disaffection the majority ( $\sim 89 \%)$ of the time. Unlike supportive responses, which often were an amalgamation of different kinds of positive responses, teachers defensive responses were more often characterized by a single kind of negative response, such as asserting power, extrinsic control, or withholding of resources. To some extent, it appeared that teachers each had their own predilection toward a particular defensive response. For instance, Ms. Stillman made extensive use of a point system in her class, which was often used to exert extrinsic control over her students' disaffection. One illustration of this occurred after Monique returned from the restroom and was aimlessly wandering around the front of the classroom rather than returning to her seat. Ms. Stillman said, while looking at Monique and simultaneously subtracting points from her table: "I see two people out of their seats, one of whom has permission." Despite this statement being clearly aimed at her, Monique remained up out of her seat for approximately the next minute before finally returning to her seat.

Ms. Zacks had a tendency to assert power over her disaffected students with frequent threats of seat moves. For example, addressing her group of socially off task girls, Ms. Zacks threatened 'OK, if you don't stop talking at this table, I'm going to move all of you to different spots." However, this threat (and several others) ultimately had 
little impact on their socializing. More rarely, Ms. Zacks took her power assertion further by actually requiring students to move seats. For instance, Ms. Zacks stopped midsentence while teaching about the vocabulary term "guild" and said:

“...Ok, I think I need to move two people... [then after moving another student] Kay-Kay, I think I need to move you, umm, I'm going to move you over by Tim, right across from Tim."

Kay-Kay then got up in a leisurely manner and started to move, but she took her time stopping along the way to first talk to Adele. Then when she arrived at her new seat, she tossed her book down looking at one of the students at her new table, and making a bowing motion with her hands almost as if to say 'Here I am; I've arrived.' She then did not sit in her seat, but instead knelt on it leaning against the back and looked over at Patricia (who was sitting toward the back of the classroom). Kay-Kay then started a new conversation with Patricia. Thus, leaving her socially off-task disaffection unresolved by the seat move.

Finally, two teachers resorted to the defensive response of withholding of resources in their interactions with their disaffected students. At one point, Carmen's raised hand went unnoticed by Ms. Stillman for well over a minute. Carmen persisted in keeping her hand raised, shifting positions at times from what appeared to be a fatigued arm. Then, when finally called on, Ms. Stillman assumed Carmen was offering to answer a question she had just posed, only to find out that she was instead seeking permission to go to the restroom. This interaction served as confirmation that Ms. Stillman may not have noticed Carmen's raised hand. After Carmen returned from the bathroom, she 
immediately sat down and started talking to Monique so her disaffection went unresolved. Similarly, Ms. Hamley entirely overlooked Jaxson's raised hand at one point during the class period. Jaxson was initially sitting slumped in his chair passively inattentive, but then he raised his hand. After a short period of time passed with no response from Ms. Hamley, Jaxson even tried waving his hand around. Ms. Hamley, however, never called on him. He then briefly returned to his passive inattention again slumping in his chair, before shifting to socially off-task disaffection by looking around the classroom and mouthing something to another student.

Mixed responses. Responses that represented a mix of supportive and defensive teacher actions more often left disaffection unresolved ( $\sim 80 \%)$. Most mixed responses were composed of defensive responses (control and/or withdrawal) and low-level respect. For instance, upon noticing that Ann and Celia were preoccupied with the tape on their table, Ms. Stillman intervened by confiscating the tape (asserting power), ignored a student comment (withholding of resources), and showed some obvious irritation (negative affect), but she also used respectful language:

Ms. Stillman: "Table group 2, please don't use my tape without my permission” Celia: "Can I use your tape?"

Ms. Stillman (while approaching the students): "To do what?"

Ann: "To cover this up. Do you have white tape? That would be fantastic." Ms. Stillman uttered no response, then snatched the tape while shaking her head and returned to teaching at the front of the class. Neither Celia nor Ann seemed to pay attention to Ms. Stillman after this interaction.

Similarly, Ms. Everett asserted her power by confiscating items from her 
disaffected students while using respectful language. For example, having previously tried to redirect Freddie and Jensen's preoccupation with styling their hair, Ms. Everett approached saying "Um, gentlemen, I don't know what this stuff is, but it doesn't look like something that belongs in a classroom so how about I'll take it for now and when you leave you can have it back." Unfazed by the confiscation of the hair gel container, Freddie continued to style his hair with what he had left on his hands for the next several minutes of the class. This same teacher response also resulted in a brief escalation of Jensen's disaffection because he initially resisted Ms. Everett's attempt at confiscating the hair gel by holding it just out of her reach while she strained to get her hands on the container. Escalations of disaffection were rarely observed in this study with this example being one of only three instances where an escalation occurred.

Some mixed responses were characterized by a more balanced combination of supportive and defensive teacher responses, but these mixed responses still often resulted in no resolution of the student disaffection. For example, when the level of chatting and giggling from the group of girls in Ms. Zacks' classroom rose to a high level, Ms. Zacks approached the group and attempted to intervene:

Ms. Zacks (in an irritated tone): “OK, if you don't stop talking at this table, I'm going to move all of you to different spots."

Kay-Kay, who was part of this group at the time, replied with an inaudible response.

Ms. Zacks: “I need you, I'm sorry, I need you to stop talking. I need you to do your work... because I'm going to take this down and you're not going to have it done and then you're not going to get your 5 points for the day. So please do your work. We're back at school, I know you had four days off, but I need you to do 
your work, Kay-Kay."

Ms. Zacks started to walk away, but Kay-Kay again said something inaudible, likely objecting to being specifically singled out.

Ms. Zacks then turned around and came back to the group: "OK, you and Maria, Kara."

Then girls then said in chorus with giggles "And Maya" naming the fourth student at the table that Ms. Zacks had not specifically named.

Ms. Zacks: "and Maya, all need to do your work."

More giggles from the group.

Ms. Zacks: "OK?"

After Ms. Zacks left, Kay-Kay and the other students at this table continued to talk.

Although their voices briefly stayed lower, their volume quickly began to rise again. Ms.

Zacks interactions represented the use of both supportive responses, including respectful language and dedication of resources through the time she spent with this group of students, and defensive responses, including controlling language, asserting power, and negative affect.

On rare occasions, mixed $(\sim 13 \%)$ responses coincided with brief escalations of disaffection. An example of this kind of brief escalation of disaffection again lies in interactions between Ms. Zacks and one of her students. This interaction began when Adele, who was out of her assigned seat sitting with Yasmine and Arla, started laughing loudly enough that it caught Ms. Zacks attention.

Ms. Zacks: "OK. Adele, I need you to go back to your seat."

Adele: "I'm sorry, she just told me something"

Ms. Zacks: "I'm sorry, but you're really..." 
Adele: "I don't want to sit there, Ms. Zacks"

Ms. Zacks: "OK, I need you to move back there"

Adele: "Can I please have one more chance?"

Ms. Zacks: "No you may not..."

Adele: "I promise..."

Ms. Zacks: "I already gave you a chance that I shouldn't have given you" Adele (slightly raised voice): "I didn't know that you gave me a chance" Ms. Zacks (in a frustrated tone): "You moved out of your seat" Adele (whines): "Well, you didn't tell me"

Ms. Zacks then said (with Adele begging/interjecting along the way): "You just moved out of your seat so I'm telling you, I'm asking you please move back to your seat, please move back to your seat, [Adele: "please" ] please move back to your seat, just move back to your seat, [Adele: "please..." ] do you want to have a phone call home?"

Adele: "No, but please..."

Ms. Zacks: "Please go back to your seat"

Adele: "I'm not going to do anything. If I talk one more time, then you can call home"

Ms. Zacks: "Well that's just kind of silly because you will talk again" Adele: "I won't talk."

Ms. Zacks: “Ok, let me see this, silent game, you and me, we're on, I'm allowed to talk and you're not, OK?" (Smiling).

In this interaction, Ms. Zacks used both supportive responses, including positive affect and respect, but she also used defensive responses, including asserting power, negative affect, and discounting. Adele's disaffection briefly escalated to resistance during this interaction as she refused to move back to her assigned seat despite Ms. Zacks' repeated requests. 


\section{Discussion}

This study was designed to explore questions surrounding the development and classroom dynamics of student disaffection, including the classroom events that instigate student disaffection, how disaffection changes over the course of single class periods, teachers' general responses to disaffection, and the dynamics between specific teacher responses and the resolution or persistence of student disaffection. In doing so, several of this study's underlying expectations were confirmed while new, sometimes unexpected, findings about the classroom dynamics of student disaffection were also uncovered.

In particular, socially-driven disaffection, whether during individual or passive whole group activities, was found to be the most prevalent form of disaffection initially experienced by the students in this study. Six patterns in how disaffection changed across the course of the studied class periods were found pointing to distinct student experiences of disaffection. Generally, teacher responses to disaffection could be categorized as showing supportive or defensive tendencies, but these could only be considered response propensities; they did not reflect response styles to which teachers firmly adhered.

Finally, teacher responses to particular instances of disaffection fell into five categories: two hypothesized (supportive and defensive) and three unanticipated (mixed, redirection, no response) and each response category varied in its effectiveness at resolving disaffection. The implications of these findings, as well as, study limitations and future research directions are discussed in what follows. 


\section{Implications of the Findings}

The nature of student disaffection. Past survey-based research (Skinner, Kindermann, \& Furrer, 2009) has indicated that student disaffection is a multidimensional construct characterized by a complex set of behaviors and emotions students experience when they withdraw from academic endeavors. The six patterns of disaffection found in this study further confirm that many students experienced multiple forms of disaffection and moved from various disaffected states to engaged states and sometimes back again, verifying not only the multi-dimensional nature of disaffection, but also its state-like nature. This multi-dimensionality was observed across different students as some students had a tendency towards a particular form of disaffection (e.g., those students who showed the pattern that could be dubbed 'socializers') while others tended towards other forms (e.g., those students who leaned towards passive inattention and boredom). Additionally, the presence of multiple forms of disaffection within individual student's experiences of disaffection (e.g., Freddie in Ms. Everett's class who regularly shifted between solitary off task, socially off task, and passively inattentive behaviors) further corroborated this multi-dimensionality.

Regarding the state-like nature of disaffection, the different patterns of disaffection uncovered in this study all include fluctuations between disaffection and engagement. These patterns varied in the frequency of their fluctuations, some likely representing more mild forms of disaffection (e.g., fleeting) and some more persistent, severe forms (e.g., socializers), but there were no students in this study who appeared to remain continuously disaffected throughout the observed class period. In fact, even the 
most severely disaffected student in the study experienced brief moments of engagement. This suggests that disaffection is best conceptualized as a fluid state-like, not static traitlike, phenomenon.

Importance of student disaffection. This study provides tangible, detailed realworld examples demonstrating the costs of student disaffection both for disaffected students themselves and for their teachers. Whether chatting during individual warm-up activities, dancing off to the side during group projects, or staring out the window during whole class time, the episodes of student disaffection observed in this study prevented students from participating in the classroom experiences their teachers had designed for them thus costing them valuable learning opportunities. If these experiences of disaffection continue unabated, it seems clear that they would, as past research suggests, negatively impact student achievement (Gonzalez, Garrido, Castro, \& Rodríguez, 2015; Gonzalez \& Paoloni, 2014; Gonzalez, Paoloni, Donolo, \& Rinaudo, 2015; King, 2015). At the same time, student disaffection often interrupted teachers' plans for their classroom, at times, visibly frustrating teachers confirming student disaffection as a jobrelated stressor (Kyriacou, 2001). These descriptions of real-life classroom episodes of disaffection serve as confirmation of the importance of this phenomenon for both students and their teachers.

\section{Pervasiveness of socially-driven disaffection in middle school classrooms.}

Aligning with research on adolescents more generally, which highlights this developmental period as a time when the importance of social interactions with peers increases (Eccles, 1999), this study brings to light the pervasiveness of socially-driven 
disaffection in middle school classrooms. The prevalence of this kind of disaffection, which often took the form of socially off task behavior in this study, was clear in both the investigation of initial disaffection (research question 1) and patterns of disaffection across the class period (research question 2). First, in investigating students' initial experiences of disaffection, socially off task behavior was the most prevalent form of disaffection observed. Second, socially off task disaffection played a role in all of the six patterns of disaffection found in this study. Furthermore, only one student out of all 30 in this study exhibited no signs of socially off task disaffection at any point during the observed class period. Clearly, social aspects of the classroom are a predominant competing interest in middle school classrooms. This study demonstrates that classroom activities without sufficient appeal to override the temptation to socialize with peers, such as the individual work time and relatively passive whole group time observed in this study, will leave students open to experiencing socially-driven disaffection.

Multiple patterns of disaffection. Six different patterns of disaffection were found in this study including patterns that are prototypical for students who 1) experience only brief moments of disaffection, 2) are easily distracted, 3) find ways to multi-task during class, 4) can't get interested in particular topics, 5) care enough to resist, and 6) are just in class for opportunities to socialize. These patterns bring the phenomenon of disaffection in the classroom to life by providing vivid examples of what disaffection looks like in real-world classrooms and also offer some indication of differences between students in their experiences and expressions of disaffection that are important for both researchers and educators. 
The nature of teacher responses to disaffection. Contrary to our original hypotheses (implied in Figure 1), teachers' responses to disaffection in this study did not allow us to neatly divide teachers into those who tended to respond in strictly supportive or defensive manners. While there were teachers who appeared to have more supportive or defensive tendencies, all four teachers had their supportive and defensive moments. There was also variation not only between teachers, but also within the same class in response to different students. For example, Ms. Stillman ignored one group of students when they were off task playing with tape, but responded in a mixed, but primarily defensive manner when another pair of students was seen engaging in the same off task behavior. Perhaps what predicts a teacher's response to a particular student's disaffection may not be some general modus operandi each teacher has for interactions with disaffected students, but rather a complex amalgamation of factors including past instances of disaffection, general relationship quality, and the student's performance or standing in the class. This finding supports the notion that the classroom interactions that surround disaffection are multi-faceted in nature.

\section{Dynamic interactions between disaffected students and their teachers. The} discovery of five categories of teacher responses to disaffection, rather than two, led to a revision of the originally proposed model of the classroom dynamics of student disaffection (Figure 3.2) to reflect both the more complex set of teacher responses to disaffection and their resulting impact on disaffection. Overall, two responses were found to reduce disaffection, while the other three left disaffection unresolved, maintaining the status quo. Contrary to expectations, defensive responses did not appear to amplify 
disaffection. Fortunately, teacher responses that amplified disaffection were rarely observed in this study.

Supportive responses: Most effective and most time intensive. Of the teacher responses observed in this study, solely supportive responses were the only ones that resulted in a resolution of student disaffection a majority of the time $(68 \%)$. Supportive responses met student disaffection with teacher involvement and autonomy support, which past research suggests reduces student disaffection (Guvenc, 2015; Skinner, Furrer, Marchand, \& Kindermann, 2008). These responses were most effective at resolving disaffection when they addressed the underlying reason for the student's disaffection. For instance, by allowing a student to move away from a distracting classmate at his own request, Ms. Hamley addressed the social interests against which her planned activities were competing and, in doing so, decreased Noah's disaffection.

These tailored supportive teacher responses could only happen if the teacher noticed student disaffection, correctly interpreted the underlying cause of that disaffection, and enacted an appropriate response to meet the student's particular need. Thus, these responses imply that teachers are using disaffection as a diagnostic tool. It is not enough for teachers to just see disaffection and address it, they must also correctly intuit the underlying cause of disaffection and tailor their response to it. Embedded in these supportive responses is a time investment on the part of the teacher.

The time required to enact a supportive response is both explicitly present in some kinds of supportive responses (e.g., dedication of resources, which specifies time spent) and implicit in others (e.g. knowledge of students, which takes time to develop as it 
requires that information is gathered about the student's life outside of the classroom). Regardless of the exact type of supportive response, these findings suggest that the time investment often pays off and results in a resolution (even if only temporary) of the student's disaffection. 


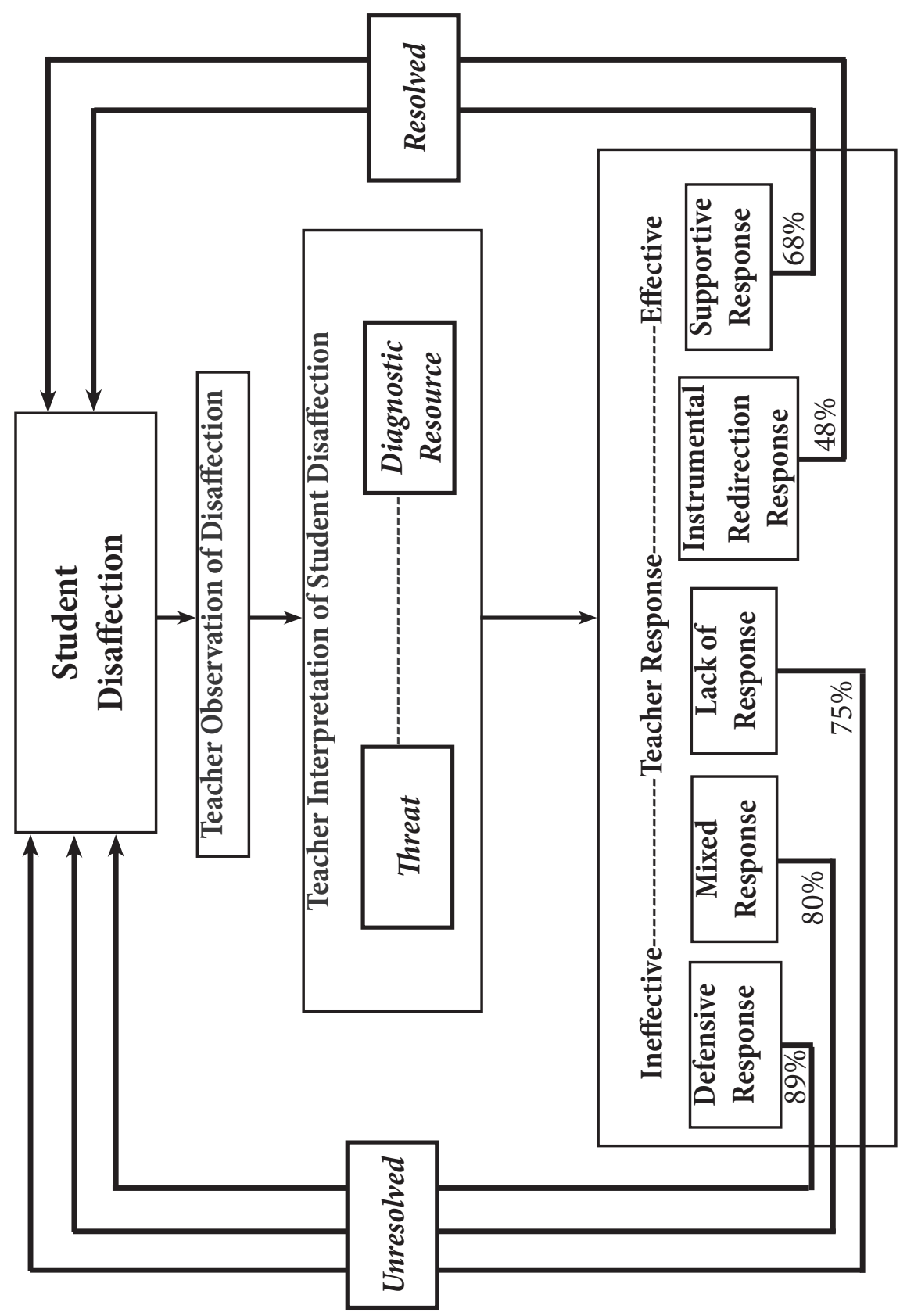

Figure 3.2. Final model of the classroom dynamics of disaffection: updated to reflect the five categories of teacher responses to disaffection and their resulting impact on student disaffection. 
Redirection: A potential quick fix if properly implemented. The most commonly used teacher response, the redirection of behavior, was effective only about half of the time $(\sim 48 \%)$. Redirection responses were successful when they had specific, instrumental cues embedded in the teacher's redirection, while the remaining, largely unsuccessful redirection responses were generally more vague. For instance, redirections that made specific requests of students to join a discussion, complete a task, or solve a problem more frequently re-engaged the disaffected student.

Given the relatively low success rate of the redirection response, the frequency of its use across all four studied classrooms is somewhat surprising. Why might teachers respond to student disaffection with a strategy that only works part of the time? Perhaps the redirection response is best thought of as an often attempted, low investment 'quick fix.' Although this study suggests that supportive responses are more effective, they also inherently require more time investment on the part of the teacher and represent a form of emotional labor, which is costly for teachers (Chang, 2009). It may, therefore, be useful for teachers to have a quick, yet effective response strategy in their repertoire. To employ a version of this quick fix redirection response that is worthwhile in terms of its resolution of disaffection, teachers may need training and support to enact redirections that are instrumental and specific so that they can effectively harness this response strategy.

Ineffective responses: Lack of response, mixed, and defensive. The remaining teacher responses in this study were predominantly ineffective in resolving disaffection. First, an absence of any response from the teachers typically resulted in disaffection that continued unabated $(\sim 75 \%)$. For instance, with no teacher intervention, bored and 
inattentive students' heads may remain down on their desks (e.g., Eddie's in Ms. Stillman's class) or socially off task students may continue their side conversations (e.g., as in many of the observed classrooms). Although this study was unable to differentiate between disaffection that was ignored and disaffection that teachers did not notice, there were likely times when teachers in this study genuinely failed to observe student disaffection and others when the teachers made note of disaffection, but chose not to respond. Perhaps there are instances where teacher make the judgment that the specific instance of disaffection does not rise to a level that necessitates a response. Nevertheless, this study's findings suggest that when teachers either choose not to respond or overlook disaffection, it is likely to continue. Thus time saved in the moment may only be postponing an inevitable response.

Second, although mixed responses were distinguished in this study from solely defensive responses, the majority of mixed responses were much more similar to defensive responses than supportive responses, since most included clearly defensive teacher actions with low-level versions of autonomy support (i.e., respectful language). Given this, it is perhaps not surprising that mixed responses were largely ineffective $(\sim 80 \%)$ at resolving disaffection. Mixed responses may reflect moments when teachers feel both threatened by disaffection, and simultaneously recognize that it is a symptom of a problem in the learning environment that they must address. Thus, in these moments teacher may invest time in addressing particular disaffected students, but may respond in ways the reflect their ambivalent state regarding what disaffection means (e.g., confiscating items or threatening seat moves while also using respectful language). 
Finally, solely defensive responses appear to be the least successful type of teacher response in terms of resolving student disaffection ( $\sim 89 \%$ unresolved). Contrary to our expectations, however, defensive responses rarely resulted in an escalation in student disaffection. In order to understand why teachers use defensive responses despite their apparent ineffectiveness, teacher interpretations of disaffection must be considered. For instance, Ms. Stillman, who had clearly invested a lot of time and energy in making expectations explicit in her classroom (i.e., repeated reference to the posters on the classroom wall outlining expectations), may have felt that her authority was threatened (Reeve, 2009; Toshalis, 2015) when students violated her behavioral expectations (e.g., when Monique was out of her seat wandering around the classroom). Thus, her defensive response of exerting extrinsic control (point system) may have been a reaction to this perceived threat. Similarly, Ms. Zacks may have begun to doubt her ability to address disaffection, perhaps even feeling helpless, when her repeated attempts to address Kay Kay's disaffection failed, thus resorting to power assertion by forcing Kay Kay to move seats (Skilling et al., 2016; Skinner \& Belmont, 1993). To avoid the pitfalls of investing time in ineffective, defensive or mixed responses to disaffection, teachers may need support in reinterpreting disaffection as a diagnostic resource rather than a threat. They may also benefit from better coping strategies to help them deal with the stressful situation that disaffection represents. 


\section{Strengths and Limitations}

As with any study, this multiple case study had both its strengths and its limitations. Regarding its strengths, the use of observational techniques allowed for the analysis of moment-to-moment interactions between disaffected students and their teachers. These observational techniques made dyadic interactions visible so that, for example, the impact of a specific supportive teacher response on a particular student's disaffection became apparent. This fine-grained examination of the dynamics between student disaffection and teacher responses is not possible with survey-based methods, which arguably capture information about participant's average experiences (whether student disaffection or teacher behavior) rather than particular in-the-moment experiences. Additionally, the focus on single class periods enabled the investigation of arcs of disaffection across a relatively short-time span leading to the identification of the six patterns of disaffection. Previous research has not been able to uncover how student disaffection changes across such short time spans because disaffection is more commonly measured with surveys administered at longer time intervals (e.g., once or twice a year with rare exceptions; see for example, Martin et al., 2015; Patall et al., 2018). This shift in focus to single class periods adds important information about how the phenomenon of disaffection unfolds in classrooms on a daily basis.

Although the intensive observation of single class periods lent strength to this study, the focus on one class period in four particular classrooms limits the generalizability of its findings both in terms of how typical the observed class was for participating students and teachers and how this study's findings might apply to other 
middle school classrooms. As such, this study cannot draw conclusions about whether the observed class periods were typical days in each of these classrooms meaning that, for example, the teacher's general response tendencies toward disaffection (e.g., Ms.

Stillman's apparent tendency towards defensive responses) and the student's patterns of disaffection (e.g., Kay Kay's preoccupation with socializing) come with the caveat that they are characteristic only of the particular observed day. Additionally, the classrooms in this study were intentionally selected as cases for this multiple case study because they were likely, based on school-level SES and student report of disaffection, to have disaffected students present; this was necessary to increase the likelihood that the phenomenon would be present for the purposes of the study, but it also means that these classrooms are not representative of an average middle school classroom.

Finally, regarding limitations in this study's coding scheme, we found for the "respect" code, which falls under the broader category of autonomy support, that a lowlevel version of this response (i.e., respectful language) was so common that it nearly obscured our findings about autonomy support. As noted in the results section, only by teasing apart the low-level version of the respect code from a higher-level version were we able to keep the prevalence of respectful language from obscuring important differences in autonomy support between teachers and across different episodes of disaffection. Although it is certainly a positive finding to discover that respectful language is frequently used in classroom settings, future research studies may benefit from thinking carefully about whether such a ubiquitous practice is relevant to the continuation or resolution of disaffection. 


\section{Implications for Future Research}

This study's findings have bearing on both future research designs and the direction of future studies of disaffection. Regarding future research directions, both the six patterns of student disaffection and the five teacher response categories uncovered in this study warrant further investigation. For instance, to what extent do disaffected students in other classrooms fit into the six observed patterns of disaffection? If any of these patterns are relevant more broadly, additional questions would also be worth pursuing such as: 1) Do students who fit into these patterns generally follow the same pattern from day to day, week to week, and instructional unit to instructional unit? and 2) What implications do these patterns have for longer-term student outcomes (i.e., grades)? Additionally, the five categories of teacher responses to disaffection are also worthy of additional investigation including the extent to which other teachers use these responses and whether the rates of resolution found in this study seem to generalize to other teacher-student dyads. Finally, the inferences made in this study regarding the underlying teacher interpretations of disaffection were unmeasured and, thus, purely theoretical in nature. Future research studies should test our assumptions regarding the teacher interpretations that underlie teacher responses to disaffection by directly interviewing teachers regarding specific episodes of disaffection.

Ultimately, the findings from this study can not only stimulate additional research questions, such as those posed above, but also inform the design of future studies. First, this study suggests that the phenomenon of student disaffection is more complex than prior research, which has relied on relatively infrequent and sometimes unidimensional 
surveys, has implicitly implied. To rectify this shortcoming, measurement strategies should be multidimensional to adequately capture the complexity of how disaffection manifests itself in classrooms and, given that disaffection is also state-like and pliable, researchers should carefully consider the time scale over which their research design operates. Otherwise, research designs that continue to use unidimensional measures and larger-time scales will likely continue to underestimate the complexity of student disaffection. Second, given that this study suggests that disaffection manifests itself differently for different students even within the same classroom setting, researchers should ensure they are modeling disaffection data in ways that will investigate not only the average disaffected student's experience, but also the variations between different student's experiences. Growth curve modeling, which requires multiple measurement waves and can include random effects in addition to fixed effects, is one quantitative methodology that can capture more complex models of disaffection.

\section{Implications for Educators}

This study's findings, which indicate that middle school teachers are competing against newly heightened social interests and often contending with multiple disaffected students, each of whom may be experiencing disaffection in different and changing ways, help explain why disaffection is such a stressful challenge for teachers (Chang, 2009; Hakanen, Bakker, \& Schaufeli, 2006; Kyriacou, 2001). If teachers do not have the necessary resources to address the challenge of disaffection in their classrooms, they may attempt to cope with disaffection in ineffective ways which can further compound their stress (Lazarus, 2006). To cope effectively, teachers need ample resources for effectively 
addressing disaffection. This study's findings suggest at least two tangible ways teachers may more effectively cope with student disaffection: supportive responses and quick fix, instrumental redirection responses. Implicit in these findings, however, is the need for professional development and support to help teachers interpret student disaffection as a useful signal, or a diagnostic tool, that students' needs are not being met rather than a threat to their own abilities or authority. 


\section{Chapter 4: Study 2}

Student Disaffection in Early Adolescence: Developmental trajectories and classroom dynamics

\section{Purpose}

When viewed through the eyes of an adolescent, middle school may be more than a place of learning and development. It may also be experienced as a place that is compulsory in nature, filled with monotonous moments, lacking relevance to everyday life, marked by competing interests (socializing versus academics), or controlled by teachers. If any of these latter features are what is most salient to early adolescents, school may undermine their motivation and contribute to disaffection, which can manifest itself in a variety of ways such as boredom and inattention, disinterest and off task behavior, or frustration and disruptive behavior. Regardless of its exact form, student disaffection blocks the true intended function of schools, that of learning and development. As a whole, past research suggests that disaffection is harmful to students' academic success (grades, e.g., King, 2015; academic coping, Skinner, Pitzer, \& Steele, 2016; educational aspirations, Green, Martin, \& Marsh, 2007) and longer-term progress toward graduation (grade retention, Galand \& Hospel, 2013; high school drop out, e.g., Balfanz, Herzog, \& Mac Iver, 2007).

Precisely because disaffection is so costly for students, educators and researchers are interested in learning more about how disaffection changes as students progress through school and the factors that shape its development, especially those that may prevent or reverse it. Perhaps surprisingly, however, our current understanding of the development of disaffection during early adolescence is limited 
to a handful of studies, which largely rely on investigations of average differences (i.e., ANOVA/MANOVA frameworks). Additionally, studies addressing the classroom dynamics of disaffection have largely focused on relatively simple models while neglecting the possibility of more complex classroom dynamics. One final limitation of past research is the lack of studies in science classrooms. Despite evidence that motivation in science classrooms declines during middle school (Gottfried, Marcoulides, Gottfried, \& Oliver, 2009; Gottfried, Fleming, \& Gottfired, 2001), most previous research on disaffection either does not specify the disciplinary context of the research (e.g., Engels et al., 2017) or merely notes it in passing in the methods section (e.g., Martin, Way, Bobis, \& Anderson, 2015). As a result, this study seeks to add to our current, but limited understanding of how and why disaffection, with science specifically, develops across the early adolescent years. The goals of this study are (1) to explore the development of disaffection by examining (a) whether the normative trajectories of disaffection increase, decrease, or remain stable across the early adolescent years and (b) if there are differences in individual students' disaffection trajectories, and (2) to investigate the classroom dynamics of disaffection by exploring (a) whether teacher views of disaffection and student-teacher relationships relate to concurrent student experiences of disaffection and (b) whether student experiences of disaffection and teacher views of disaffection are reciprocally linked across the school years. 


\section{Academic Costs of Disaffection}

Accumulating evidence suggests that disaffection is harmful to students' academic success. Across a variety of metrics of academic performance (i.e., final grades, GPA), multiple studies establish consistent negative correlations (range: -.31 --.53 ) with disaffection, as reported both by teachers (TR: Gonzalez \& Paoloni, 2014; Gonzalez, Garrido, Castro, \& Rodríguez, 2015) and students (SR: Gonzalez, Paoloni, Donolo, \& Rinaudo, 2015; King, 2015; Wang, Chow, Hofkens, \& SalmelaAro, 2015). These associations remain significant even in the subset of studies that tested more complex models (i.e., that controlled for other variables; Gonzalez \& Paoloni, 2014; Gonzalez et al., 2015; King, 2015). Most compelling are findings from two studies that use growth curve modeling to explore how disaffection and academic performance relate within the school year. Focusing on two forms of emotional disaffection, Ahmed, van der Werf, Kuyper, and Minnaert (2013) found that $7^{\text {th }}$ graders initial levels of both anxiety and boredom negatively predicted fall achievement in mathematics and that increases in anxiety and boredom each predicted decreases in achievement. King (2015) found that high school students' initial levels of disaffection (behavioral and emotional forms combined) at the beginning of the school year as well as increases in their disaffection across the school year were predictive of lower final GPA in a growth model, which controlled for relatedness with social partners (parents, teachers and peers), engagement, and gender. 
Moving beyond metrics of academic performance, a handful of studies suggest that disaffection also harms students' global academic functioning. In a longitudinal model accounting for concurrent engagement, higher levels of disaffection (SR) predicted academic coping profiles that were relatively more maladaptive than adaptive (Skinner, Pitzer, \& Steele, 2016). Subject-specific disaffection (SR) was also strongly and negatively correlated with educational aspirations in each of three different subjects (English, mathematics, and science) (Green, Martin, \& Marsh, 2007). Finally, disaffection in middle school has broader implications for student progress through the K-12 education system, including shortterm grade retention (Galand \& Hospel, 2013) and the longer-term consequence of high school drop out (Balfanz, Herzog, \& Mac Iver, 2007; Juvonen, Le, Kaganoff, Augustine, \& Constant, 2004; Rumberger \& Lim, 2008). Taken together, these findings suggest that disaffection is costly for students' short-term and long-term academic progress and success.

\section{Trajectories of Disaffection across Adolescence}

Although prior research has established disaffection as a motivational vulnerability, a clear picture of how disaffection develops across the middle school grades has not yet been documented empirically. Scholars have noted a general trend in which academic motivation declines steadily beginning in the early grades and continuing into secondary school with conspicuous declines across the middle school transition (Wigfield, Byrnes, \& Eccles, 2006; Wigfield et al., 2015). However, surprisingly little of this research has focused explicitly on disaffection; instead it 
primarily focuses on positive markers of motivation, such as engagement. As a result, only a small number of studies currently shed light on the developmental trajectory of disaffection during early adolescence and none of these studies focuses on trajectories of disaffection with science.

Among these studies, three explicitly examine changes in disaffection within the same school year, specifically during early adolescence. One study, which drew from a sample that included $6^{\text {th }}$ and $7^{\text {th }}$ grade middle school students, found that levels of behavioral disaffection increased significantly from fall to spring (Skinner, Furrer, Marchand, \& Kindermann, 2008). Evidence regarding within year changes in emotional disaffection is more mixed and appears to depend on which forms of emotional disaffection are measured and the statistical analyses that are used. The sole study that operationalized emotional disaffection holistically (with the emotions of anxiety, boredom, and frustration all represented) found increases from fall to spring (Skinner et al., 2008). However, findings are not consistent when individual forms of emotional disaffection are investigated. Across single school years, two studies found evidence that boredom increases (Skinner et al., 2008; Ahmed et al., 2013), however, a third study found no differences in levels of boredom (Larson \& Richards, 1991). Regarding anxiety, Ahmed and colleagues (2013) used growth curve modeling and found evidence that $7^{\text {th }}$ graders levels of anxiety were relatively stable across three time points in the same school year; however, using t-tests, Skinner and colleagues (2008) found that levels of anxiety in spring were significantly higher than the previous fall. Finally, regarding frustration, two studies found support for 
increases in frustration within the same school year (Larson \& Richards, 1991; Skinner et al., 2008).

Three studies provide mixed evidence for patterns of change across multiple school years, with findings seemingly dependent on the forms of disaffection (behavioral or emotional) that are measured. Regarding behavioral disaffection, past studies generally suggest that this form of disaffection increases across the transition to middle school and then further increases across the middle school years (Engels et al., 2017; Martin, Way, Bobis, \& Anderson, 2015; Skinner et al., 2008); although, in one study, these increases were not significant after Bonferroni adjustment (Plenty \& Heubeck, 2013). Most compelling among these studies, are the findings of Engels and colleagues (2017), who used latent growth curve modeling and found increases in behavioral disaffection across $7^{\text {th }}$ to $11^{\text {th }}$ grade. Based on four studies to date, emotional disaffection also appears to increase across the middle school transition, but then appears to remain relatively stable across the middle school grades (Engels et al., 2017; Larson \& Richards, 1991; Plenty \& Heubeck, 2013; Skinner et al., 2008). Overall, most existing evidence points to trends in which behavioral disaffection increases across the middle school years while students' emotional disaffection may rise to new levels upon transitioning to middle school, but then appears to remain relatively stable across the middle school grades.

Because of a heavy reliance on MANOVA and regression frameworks in past research, few studies to date explicitly examine whether there are substantial individual differences in the trajectories of students' disaffection within the school 
year or across early adolescence. Regarding differences between students' emotional disaffection within the same school year, Ahmed et al. (2013) found support for significant differences in students' levels of both anxiety and boredom in fall of $7^{\text {th }}$ grade. There is also support for individual differences in changes in emotional disaffection (anxiety) within the $7^{\text {th }}$ grade school year (Ahmed et al., 2013) and across $7^{\text {th }}$ to $9^{\text {th }}$ grade school years (Plenty $\&$ Heubeck, 2013). Plenty and Heubeck's (2013) study, however, only indirectly points to such individual differences with the finding that $9.2 \%$ of students experienced a "noteworthy" increase (i.e., $\geq 2$ points on a 7 point Likert scale) in emotional disaffection (anxiety) while another 7.9\% of students reported a "noteworthy" decrease. This same study contributes the only evidence to date indicating that students may also differ in their trajectories of behavioral disaffection (withdrawal), finding that $11.2 \%$ of students experienced a "noteworthy" increase while another $7.1 \%$ of students experienced a "noteworthy" decrease (Plenty \& Heubeck, 2013).

Taken together, these findings suggest that disaffection may be amplified by the transition to middle school and that disaffection, particularly behavioral forms, may then normatively continue to increase across the early adolescent years. At the same time, there may also be significant differences between students in their trajectories of disaffection. Given these findings, one explicit goal of this study is to add to our growing understanding of the development of disaffection in early adolescence. Thus, this study aims to map trajectories of disaffection (SR) across $6^{\text {th }}$ through $8^{\text {th }}$ grade using latent growth curve modeling, which allows for the 
examination of both normative change and inter-individual differences in that normative change.

\section{Classroom Dynamics of Disaffection}

The second goal of this study was to investigate the classroom dynamics underlying the development of student disaffection by exploring a model suggesting that teacher views of disaffection and student-teacher relationships both contribute to student experiences of disaffection (see Figure 4.1). Because, in most middle schools, student assignment to teachers changes on an annual basis, the classroom dynamics of disaffection are modeled within the school year in this study to maintain consistent student - teacher dyads across time points. Evidence supporting each link in the proposed model is summarized below.

\section{Contributions of student-teacher relationship quality to student} experiences of disaffection (SR). Although there are many features of the classroom that may explain disaffection (e.g., classroom-level disaffection, Martin, Anderson, Bobis, Way, \& Vellar, 2012), foremost among these contributing factors are social interactions (Bronfenbrenner \& Morris, 1998), including relationships with teachers. Past motivational research posits 


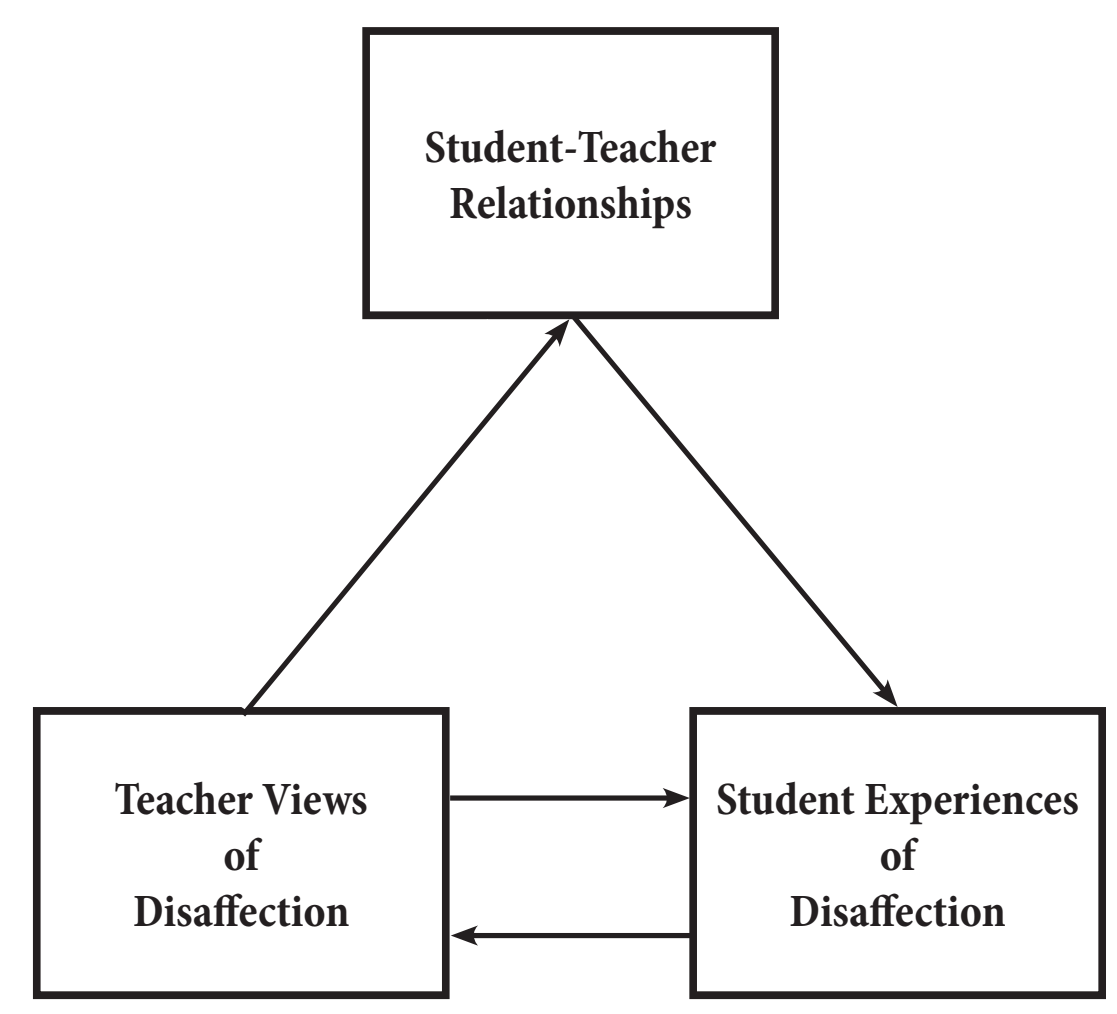

Figure 4.1. The classroom dynamics model of disaffection: this model proposes that teacher views of disaffection (TR) and student-teacher relationships predict concurrent student experiences of disaffection (SR) and that student experiences of disaffection (SR) and teacher views of disaffection (TR) are reciprocally related over time.

that when students feel that their teachers care for and understand them, provide choices, and address the relevance of learning activities, students are less likely to become disaffected. Supporting this expectation, past research has found that high quality student-teacher relationships, which are often operationalized as the collective teacher practices of involvement, structure, and autonomy support, are associated 
with lower levels of adolescent disaffection (SR) (Galand \& Hospel, 2013; Guvenc, 2015; Skinner, Furrer, Marchand, \& Kindermann, 2008); moreover, these associations remain significant even in more complex models that account for other social relationships (e.g., parent and peer support; Galand \& Hospel, 2013) and student attributes (e.g., autonomy and engagement; Guvenc, 2015). Thus studies indicate that student-teacher relationships may play an important role in the classroom dynamics of disaffection.

\section{Teacher views of disaffection (TR) and student-teacher relationships.}

Student-teacher relationships, like all relationships, are dyadic in nature, meaning that teachers and students both play a role in the quality of the relationship (Noddings, 2012). To date, however, most research investigating student disaffection and student-teacher relationships has relied on student reports of disaffection, even though teachers have their own views on disaffection and the small number of studies that consider these teacher perspectives indicate that they are also connected to the quality of student-teacher relationships. Concerningly, evidence to date suggests that when teachers view their students as disaffected, their responses to disaffection may strain rather than strengthen their relationships with students. Past qualitative studies indicate that once teachers see a student as disaffected, they may respond by withdrawing from or attempting to control students' disaffected behaviors, both of which may undermine relationship quality. In fact, in a qualitative study, interviews with students, who were selected based on teacher nominations of students as disaffected, uncovered a 'strong theme' in which these students reported that their 
"teachers did not like, respect, or care" about them (Lumby, 2012, p. 271), thus suggesting that teachers may withdraw from their disaffected students. Teachers themselves provide some indication that, when they perceive students as disaffected, they at times respond with controlling tactics. For instance, when Skilling and colleagues (2016) interviewed teachers regarding the teaching strategies they used to address "engagement issues", some middle school teachers reported using controlling teaching styles (e.g., demerits, sanctions) in response to students they perceived as disaffected (e.g., off task behavior or not participating in class discussions).

\section{Student experiences of disaffection (SR) and teacher views of disaffection}

(TR). To form a complete picture of the classroom dynamics of disaffection, links between student and teacher perspectives of disaffection must also be considered. Previous research has documented concurrent correlations between the two perspectives (Skinner et al., 2008), the strength (range .28 to .36) of which suggest that the two perspectives are related, but not identical. Perhaps teacher reported views

of disaffection represent the observable, external manifestation of student disaffection while student reports of disaffection represent more internal manifestations. Although no study to date has examined how these two perspectives are related over time, it seems plausible that they may reciprocally shape each other.

The feed forward effects depicted in the bottom portion of Figure 4.1 suggest that teacher's views of a student's disaffection may impact the student's own disaffection either directly or through the previously discussed impact on studentteacher relationships. For instance, if a teacher labels a student as "disaffected" (e.g. 
"In my class, this student is always off task and chatting with their neighbors.") such a fixed evaluation could lead the student to internalize that view of themselves (e.g. “I'm just a chatty student by nature; I can't help myself'). In this way, what is initially relatively minor disaffection (disinterest with off-task behavior) can develop into a more severe form of disaffection (frustration and resistance).

The feedback effects shown in Figure 4.1 suggest that student experiences (and presumably, their expressions) of disaffection also reciprocally influence teachers' views of students' motivational states. In fact, such effects could also snowball over time, if students' own disaffection shapes the way a teacher interprets signs of student disaffection in the future. For example, a student who is disinterested in classroom activities, perhaps because social interactions with peers hold greater interest, may be frequently off task (e.g. whispering with peers) and this student experience of disaffection is likely readily apparent to the teacher. Such behavior would then frame how that teacher views future instances of the same student talking to peers, perhaps leading the teacher to assume the student is socially off-task, even when that student is actually discussing something relevant to the lesson at hand.

The current study aims to leverage prior findings to examine the classroom dynamics of disaffection by exploring concurrent effects of teacher views of disaffection and student-teacher relationships on student experiences of disaffection and by exploring possible reciprocal effects between student and teacher perspectives on disaffection (see Figure 4.1). Thus the second research goal in this study was to explicitly investigate whether teacher views of disaffection (TR) and student-teacher 
relationships (SR) explain the classroom dynamics that underlie student experiences of disaffection (SR) as well as whether earlier student experiences of disaffection are reciprocally connected with teacher views of disaffection across the school year. As can be seen, in Figure 4.1, such reciprocal effects could lead to worsening trajectories of disaffection across school years.

\section{Study Aims and Research Questions}

The purpose of this study is two-fold. First, it seeks to describe the normative trajectories of behavioral and emotional disaffection across the early adolescent years by using growth curve modeling. Second, it examines the classroom dynamics that underlie developmental changes in disaffection using latent structural models. To accomplish these goals, this study draws from a larger 5-year longitudinal project that stemmed from a collaboration between a garden-based education program, a local middle school, and a team of motivational researchers. To examine disaffection trajectories, this study drew from six cohorts of the larger dataset. Next, a smaller subset of students $(n=523)$ was included in the classroom dynamics model, selecting students for whom both student-report and teacher-report data were available for both semesters.

Four research questions framed this study: (1) What are the developmental trajectories of disaffection (for both behavioral and emotional forms) across the middle school years according to the student perspective (SR)?, (2) Do individual student's trajectories vary significantly in either their starting point at the beginning 
of middle school or their rate of change across middle school?, (3) Are teacher views of disaffection (TR) and student-teacher relationships linked to concurrent student experiences of disaffection (SR)?, and (4) How are student experiences of disaffection (SR) and teacher views of disaffection (TR) reciprocally related across the course of a single school year (fall to spring)? The following hypotheses were posited regarding the development of disaffection: First, linear growth in disaffection during the early adolescent years was expected for behavioral disaffection. However, emotional disaffection was expected to be stable across the same developmental period. Second, significant variability between middle school students was expected both in terms of the intercept (disaffection in Fall of $6^{\text {th }}$ grade) and slope (rate of change across $6^{\text {th }}-8^{\text {th }}$ grade) of disaffection across both forms of disaffection. Regarding the classroom dynamics of disaffection, (1) teacher views of disaffection (TR) were expected to be related to student experience of disaffection, both directly and indirectly through student-teacher relationships and (2) student experiences of disaffection were expected to be reciprocally connected to teacher views of disaffection across the school year, resulting in a pattern of worsening disaffection from both perspectives.

\section{Research Design and Methods}

Participants. Based on publicly available data, the student body of the participating middle school was diverse, low socioeconomic status $(\mathrm{SES})($ Average $=$ $86.5 \% ; 81.2-94.2 \%$ of students in the school were eligible for free and reduced lunch during all study years), and partially from non-English speaking background 
(Average $=16.2 \%$; participation in English as a second language program ranged from $10.5 \%-19.9 \%)$. Participants include 589 students in $6^{\text {th }}-8^{\text {th }}$ grade. Students were $52.5 \%$ female and came from diverse ethnicities (27.7\% Caucasian; $19.0 \%$ Hispanic; 17.1\% Multi-racial; 14.6\% Asian; 4.8\% African American).

Design and procedure. A cohort-sequential design was used in this study to follow: six cohorts of students across up to six waves of data collection (Fall and Spring) over the middle school years $\left(6^{\text {th }}-8^{\text {th}}\right.$; Table 4.3$)$. The number of waves per cohort varied primarily because of two factors. First, the alignment between when each cohort began middle school and the study's start and end dates impacted the number of measurement waves for each cohort (e.g., $6^{\text {th }}$ graders in the last year of the study were only followed for 2 waves of data collection). Second, during three years of the study, only one semester of science was offered to $7^{\text {th }}$ and $8^{\text {th }}$ grade students, which created an unbalanced data structure across cohorts. Parent consent and students assent were obtained at the beginning of each school year. Surveys were administered to students in either their science class or homeroom with teachers present in the classroom during the administration. 
Table 4.1

\section{The Data Collection Design of the Study}

\begin{tabular}{|c|c|c|c|c|c|c|}
\hline \multirow{3}{*}{$\begin{array}{l}\text { School } \\
\text { Year }\end{array}$} & \multicolumn{6}{|c|}{ Grade } \\
\hline & \multicolumn{2}{|c|}{$6^{\text {th }}$} & \multicolumn{2}{|c|}{$7^{\text {th }}$} & \multicolumn{2}{|c|}{$8^{\text {th }}$} \\
\hline & $\begin{array}{c}\text { Semester } \\
1\end{array}$ & $\begin{array}{c}\text { Semester } \\
2\end{array}$ & $\begin{array}{c}\text { Semester } \\
1\end{array}$ & $\begin{array}{c}\text { Semester } \\
2\end{array}$ & $\begin{array}{c}\text { Semester } \\
1\end{array}$ & $\begin{array}{c}\text { Semester } \\
2\end{array}$ \\
\hline $\begin{array}{l}2008- \\
2009\end{array}$ & $\begin{array}{l}\text { Cohort } 1 \\
\text { (W1) }\end{array}$ & $\begin{array}{c}\text { Cohort } 1 \\
\text { (W2) }\end{array}$ & \multicolumn{2}{|c|}{$\begin{array}{c}\text { Cohort } 5 \\
\text { (W1) }\end{array}$} & \multicolumn{2}{|c|}{$\begin{array}{l}\text { Cohort } 6 \\
\text { (W1) }\end{array}$} \\
\hline $\begin{array}{l}2009- \\
2010\end{array}$ & $\begin{array}{l}\text { Cohort } 2 \\
\text { (W1) }\end{array}$ & $\begin{array}{l}\text { Cohort } 2 \\
\text { (W2) }\end{array}$ & \multicolumn{2}{|c|}{$\begin{array}{l}\text { Cohort } 1 \\
\text { (W3) }\end{array}$} & \multicolumn{2}{|c|}{$\begin{array}{l}\text { Cohort } 5 \\
\text { (W2) }\end{array}$} \\
\hline $\begin{array}{l}2010- \\
2011\end{array}$ & $\begin{array}{c}\text { Cohort } 3 \\
\text { (W1) }\end{array}$ & $\begin{array}{c}\text { Cohort } 3 \\
\text { (W2) }\end{array}$ & \multicolumn{2}{|c|}{$\begin{array}{l}\text { Cohort } 2 \\
\text { (W3) }\end{array}$} & \multicolumn{2}{|c|}{$\begin{array}{l}\text { Cohort } 1 \\
\text { (W4) }\end{array}$} \\
\hline $\begin{array}{l}\text { 2011- } \\
2012\end{array}$ & $\begin{array}{c}\text { Cohort } 4 \\
\text { (W1) }\end{array}$ & $\begin{array}{c}\text { Cohort } 4 \\
\text { (W2) }\end{array}$ & $\begin{array}{c}\text { Cohort } 3 \\
\text { (W3) }\end{array}$ & $\begin{array}{c}\text { Cohort } 3 \\
\text { (W4) }\end{array}$ & $\begin{array}{c}\text { Cohort } 2 \\
\text { (W4) }\end{array}$ & $\begin{array}{c}\text { Cohort } 2 \\
\text { (W5) }\end{array}$ \\
\hline
\end{tabular}

Note. Science was only offered one term per year for cohort 1 (W3 \& W4), cohort 2 (W3), cohort 5 (W2), and cohort 6 (W1), therefore, students-teacher dyads for these cohorts during these grades could not be included in the dynamics model.

Measures. The response format for all survey items used a 5-point Likert response scale: Not true at all (1), A little bit true (2), Somewhat true (3), Fairly true (4), Totally true (5). All scales are briefly described below, including item examples (see appendix B for full list of items), descriptive statistics (mean, SDs), and internal consistency (alphas and omegas) are reported in Table $4.2-4.3$.

\section{Perspectives on Student Disaffection.}

Student report (SR) of disaffection. To address the first set of developmentbased research question, separate scales for behavioral and emotional disaffection were used in the growth curve models. The behavioral disaffection (BD) scale was 
composed of five items tapping a variety of disaffected behaviors including low effort and withdrawal while the emotional disaffection (ED) scale included four items assessing boredom, aversion, and apathy. These items were adapted from the Skinner, Kindermann, and Furrer's (2009) Engagement versus Disaffection with Learning survey. Reliabilities for these scales across waves were acceptable on average (BD $\alpha$ average: .71; $\omega$ average: .76; ED $\alpha$ average: .69; $\omega$ average: .73; Table 4.2).

Additionally, a five item disaffection scale (SR), combining behavioral and emotional forms, was used in the dynamics model for the second set of dynamicsfocused research questions. Three items tap behavioral disaffection (e.g., "I don't try very hard in science.") while another two items tap emotional disaffection (e.g., "When we work on something in class, I feel bored."). Across the fall and spring measurement waves, reliabilities for this scale were acceptable (Table 4.3).

Teacher report of student disaffection. Four items were adapted from the teacher-report version of the Engagement versus Disaffection with Learning survey (Skinner, Kindermann, \& Furrer, 2009) for this study. Two items assessed behavioral disaffection (e.g., "When faced with setbacks, this student gives up."). Another two items described teachers' perceptions of emotional disaffection (e.g., "In my class, this student does not really care.”). Reliabilities for this scale across fall and spring were good (Table 4.3).

Student-Teacher Relationships. Five student-report items, adapted from the Teacher As a Social Context Questionnaire (Belmont, Skinner, Wellborn, \& Connell, 1992), composed the student-teacher relationships scale in this study including two 
items measuring student perceptions of their teachers' involvement (e.g., "I can't really count on my teachers.", reverse-coded) and three tapping autonomy support (e.g., "My teachers explain why the things I learn in school are important." and "People here are always telling me what to do.", reverse-coded). Reliabilities for this scale across fall and spring were acceptable (Table 4.3).

Analysis Plan. First, to assess the feasibility of using latent growth curve analysis measurement invariance was assessed. Next, the structural equation modeling (SEM) framework was used to explore questions regarding the trajectories of disaffection. Initially, a random sample of students $(n=20)$ was first selected and their individual growth curves were plotted and inspected. Then, informed by the individual growth curves, a series of unconditional models (no growth, linear, quadratic) were tested. Given that differences in individual disaffection trajectories were hypothesized, the random effects for both intercept and slope were also examined.

Second, to explore the within year classroom dynamics of disaffection, latent structural models in the SEM framework were tested. Following best practices of specifying and testing plausible alternative models (particularly those testing other directions of effects; Kline, 2011), multiple models were tested and compared. Model fit was evaluated by considering the $\chi^{2}$ test, the Comparative Fit Index (CFI) and Root Mean Square Error of Approximation (RMSEA). The following cut points were used as general guidelines for interpreting model fit: CFI $>.95$ is considered good and $>$ .90 adequate; RMSEA $<.06$ is good and $<.08$ adequate (Hu \& Bentler, 1999). Models 
were compared with the chi-square difference test, Akaike Information Criterion (AIC), Bayesian Information Criterion (BIC), and $\triangle \mathrm{CFI}(<-.01)($ Cheung \& Rensvold, 2002).

\section{Results}

\section{Preliminary Analyses}

Missing data analysis. Patterns of missing data were examined and revealed that the variables in this study had between $7.7-26.1 \%$ unit missingness. Teacher report of student disaffection had the highest percentage of unit missingness during wave 5 (fall of $8^{\text {th }}$ grade) because one teacher did not complete their surveys at that time point. Attrition varied at each wave (.7\% wave $1(\mathrm{~W} 1), 5.8 \% \mathrm{~W} 2,4.2 \% \mathrm{~W} 3$, $5.3 \% \mathrm{~W} 4,4.1 \% \mathrm{~W} 5,8.3 \% \mathrm{~W} 6)$. Results of a series of univariate $t$ tests showed that students who dropped out at later measurement waves did not differ on earlier levels of either behavioral or emotional disaffection. Little's missing completely at random (MCAR) test (Little, 1988) suggested that the mechanism of missingness met the assumptions for $\operatorname{MCAR}\left(\chi^{2}(23896)=23869.09, p=.55\right)$. Missing data were addressed with full information maximum likelihood estimation.

Descriptive statistics. Initial descriptive statistics including means, standard deviations, and correlations are presented in Tables 4.2 - 4.3. Based on an inspection of the means for behavioral disaffection, a generally increasing pattern from $6^{\text {th }}$ to $8^{\text {th }}$ grade appears to be present particularly across measurement waves within the same school year. The observed means for emotional disaffection also suggest a generally increasing pattern, however, the increases are not as clearly confined to measurement 
waves within the same school year (i.e., the largest average increase is between spring of $6^{\text {th }}$ grade and fall of $\left.7^{\text {th }}\right)$. Regarding the remaining study variables, the means suggest that both teacher views of disaffection and the quality of student-teacher relationships slightly worsen over the course of the school year. The correlations suggest relatively high cross-time stability in student experiences of disaffection, teacher views of disaffection, and student-teacher relationships from fall to spring.

Measurement invariance. Both the behavioral and emotional disaffection scales were tested for measurement invariance across the six time points (fall and spring $6^{\text {th }}-8^{\text {th }}$ grade) included in this study's growth curve models. Across a series of progressively constrained models (configural, weak, strong) both the behavioral disaffection scale $(\mathrm{CFI}>.94$; RMSEA <.06) and emotional disaffection scale $(\mathrm{CFI}>$ $.93 ;$ RMSEA < .08) showed adequate fit (Table 4.4). Although the $\Delta \mathrm{CFI}_{\text {weak to strong for }}$ emotional disaffection was outside of the generally used cut mark for evaluating change in model fit (Cheung \& Rensvold, 2002), the collective evidence regarding model fit led us to the conclusion that the assumption of strong invariance was adequately met. Given that strong invariance is considered sufficient to satisfy the assumption that the same construct is being measured in the same metric over time (Widaman, Ferrer, \& Conger, 2010), the planned growth curve modeling proceeded for both the behavioral and emotional disaffection scales. 


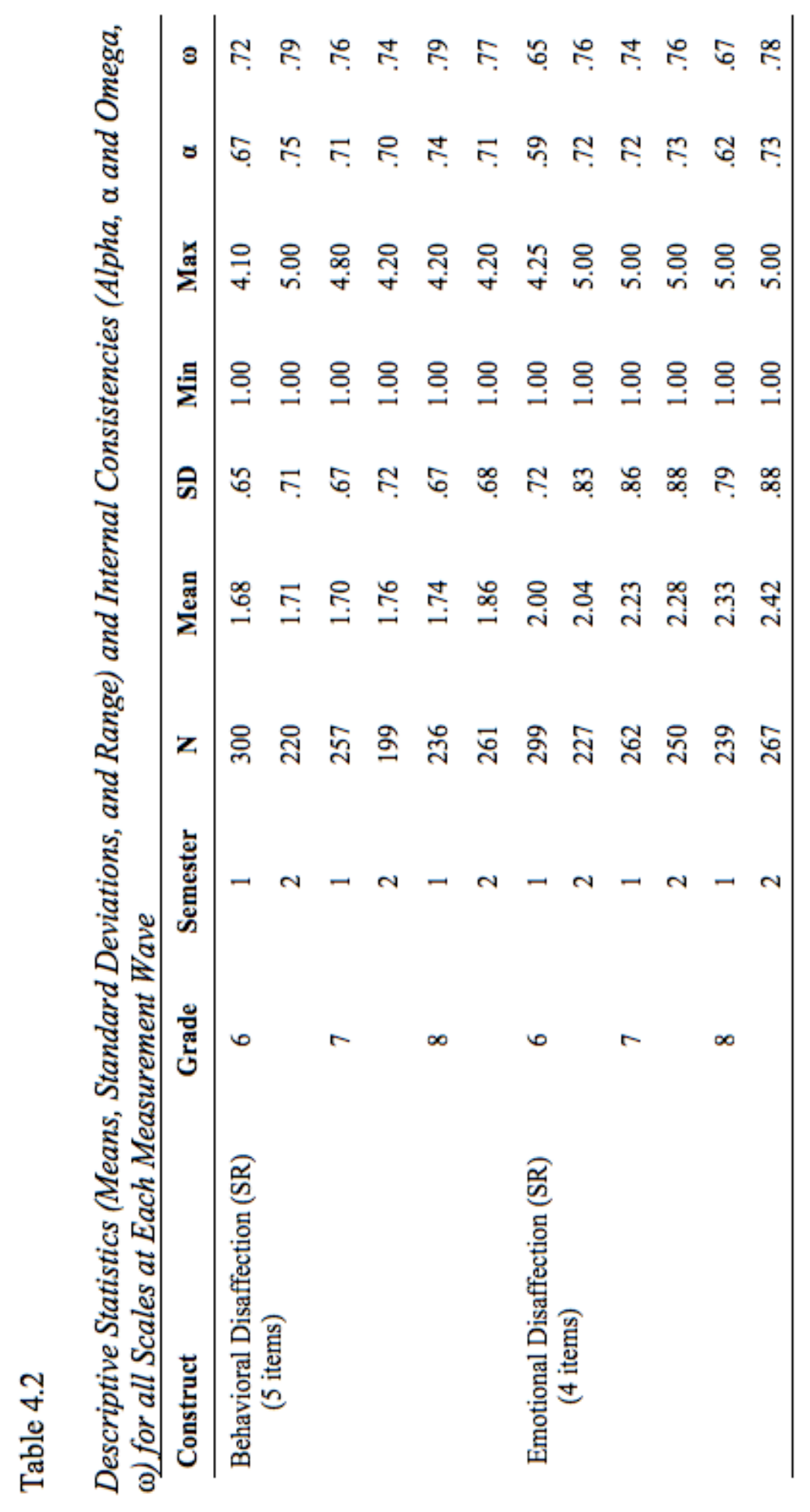


Chapter $4 \quad 135$

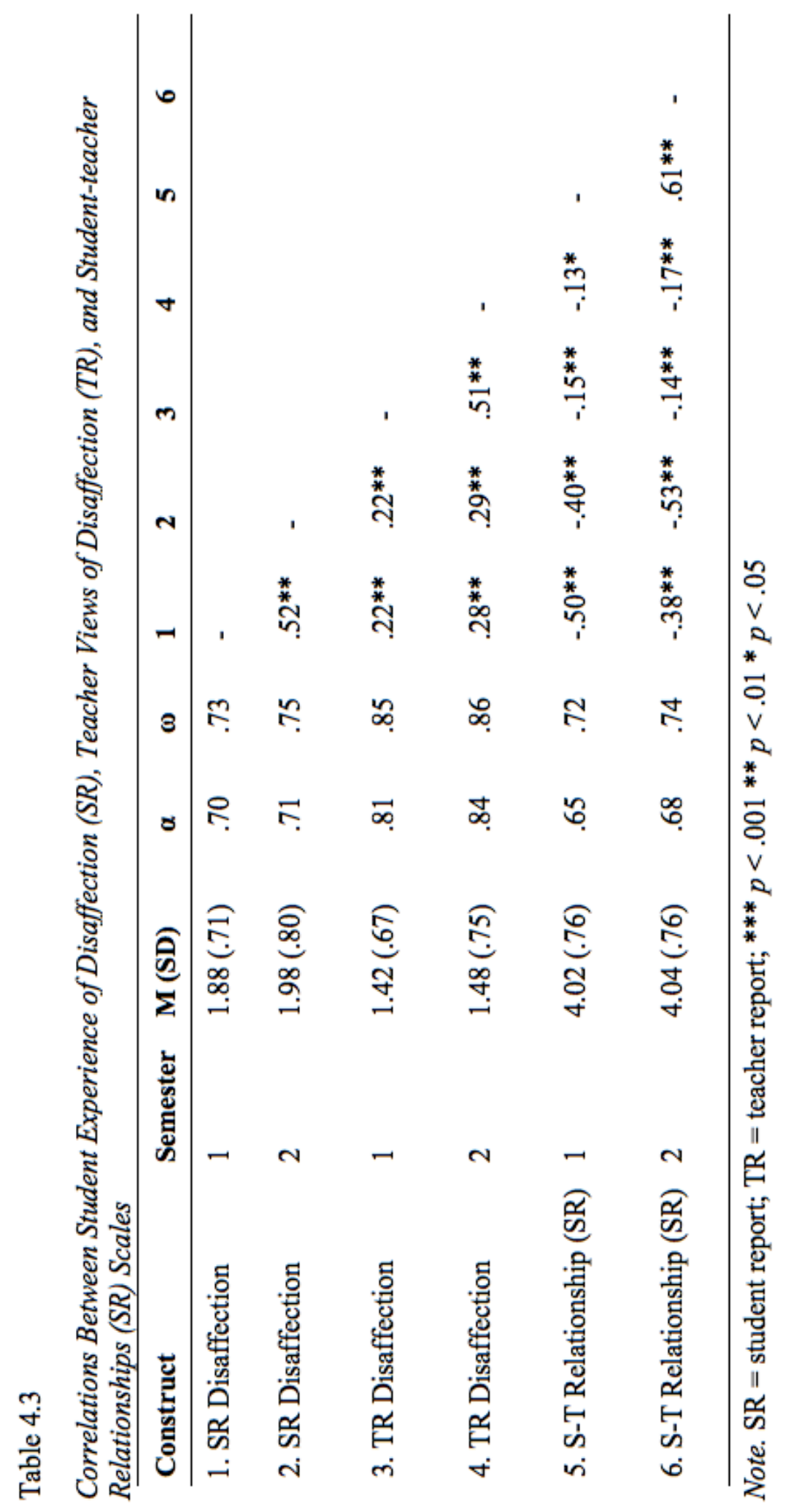




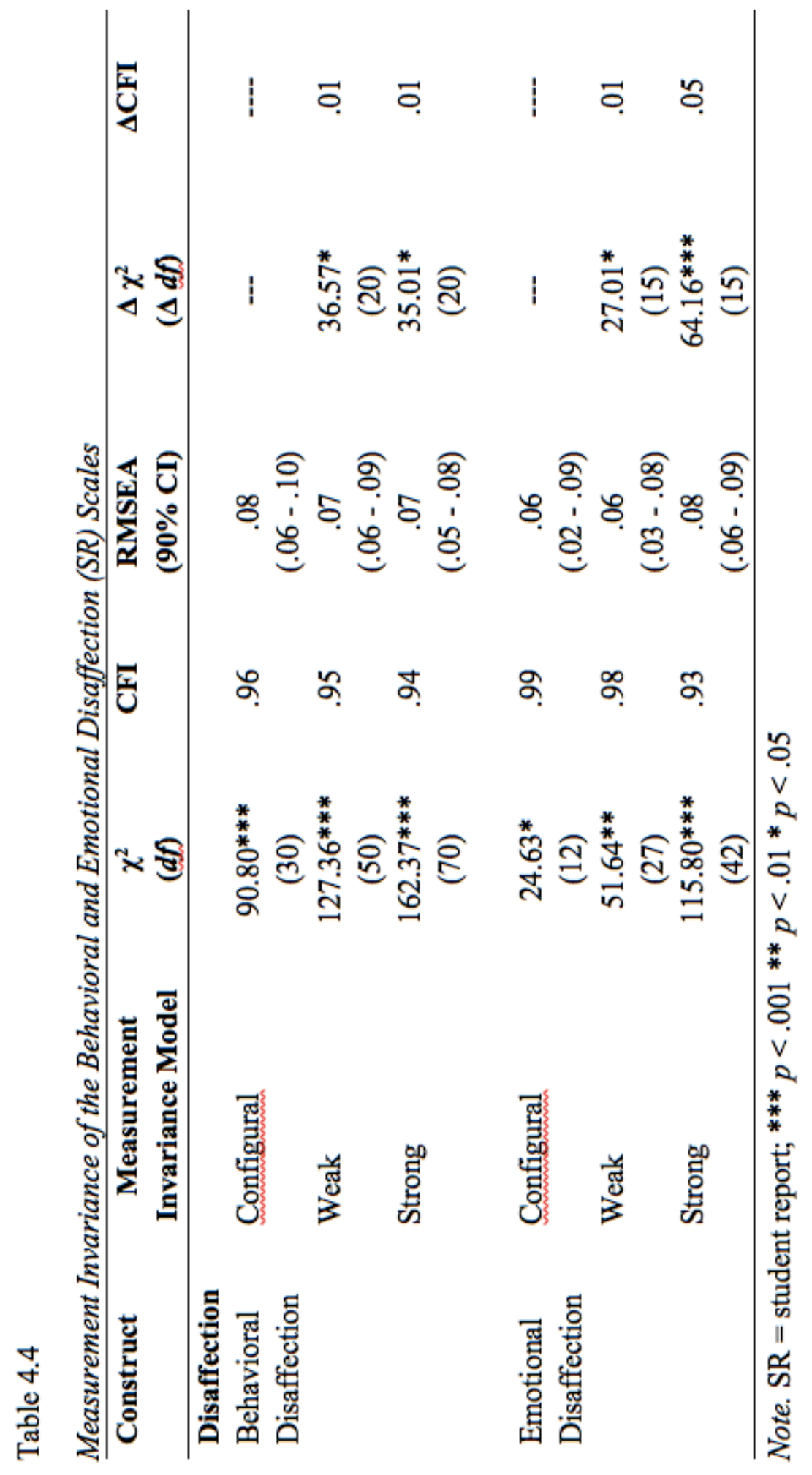




\section{Normative Trajectories in Disaffection Across the Early Adolescent Years}

A series of unconditional latent growth curve models were tested and compared to determine which, if any, shape of growth best described the normative trajectories of behavioral and emotional disaffection across $6^{\text {th }}$ through $8^{\text {th }}$ grade. While the quadratic model had better fit for both behavioral and emotional disaffection ${ }^{2}$, the quadratic slope mean and variance were not significant so we chose to interpret the linear model for both constructs. For behavioral disaffection, the linear model of change (Model 2a; Table 4.5) demonstrated good to adequate fit, $\chi^{2}(21)=44.51, p=.00$, CFI $=.93$, and RMSEA $(90 \%$ $\mathrm{CI})=.05(.03-.06)$. On average, students reported experiencing moderately low levels of behavioral disaffection in their science classes in the fall of $6^{\text {th }}$ grade and, as indicated by the significant positive slope, small increases in behavioral disaffection were reported across the middle school years. There were also significant variations between students in both initial levels of and changes in behavioral disaffection.

For emotional disaffection, the linear model of change (Model 2b; Table 4.5) had good to adequate fit, $\chi^{2}(21)=58.76, p=.00, \mathrm{CFI}=.91$, and $\mathrm{RMSEA}(90 \% \mathrm{CI})=.06(.04$ - .07). Based on this linear growth model, students, on average, reported moderately low levels of emotional disaffection with science in the fall of $6^{\text {th }}$ grade. Then, across the middle school years, students experienced small linear increases in their emotional disaffection as indicated by the significant, positive slope. Students also differed in both

\footnotetext{
${ }^{2}$ We encountered an error in running the quadratic model for emotional disaffection related to negative latent covariance values. This error was not present for either the no growth or the linear models; however, we suspect that the error can be traced back to issues with missing data that only became an issue when estimating the more complex quadratic model. This error is an additional reason that the quadratic model was not selected in this study.
} 
their initial levels of and changes in emotional disaffection. Parameter estimates and the model-implied trajectories for both behavioral and emotional disaffection are presented in Table 4.6 and Figure 4.2. In summary, both forms of disaffection were moderately low in fall of $6^{\text {th }}$ grade, increased at modest rates across the middle school years, and varied significantly both in terms intercepts and slopes, but emotional disaffection was consistently higher than behavioral disaffection across the early adolescent years.

Table 4.5

Behavioral and Emotional Disaffection: Comparisons of Unconditional Latent Growth Model Fit

Growth

$\chi^{2} \quad p \quad$ CFI $\quad$ RMSEA
$(90 \%$ CI)

AIC

(df)

model

1a. No growth

67.14

(24)

2a. Linear

44.51

(21)

3a. Quadratic

34.96

(17)

1b. No growth

$$
123.41
$$

2b. Linear

58.76

(21)

3b. Quadratic ${ }^{1}$

\section{Behavioral Disaffection}

.00

.87

$.00 \quad .93$

$.01 \quad .95$

.06

$(.04-.07)$

.05

$(.03-.06)$

.04

$(.02-.06)$

Emotional Disaffection

\begin{tabular}{cccccc}
.00 & .76 & .09 & 3473.55 & 3486.50 & -- \\
.00 & .91 & $.07-.10)$ & & & \\
& & .06 & 3414.90 & 3440.82 & $64.64 * * *$ \\
.00 & .93 & .06 & 3410.17 & 3453.36 & $12.74 *$ \\
& & $(.04-.08)$ & & & $(4)$ \\
\hline
\end{tabular}

Note. $\mathrm{N}=555 ; \mathrm{CFI}=$ confirmatory fit index; RMSEA = root mean square of approximation; AIC $=$ Akaike information criterion; $\mathrm{BIC}=$ Bayesian information criterion; $\mathrm{df}=$ degrees of freedom . 
Table 4.6

Model Estimates for Unconditional Linear Latent Growth Curve Models

\begin{tabular}{lcccc}
\hline & \multicolumn{2}{c}{ Behavioral Disaffection } & \multicolumn{2}{c}{ Emotional Disaffection } \\
Parameter & Estimate & SE & Estimate & SE \\
\hline Fixed Effects & & & & \\
$\quad$ Intercept mean & $1.70^{* * *}$ & .03 & $2.06^{* * *}$ & .037 \\
$\quad$ Linear slope mean & $.03^{* *}$ & .01 & $.08^{* * *}$ & .011 \\
Random Effects & & & & \\
$\quad$ Intercept variance & $.26^{* * *}$ & .03 & $.27^{* * *}$ & .041 \\
$\quad$ Linear slope variance & $.01^{* *}$ & .00 & $.01^{*}$ & .003 \\
$\quad$ Covariance & $-.01^{\mathrm{ns}}$ & .01 & $.00^{\mathrm{ns}}$ & .010 \\
\hline
\end{tabular}

Note. Estimates are unstandardized. $* * * p<.001 * * p<.01 * p<.05$;

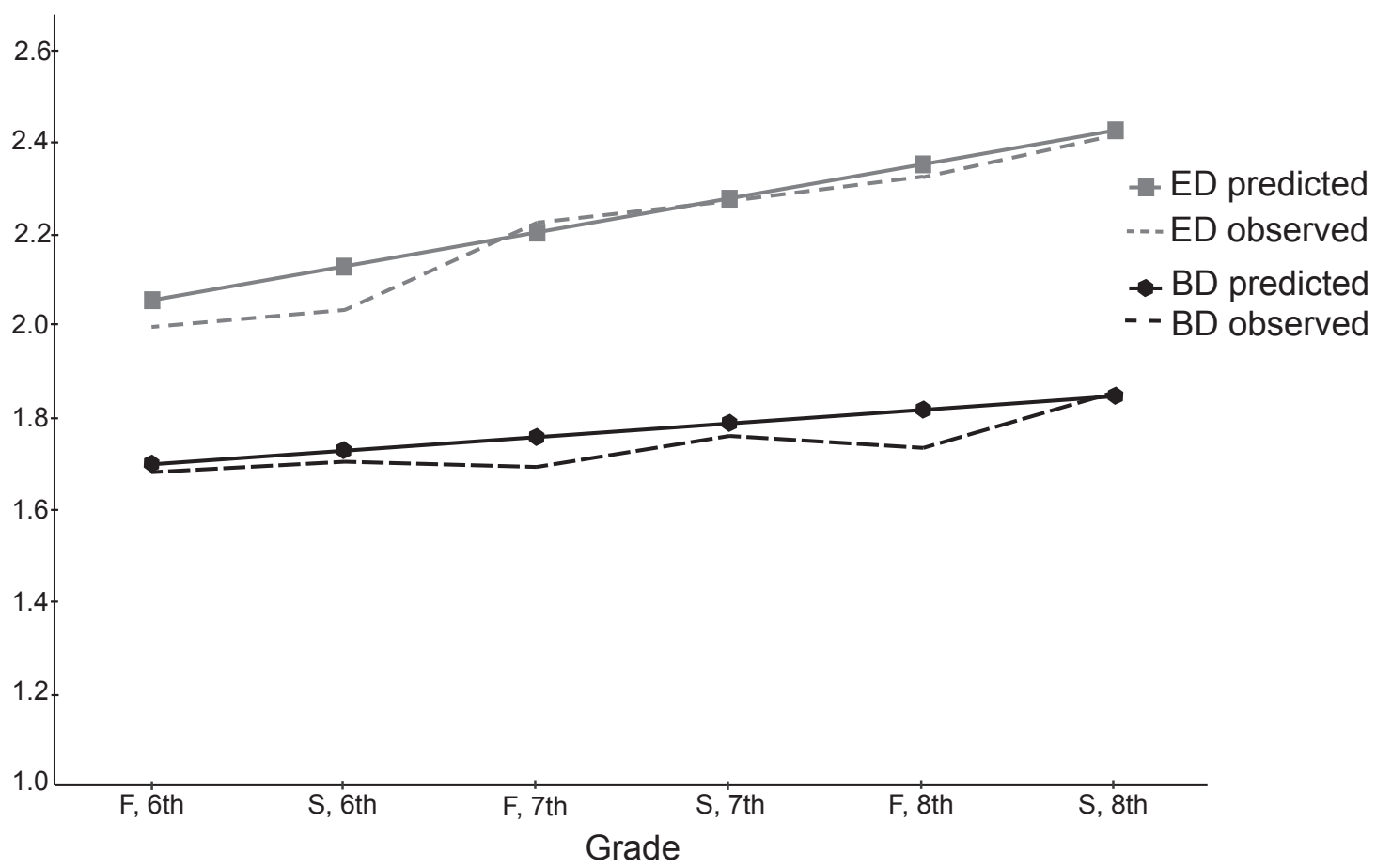

Figure 4.2. Student's predicted and observed behavioral (BD) and emotional (ED) disaffection trajectories from fall of $6^{\text {th }}$ grade to spring of $8^{\text {th }}$ grade. 


\section{Classroom Dynamics of Disaffection}

Latent structural modeling was used to examine the proposed model of classroom dynamics of disaffection. Teacher views of disaffection (TR) and student-teacher relationships were hypothesized to relate to concurrent student experiences of disaffection (SR). Additionally, we had the goal of exploring possible reciprocal effects between the two perspectives on disaffection. Alternative models were tested in which the direction of concurrent effects were reversed, and in which additional cross-time linkages were included. For example, one alternative model tested whether teacher views of disaffection (TR) predicted changes in student experiences of disaffection (SR) across the school year rather than at concurrent time points. Another alternative model tested whether the reciprocal effects between the perspectives operated in the opposite direction so that student experiences of disaffection (SR) were related to concurrent teacher views of disaffection (TR) and earlier teacher views of disaffection (TR) predicted changes in student experiences of disaffection (SR) across the school year rather than at concurrent time points. The final model had significantly better fit than either of these alternative models (alternative model one, $\Delta \chi^{2}(1)=11.63, p=.00 ;$ alternative model two, $\Delta \chi^{2}(0)$ $=2.14, \mathrm{p}=.00)$.

The final structural model (Figure 4.3), which also included indicators for all latent constructs and cross-time item error correlations, had good to adequate fit to the data, CFI $=.94 ;$ RMSEA $(90 \% \mathrm{CI})=.04(.03-.04)$. In this model, teacher views of disaffection (TR) were directly and positively related to concurrent student experiences of disaffection (SR). Student-teacher relationships also partially mediated the relationship 
between the views of disaffection such that higher teacher views of disaffection (TR) led to lower quality relationships, which in turn led to higher levels of student experiences of disaffection (SR). These classroom dynamics found in fall were then replicated in spring. Finally, student experiences of disaffection (SR) in fall predicted increases in teacher views of disaffection (TR) across the school year suggesting a mechanism through which the concurrent classroom dynamics may develop over time. Moreover, two of the three concurrent effects, teacher views to student views of disaffection and relationships to student views of disaffection, were stronger in spring than fall. 


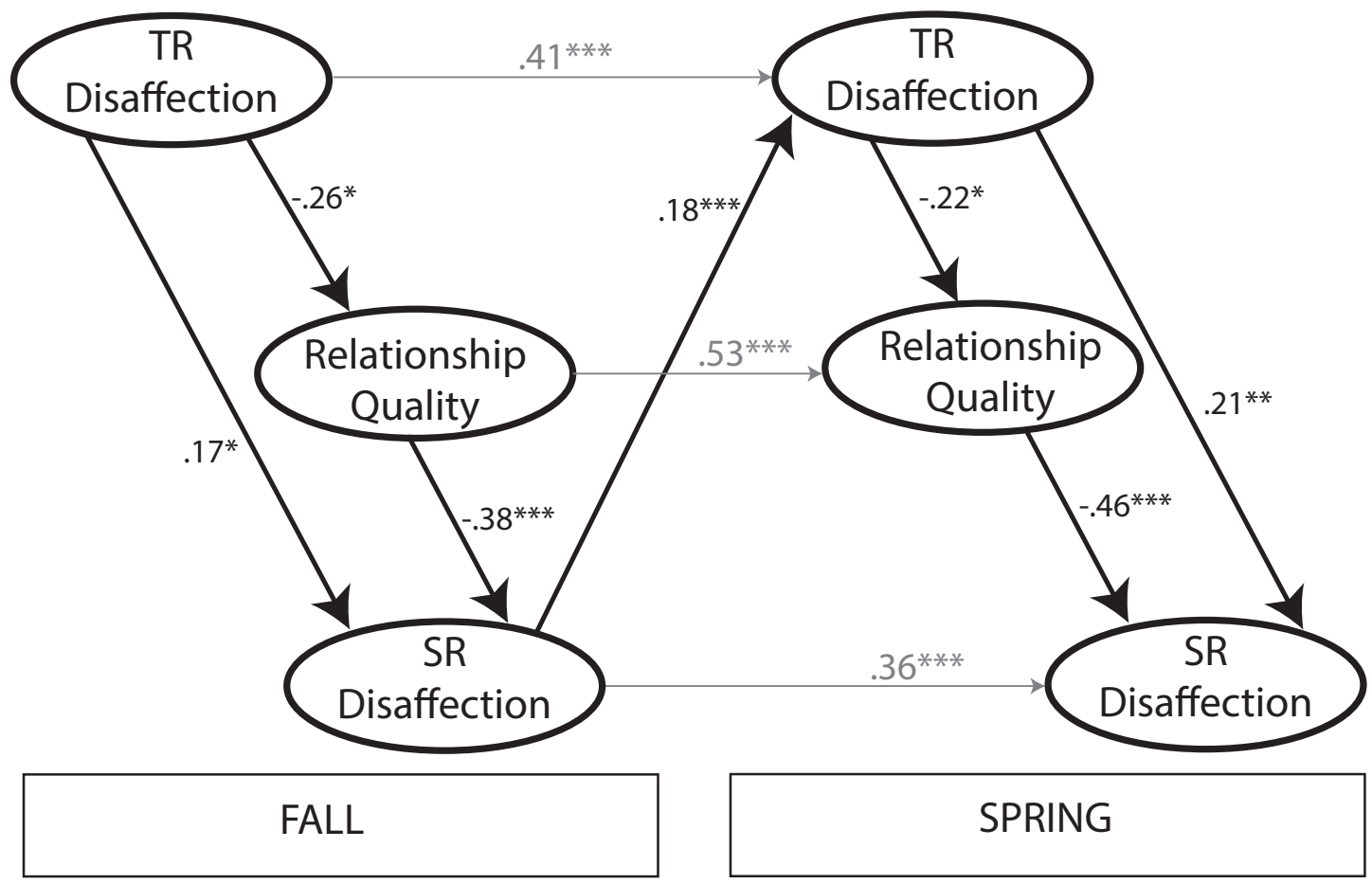

Figure 4.3. Latent structural model depicting the classroom dynamics of disaffection, in which teacher views of disaffection and student-teacher relationships were related to concurrent student experiences of disaffection, which in turn predicts changes in teacher views of disaffection from fall to spring. $\mathrm{N}=523$ students in Grades 6 through 8 . ${ }^{* * *} p<$ $.001 * *<<.01 * p<.05 ; \chi 2(327)=572.14, \mathrm{CFI}=.94, \mathrm{RMSEA}(90 \% \mathrm{CI})=.04,(.03$ .04). Model included indicators for all latent constructs and cross-time correlated item errors, but they are not shown for the sake of clarity.

\section{Discussion}

The main goals of this study were two-fold: 1) to investigate the developmental trajectories of middle school students' behavioral and emotional disaffection in science 
class and 2) to explore the classroom dynamics that underlie these trajectories. Based on past research findings, we hypothesized that behavioral forms of disaffection would increase linearly (Engels et al., 2017; Martin, Way, Bobis, \& Anderson, 2015; Skinner et al., 2008) across the middle school years while emotional forms were expected to remain stable (Engels et al., 2017; Larson \& Richards, 1991; Plenty \& Heubeck, 2013; Skinner et al., 2008). As expected, we found modest linear increases in the developmental trajectories of behavioral disaffection. We also found that emotional disaffection had a linear developmental trajectory indicative of a gradual worsening of this form of disaffection across the middle school years, rather than the stability that was expected based on prior research. Both behavioral and emotional forms of disaffection started out in fall of $6^{\text {th }}$ grade at moderately low levels and, although both forms increased across $6^{\text {th }}$ to $8^{\text {th }}$ grades, emotional forms were consistently slightly higher than behavioral forms across the entirety of early adolescence.

Regarding the classroom dynamics of disaffection, this study simultaneously set out to examine whether past findings demonstrating the importance of student-teacher relationships to student experiences of disaffection (SR) could be replicated (Galand \& Hospel, 2013; Guvenc, 2015; Skinner, Furrer, Marchand, \& Kindermann, 2008) and to explore the role that teacher views of disaffection play in models of these classroom dynamics. We hypothesized that teacher views of disaffection (TR) and student-teacher relationships would both influence concurrent student experiences of disaffection (SR) and we also set out to explore how the two perspectives might be reciprocally connected across the school year. 
This model, which showed better fit than other alternative models, indicates that teacher views of disaffection are related to student experiences of disaffection both directly and indirectly through student-teacher relationships. When teachers viewed students as more disaffected, relationship quality was worse, such that students perceived teachers as less warm and caring, offering fewer relevant learning opportunities, and behaving in a more controlling manner. Lower relationship quality, in turn, was linked to higher levels of student experiences of disaffection. At the same time, this classroom dynamics model also suggests that teacher's views of students as disaffected was associated with worsening student experiences of disaffection even when the role of relationship quality was accounted for. More specifically, when teachers perceived students as prone to giving up, refusing to complete work, or as feeling apathetic or averse to their science classwork, students themselves reported exerting low effort, giving up, or feeling bored during and averse to their science classwork. The significant connections between the two perspectives on disaffection and relationship quality were replicated at a second time point later in the school year. Furthermore, students' earlier experiences of disaffection (SR) in fall predicted increases in teacher views of disaffection across the school year.

Taken together, this model reveals the concurrent relations that exist between teacher and student perspectives on disaffection and student-teacher relationships. It also suggests, through both the replication at a later time point and the stability of the constructs themselves, that these classroom dynamics are relatively stable once established early in the school year. Finally, because earlier student experiences of 
disaffection seemed to intensify the way teachers viewed student disaffection later in the school year, these findings suggest a possible mechanism for how such dynamics lead to the development (i.e., gradual worsening) of disaffection over time.

\section{Study Strengths and Limitations}

Before interpreting this study's findings its strengths and limitations are discussed. Two strengths of this study include its focus on the discipline of science and its sampling of a school population that was diverse in terms of ethnicity and high needs in terms of serving low socioeconomic status (SES) families. First, prior research has demonstrated that disaffection is especially prevalent in low SES populations (Martin, Anderson, Bobis, Way, \& Vellar, 2012; Martin, Way, Bobis, \& Anderson, 2015), therefore, the phenomenon of disaffection is both relevant to and important in high needs schools. Second, even though most middle schools are departmentalized by disciplinary subject, prior disaffection research has predominately examined disaffection with school more generally (e.g., Engels et al., 2017; with the notable except of a group of studies focused on mathematics e.g., Ahmed et al., 2013). Most likely this methodological choice is related to the assumption that the underlying motivational processes are universal in nature. This study, however, is among the first to pursue questions about disaffection in the science education context specifically and, as a result, serves as a test of the assumption that the development and classroom processes of disaffection are generalizable across disciplines. With these strengths noted, it is also worth mentioning that this study is limited in its generalizability as it was conducted in a single school. 
In terms of design and analysis, two additional strengths of this study include the longitudinal design involving two measurement waves per year for 6th through 8th grades and the use of growth curve modeling techniques. These methodological features allowed us to test multiple alternative growth models each representing a different shaped change trajectory, as well as, investigate whether there were significant inter-individual differences in these trajectories. Previous studies that relied on other analysis frameworks (e.g., MANOVA) or annual measurement waves, have been unable to test for the more complex developmental trajectories of disaffection. Despite these strengths, however, the two time points within each school year were not optimally spaced for answering our second set of research questions. Thus this spacing represents a limitation of the research design as applied to the dynamics-focused research questions. Instead, it is likely that the processes that underlie the classroom dynamics of disaffection take place over a much shorter time scale (i.e., daily or weekly). As such, it will be important to further test these classroom dynamics in, for example, daily diary studies so that future studies can draw on more timepoints to further our understanding by moving beyond concurrent relations and making it possible to test for additional reciprocal relationships over time.

Finally, this study's student-teacher relationship scale was limited by both general item phrasing and the scope of teacher behaviors it measured. The student-teacher relationship scale was designed to tap the overall relationship quality as perceived by students, not relationship quality specifically tied to episodes of disaffection. Additionally, items tapping negative, controlling teacher behaviors were worded in a general manner (e.g., "People here are always telling me what to do.") due to the 
sensitive nature of singling out a specific teacher's negative behavior. Whether this type of general phrasing had an impact on our measurement of relationship quality or the magnitude of effects found in our models is an empirical question that future studies could examine using measures that are more detailed and specific to disaffection. This and other future research and the broader implications of this study's findings are discussed in the following section.

\section{Implications and Future Research}

Development of disaffection across early adolescence. The following section discusses two key findings regarding the development of behavioral and emotional disaffection: overall trends of disaffection gradually worsening across early adolescence and variations between students. Additionally, we discuss the future research that these findings may prompt.

Developmental trends of gradually worsening disaffection. On average, the middle school students in this study experienced a gradual worsening of both behavioral and emotional disaffection with science across the early adolescent years. This finding is concerning despite its gradual rate because disaffection is costly for students' academic success (Ahmed et al., 2013; Gonzalez \& Paoloni, 2014; Gonzalez et al., 2015; King, 2015) and functioning (Galand \& Hospel, 2013; Green et al., 2007; Skinner et al., 2016). Overall, these findings align with both the broader field of motivational research, which characterizes the early adolescent years as a time of declining motivation (generally: Wigfield, Byrnes, \& Eccles, 2006; Wigfield et al., 2015; in science specifically: 
Gottfried, Marcoulides, Gottfried, \& Oliver, 2009; Gottfried, Fleming, \& Gottfired, 2001). Regarding behavioral disaffection more specifically, this study confirms the increasing trends found in other studies (Engels et al., 2017; Martin, Way, Bobis, \& Anderson, 2015; Skinner et al., 2008), which not only reinforces our growing understanding of how behavioral disaffection changes across early adolescence, but extends these findings to the science education context. Based on the observed trajectory (Figure 4.2) of behavioral disaffection, the increases seem to be largely located within each school year while summers appear to be either times of stability or slight recovery, however, it will be important for additional studies to attempt to replicate these apparent trends.

Regarding emotional disaffection, past studies that focused on between year changes led us to expect stable developmental trajectories across the early adolescent years (Engels et al., 2017; Larson \& Richards, 1991; Plenty \& Heubeck, 2013; Skinner et al., 2008); however, we found evidence of small linear increases, which by the end of $8^{\text {th }}$ grade were beginning to approach the mid-point of the survey scale. Based on the observed trajectory (Figure 4.2) of emotional disaffection, the summer after $6^{\text {th }}$ grade appears to be marked by an especially sharp increase, which is suggestive of the possibility of age-based explanations (e.g., the onset of puberty) rather than school contextual explanations. The explicit investigation of the causes of within-school year versus summer changes of disaffection could be a fruitful avenue for future research studies. 
Finally, aligning with past findings (Engels et al., 2017; Skinner et al., 2008), levels of emotional disaffection were higher than levels of behavioral disaffection. This trend of higher levels of emotional disaffection is especially concerning because past research suggest that emotional forms of disaffection may predict increases in behavioral disaffection and declines in engagement (Skinner et al., 2008); therefore, emotional disaffection can be thought of as a risk factor for further struggles with motivation. Future research studies should seek to replicate these findings, particularly the linear increases in emotional disaffection, as well as, test whether emotional disaffection predicts behavioral disaffection and other relevant motivational constructs.

Variations between students in initial levels and rates of change. For both behavioral and emotional disaffection, the significant intercept variance suggests that perhaps the transition to middle school, which is marked by changes in school structure (e.g., departmentalization leading to shifts from single to multiple teachers; Mac Iver, Young, \& Washburn, 2001), may impact students differentially. We also found a small, but significant linear slope variance for both behavioral and emotional disaffection, indicating that there are some slight differences in the rate of change in both forms of disaffection across the middle school years. Future studies should explore a variety of predictors and time-varying covariates in order to explain how these differences in the developmental trajectories of disaffection come about.

Classroom dynamics of disaffection. The following section discusses three patterns from the classroom dynamics of disaffection model: the confirmation of the importance of student-teacher relationships, the potential importance of the teacher 
perspective on disaffection, and the influence of student experiences of disaffection on changes in teacher perspectives across the school year. We also discuss possible future research following up on these patterns. Finally, we conclude with a discussion of broader implications for researchers, interventionists, and educators.

Confirmed importance of student-teacher relationships. The model of classroom dynamics supported in this study serves as further confirmation of past research, which has demonstrated that high quality student-teacher relationships have the power to decrease levels of adolescent disaffection (SR) (Galand \& Hospel, 2013; Guvenc, 2015; Skinner, Furrer, Marchand, \& Kindermann, 2008). Beyond confirming this link, the model also pushes our understanding further by demonstrating the centrality of relationship quality in terms of its role in partially mediating the relation between teacher views of disaffection and student experiences of disaffection. This link suggests that one way in which teachers' views of students' disaffection impact students is through their negative effects on the quality of relationships.

While this study focused on multiple aspects of student-teacher relationships including involvement (knowledge of students and dependability) and autonomy support (relevance and controlling teacher behaviors), its operationalization of student-teacher relationship quality was as a broad construct. As such, specific aspects of relationship quality were not singled out and tested individually. Given that recent research on autonomy supportive teacher practices has demonstrated that some components of autonomy supportive teacher practices (i.e., controlling messages and uninteresting activities) are more strongly related to student disaffection than others (i.e., choice) 
(Patall et al., 2018), it will be worthwhile for future classroom dynamics studies to use measures of relationship quality that allow for more fine-grained testing of the effects of specific sub-components of relationship quality. The more specific information generated from such investigations will create tangible and, therefore, more actionable information for both interventionists and educators.

Importance of teacher perspective. This study's model of the dynamics of disaffection suggests that teacher perspectives are essential to our understanding of the classroom interactions that surround disaffection. Thus, teacher reports of disaffection should be thought of both as an alternative measurement strategy, which affords the advantage of reducing common method variance, and as a genuinely important factor that shapes student's experiences of disaffection in its own right. First, the inclusion of the teacher perspective can extend our theories and models of disaffection beyond of the internal experience and perceptions of the student. In doing so, common method variance may be reduced, thus preventing estimates of the relations between disaffection and student-teacher relationships from being inflated, as may happen when students are the only reporters of both constructs (Podsakoff, MacKenzie, Lee, \& Podsakoff, 2003).

Second, past research has suggested that there may be genuine differences between student and teacher perspectives on disaffection. For instance, students may have a tendency to under-report certain disaffected behaviors, while teachers may be less attuned to certain disaffected emotions (Bishop \& Kalogeropoulos, 2015; Ravet, 2007; Riley \& Docking, 2004; Skinner et al., 2009). This may in part be attributed to the fact that the two perspectives are tapping slightly different manifestations of the same 
construct with teachers reporting on external, readily observable indicators and student reporting on their own internal experiences of disaffection. While constructing our respective measures of the two perspectives for this study, we found ourselves grappling with important questions related to potential real world difference in these perspectives. For example, What does student boredom look like from the teacher perspective? and Would students ever label their own behavior as disruptive? Future investigation of questions regarding the potential genuine differences in teacher and student perspectives would be worthwhile. For example, interviews with both students and teachers about specific instances of disaffection may further our understanding of the differences and similarities between the perspectives.

\section{Influence of student experience on teacher views of disaffection: Potential}

mechanism for changing dynamics over time. One final implication of this study's investigation into the classroom dynamics of disaffection is based on the finding that student's earlier experiences of disaffection in the fall of the school year predicted changes in teacher views of disaffection across the school year. Given that the concurrent effects between the two perspectives on disaffection and student-teacher relationships were replicated at a second time point in spring and that the effects were generally stronger at that later time point despite moderate cross-time stabilities, our findings imply that the effects we found at a single time point represent a dynamic that not only continues, but potentially worsens over the course of the school year. The connection between earlier student experiences of disaffection and increases in teachers' subsequent views of disaffection can be thought of as one mechanism that may lead to the kinds of 
within-year increases in disaffection that were seen in both the means and growth curve models in this study. After all, teachers are skilled observers of their students, and although some components of disaffection may be less observable than others, it is reasonable to expect that teachers notice student disaffection in their classrooms and that past observations of a student being disaffected will logically influence a teacher's interpretations of that student's disaffection in the future.

Future research should attempt to replicate the classroom dynamics found in this study as well as extend these findings by shifting towards daily diary or observational research designs that would allow for more detailed inspection of both the effects found in this study and the possibility of more complex dynamics. For example, past research suggests a possible feedback effect between student experiences of disaffection and student-teacher relationships. For example, Jang, Kim, and Reeve (2016) found that higher levels of disaffection (SR) predicted declines in students' experiences of the quality of their relationships with teachers (specifically, higher levels of controlling behaviors and lower autonomy support) across both the beginning to middle and middle to end of a semester. Although we did not find this feedback effect when we tested a version of our model including this link, it is possible that this effect might be supported in future studies with a model that is less reliant on concurrent effects or that examines shorter time gaps.

\section{Larger implications of the development and classroom dynamics of}

disaffection. Taken together, this study's findings have implications for researchers, interventionists, and educators. A variety of studies across several disciplines (i.e., school 
in general, math, and now science) have found the same increasing linear trends in behavioral disaffection during early adolescence, therefore, a next step for researchers is to begin trying to explain why these increases are occurring. The dynamics uncovered in this study suggest one possible set of explanatory factors. That is, researchers' theories, measures, and analytic models should continue to include student-teacher relationship quality and also expand to include the teacher perspective on disaffection; there are also other features of the classroom worth considering such as the nature of academic work and peer relationships (e.g., Engels et al., 2017). Studies of the developmental trajectories of emotional disaffection have not yet reached the same level of consistent findings as that of behavioral disaffection, therefore, it may be worthwhile for researchers to carefully evaluate why the different developmental trends (i.e. stability versus linear increases) have been found; for instance, the operationalization of emotional disaffection, study design, and populations sampled are all possible explanations for the as of yet inconsistent findings.

For interventionists, the observed trajectories suggest that both behavioral and emotional forms of disaffection are worsening over the course of each school year, even if only gradually, thus it seems clear that disaffection is a challenge for many middle school teachers. Further supporting this conclusion, past research demonstrates that some forms of disaffection (e.g., disruption) are listed high among job-based stressors for teachers (Kyriacou, 2001). Interventionist should, therefore, design professional development to help middle school teachers more effectively cope with and address student disaffection. For example, the direct effect between teacher perspectives on 
disaffection and student experiences of disaffection suggests that teachers may need support in reframing how they view signs of student disaffection so that these signs of disaffection can be seen as signals of momentary declines in motivation (e.g., "This student is experiencing disaffection right now") rather than evidence of static traits of the student (e.g., "This is a disaffected student.").

For educators, the presence of both perspectives on disaffection in the classroom dynamics model implies that no one party, neither the student nor the teacher, is solely responsible for the interactions that explain how disaffection comes about in classroom settings. This finding, therefore, clarifies the role of the teacher in the classroom dynamics of disaffection - that is they are neither solely responsible nor are they powerless against student disaffection. Far from powerless, this study suggest that educators can decrease student disaffection with warm, caring, and autonomy supportive responses and intentional efforts to label student disaffection as a fleeting state rather than enduring trait. 


\section{Chapter 5: Discussion}

Student disaffection is clearly important because of its negative consequences for students and teachers, but the development and classroom dynamics of disaffection are currently understudied and, therefore, insufficiently understood. To address these gaps in our current understanding of disaffection, the two studies in this dissertation each focused on the development and classroom dynamics of disaffection across different time scales. The first investigation, a multiple case study of episodes of disaffection, aimed to describe how disaffection is initially sparked, how it changes over single class periods, and how teacher responses to student disaffection amplify or reduce it. The second investigation, a longitudinal study, examines disaffection trajectories across the early adolescent years and then models within year classroom dynamics of disaffection by exploring relations between student experiences of disaffection, teacher perspectives of disaffection, and student-teacher relationships. Taken together, this collection of studies had both strengths and limitations, which are discussed in more detail below.

\section{Strengths}

Samples from low socioeconomic status populations. Previous research has established that schools serving lower socioeconomic status (SES) populations tend to have students with higher levels of disaffection (Martin, Anderson, Bobis, Way, \& Vellar, 2012; Martin, Way, Bobis, \& Anderson, 2015). The samples from both studies in this dissertation drew from schools with high proportions of students from economically disadvantaged backgrounds. Study 1 drew from schools that had between $65-90 \%$ of students eligible for free or reduced lunch. Study 2 took place in a school that had even 
higher levels of students from low SES backgrounds (range: $81.2-94.2 \%$ across the school years included). Sampling from these populations was a strength of these studies because it increased the likelihood that the phenomenon of interest, disaffection, was present in the studied populations. Additionally, the findings from these studies may also generalize to other schools serving similarly high needs populations.

Measurement. Two key strengths of this collection of studies are related to the measurement of disaffection: the use of multiple perspectives on disaffection (study 1: third-party observers and students; study 2: students and teachers) and the use of measures that cover multiple dimensions of behavioral and emotional disaffection.

Multiple perspectives on disaffection. Both studies in this dissertation drew from multiple perspectives on disaffection, which afforded the advantage of balancing biases in any individual perspective. For instance, study 1 used student report of disaffection to help select classroom cases for inclusion in the study, and then relied on trained observer ratings of student disaffection as the main data source. The inclusion of the student perspective on disaffection in selecting cases not only helped narrow down the number of classrooms that needed to be review for inclusion in the study, but also prevented this study from relying solely on the researcher's determination that student disaffection was occurring in the observed classrooms. In study 2 , the use of both student-report and teacher-report was beneficial because past research suggested (Bishop \& Kalogeropoulos, 2015; Ravet, 2007; Riley \& Docking, 2004), and our findings ultimately confirmed, that there may be genuine differences between student and teacher perspectives on 
disaffection, which then carry real implications for the classroom dynamics of disaffection.

The use of broad and multidimensional measures of disaffection. A strength of the disaffection measures used in these studies is that they can all be categorized as broad and multidimensional, which was previously defined as measures that tap multiple dimensions of both behavioral and emotional disaffection. In study 1, the student-report survey of disaffection tapped two components of behavioral disaffection (low effort, inattention) and three components of emotional disaffection (anxiety, frustration, aversion). The observation protocol in this study was also designed to measure both behavioral (off-task behavior, passive inattention, disruption) and emotional (boredom, aversion, frustration) forms of disaffection. Similarly in study 2's surveys, students were asked about their experiences of behavioral disaffection (low effort, giving up, withdrawal) and emotional disaffection (boredom, apathy, aversion) while teachers were asked about their views of individual students' behavioral (giving up, withdrawal) and emotional (apathy, disinterest) disaffection. Such broad and multidimensional measures of disaffection are richer in their conceptualization because they capture the scope and multidimensionality of the construct, which is a strength for studies seeking to understand how disaffection manifests itself in real classroom settings.

Diverse methods: Triangulation and complementarity. Finally, the collective studies in this dissertation used diverse methods (multiple case study and longitudinal quantitative study designs) to address the same underlying goals, those of understanding the development and classroom dynamics of disaffection. In employing these diverse 
methods, the goal of complementarity was pursued. Morgan (1998) explains that complementarity is achieved through the careful balance of the strengths of different methods and the measurement of different components of the same phenomenon; if achieved, complementarity can result in a more detailed and enhanced understanding of the phenomenon of interest. One tangible example of how complementarity was achieved in this set of studies lies in how the multiple case study informed our revisions of the classroom dynamics of disaffection model. The detailed observational analyses of student and teacher interactions in the multiple case study revealed that the classroom dynamics of relevance to disaffection were occurring in real time. This enhanced understanding led us to test a revision of the classroom dynamics model that was originally proposed where we moved many of the effects from across the school year to within the same time point. This revision helped us more accurately model what we had observed in the classroom leading us to a still better understanding of the dynamics of disaffection.

\section{Limitations}

Design limitations. Both studies in this dissertation drew from secondary datasets, which necessarily placed some constraints on the research designs used in the two studies. These constraints resulted in unique design limitations for each study.

Study 1: Missing member checks. Ideally the multiple case study would have included member checks with both students and teachers by bringing the appropriate individual case description back to teachers and students to check if they agreed with the interpretations that were drawn about the disaffection episodes. Member checks are considered a valuable technique for strengthening a qualitative research study's 
trustworthiness (Merrick, 1999). Unfortunately, there was no plan in the original randomized control study to follow-up with teachers or students after the three-year study period had concluded, so there was no mechanism to perform member checks in this particular study. As a consequence, some of the interpretations we draw from the results of the multiple case study (e.g., conclusions regarding teacher interpretations of disaffection) are strictly speculative in nature. As suggested in the discussion section of chapter 3 of this dissertation, a potentially valuable avenue for future research would be to explicitly examine these interpretations.

Study 2: Timing of measurement waves. The timing of the measurement waves in study 2 (fall and spring) were based on what was available in the secondary dataset, rather than on an a priori, theoretically-based hypothesis regarding the timing of the classroom dynamics of disaffection. Although there are good reasons to suspect that both disaffection and student-teacher relationships change over the course of the school year (Wigfield et al., 2015; Wentzel, 2009), two measurement waves spaced roughly 5-6 months apart were not the ideal design for questions regarding reciprocal relationships between disaffection and student-teacher relationships. Fortunately, the collective studies in this dissertation examined the classroom dynamics of disaffection at different time scales, with study 1 also shedding light on these dynamics over single class periods. However, future studies should examine the classroom dynamics of disaffection across multiple more closely spaced time points during the same school year (e.g., daily or weekly for several weeks), perhaps using developmental cascade models, as these will be 
able to explicitly examine whether the reciprocal effects found in this dissertation also seem to be unfolding over shorter time windows.

\section{Study 2: Lack of teacher-report of student-teacher relationships. As}

mentioned in the strengths section above, study 2 drew from both student and teacher perspectives on student disaffection. However, the same was not the case for studentteacher relationships. Only students were asked about their perceptions of their relationships with their teachers. As a result, despite these relationships being an inherently dyadic phenomenon, the operationalization of student-teacher relationships did not include both perspectives. While the student perspective on these relationships provided valuable information on the teacher's contribution to the quality of the relationship though the eyes of their students, teachers have their own views of these same relationships and these views may also shape classroom dynamics. Therefore, our understanding of the dynamics of disaffection would likely be further enriched if future studies were designed to model how student and teacher perspectives on both disaffection and relationship quality interact over time. For example, it is possible that teacher perspectives on relationship quality are reciprocally connected to student views on relationship quality in a similar fashion to the reciprocal effects that were found between the two perspectives on disaffection.

\section{Overarching Implications}

The development of disaffection across early adolescence. As mentioned in the introduction, the studies in this dissertation tapped different developmental time scales: micro-time (study 1: in depth study of single class periods), meso-time (study 2: within year), and macro-time (study 2: six measurement waves across early adolescence) (Figure 
1.1). Studying disaffection across these multiple time scales afforded us the opportunity to develop a richer understanding of the developmental trends of disaffection including how disaffection is initially sparked in classrooms (study 1), and how it changed over class periods (study 1$)$, school years (study 2$)$, and across the early adolescent years $\left(6^{\text {th }}-\right.$ $8^{\text {th }}$ grade; study 2). We were able to draw two broad conclusions regarding the development of disaffection that were bolstered by the collective findings of this dissertation: 1) developmental trajectories of disaffection are best characterized as gradual in nature and 2) individual students differ in their developmental trends of disaffection.

Gradually worsening developmental trends. Regardless of whether we were observing student disaffection from moment-to-moment during a single class period (study 1) or modeling disaffection across early adolescence (study 2), we found ourselves drawing the same broad conclusion: overall student disaffection was changing at gradual rates. First, contrary to our original hypothesis in study one, we found escalations in disaffection to be relatively rare during the observed class periods. Among the studied episodes of disaffection, escalations in student disaffection were only observed in three instances when students shifted temporarily from socially off task to resistance or disruption, which are arguably more severe forms of disaffection. More commonly, students oscillated between various disaffected and engaged states such that any overall changes in their disaffection would be best characterized as gradual in nature. Similarly, study two found increasing linear trends in both behavioral and emotional disaffection, but the rate of change was gradual for both forms of disaffection. On average, it appears 
that students experienced small increases in behavioral and emotional disaffection from fall to spring of each middle school year such that the overall trend across the middle school years was one of gradual linear increase. This gradual rate of change, seen in both the short and longer term, is relatively good news because it means the declines in motivation we saw in the studied samples are not as severe as one might have expected based on predictions about the overall declines in motivation that are considered characteristic of the middle school years (Wigfield, Byrnes, \& Eccles, 2006; Wigfield et al., 2015). However, considering that these gradual increases are likely preceded by more dramatic increases across the transition to middle school (Martin, Way, Bobis, \& Anderson, 2015; Skinner et al., 2008), they are nevertheless concerning.

No single path in the development of disaffection. Both studies in this dissertation also provided clear evidence that individual students differed in how their disaffection changes over the various time scales. In study 1 , the six patterns of changes in disaffection across the observed class periods demonstrate that even students in the same classroom have very distinct experiences of disaffection. For instance, some students' experienced only fleeting moments of disaffection while others spent the majority of the class period off task socializing with their peers. Similarly, study 2 found that students' behavioral and emotional disaffection differed in both their initial status in fall of $6^{\text {th }}$ grade and in their rates of change over the course of early adolescence. A foundational element of this dissertation is the conceptualization of disaffection as an ever-changing set of behaviors and emotions that are, in part, dependent on dynamic interactions between students and their teachers. Implied in this conceptualization is the 
expectation that student experiences of disaffection are unique to each student's experience in the classroom. Taken together the collective findings regarding the interindividual differences in student disaffection reinforce such a conceptualization of disaffection.

\section{Classroom dynamics of disaffection: Effective strategies for addressing}

student disaffection. Both studies in this dissertation converged on the effectiveness of teacher involvement and autonomy support in addressing student disaffection. In study 1 , supportive responses, which were characterized by involved (i.e., warmth, dedication of resources, positive affect, and knowledge of students) and autonomy supportive (i.e., provision of choice/flexibility, relevance, validating and respect for adolescent perspective, and encouraging independent thinking) teacher behaviors, were the only type of observed response that was effective in resolving disaffection the majority of the time. In study 2, student-teacher relationships, also characterized by involvement (knowledge of students and dependability) and autonomy support (relevance and absence of controlling teacher behaviors), were found to be central in the classroom dynamics of disaffection such that higher quality relationships predicted lower student experiences of disaffection. In these collective findings, both studies add to the accumulating evidence suggesting that student-teacher relationships, more typically operationalized in past studies as holistically including involvement, autonomy support and structure (Galand \& Hospel, 2013; Guvenc, 2015; Skinner, Furrer, Marchand, \& Kindermann, 2008), are a key strategy for educators who wish to reduce student disaffection. 
In addition, each study in this dissertation uncovered a new strategy that educators could add to their repertoire for effectively addressing student disaffection. First, study 1 uncovered a strategy real teachers are already using in their classrooms - the quick fix redirection response. This quick fix response strategy appeared to be effective as long as the redirection had an instrumental quality (specific guidance regarding how behavior needed to be modified) embedded within it and had the added benefit of requiring a low investment of time on the part of the teacher. Second, in study 2, the finding that teacher views of disaffection directly influence concurrent student experiences of disaffection, suggests that intentionally labeling student disaffection as a fleeting 'in the moment' state, rather than an enduring trait, is yet another strategy teachers can implement to decrease disaffection.

\section{Conclusion}

While each study in this dissertation contributes to our growing understanding of the development and classroom dynamics of student disaffection, together the studies contribute more than the sum of their parts because they simultaneously provide a rich, detailed description from study 1 and a longitudinal, quantitatively tested model from study 2. Regarding the development of disaffection across the early adolescent years, this dissertation has contributed both rich detailed descriptions of the multiple patterns that disaffection takes across middle school class periods as well as a model of the broader, gradually increasing trajectories of behavioral and emotional disaffection across the middle school years $\left(6^{\text {th }}-8^{\text {th }}\right.$ grade). Regarding the classroom dynamics of disaffection, 
this dissertation has yielded both vivid accounts of moment-to-moment interactions between disaffected students and their teachers and a model of how these dynamic interactions may lead to longer term changes in disaffection. 


\section{References}

Acee, T. W., Kim, H., Kim, H. J., Kim, J., Hsiang-Ning, R. C., Kim, M., et al. (2010). Academic boredom in under- and overchallenging situations. Contemporary Educational Psychology, 35, 17-27.

Ahmed, W., van der Werf, G., Kuyper, H., \& Minnaert, A. (2013). Emotions, selfregulated learning, and achievement in mathematics: A growth curve analysis. Journal of Educational Psychology, 105(1), 150-161.

Allen, J., Gregory, A., Mikami, A., Lun, J., Hamre, B., \& Pianta, R. (2013). Observations of effective teacher-student interactions in secondary school classrooms: Predicting student achievement with the classroom assessment scoring systemsecondary. School Psychology Review, 42(1), 76-98.

Archambault, I., Janosz, M., Morizot, J., \& Pagani, L. (2009). Adolescent behavioral, affective, and cognitive engagement in school: Relationship to dropout. Journal of School Health, 79(9), 408-415.

Balfanz, R., Herzog, L., \& Mac Iver, D. J. (2007). Preventing student disengagement and keeping students on the graduation path in urban middle-grades schools: Early identification and effective interventions. Educational Psychologist, 42(4), 223-235.

Belmont, M., Skinner, E., Wellborn, J., \& Connell, J. (1992). Teacher as Social Context (TASC). Two Measures of Teacher Provision of Involvement, Structure, and Autonomy Support. (1992). Technical Report, University of Rochester, Rochester, NY. Retrieved from: https://www.pdx.edu/psy/ellen-skinner-1 
Betoret, F. (2006). Stressors, Self-Efficacy, Coping Resources, and Burnout among Secondary School Teachers in Spain. Educational Psychology, 26(4), 519-539.

Bishop, A. J., \& Kalogeropoulos, P. (2015). (Dis) engagement and Exclusion in Mathematics Classrooms_-Values, Labelling and Stereotyping. In Diversity in mathematics education (pp. 193-217). Heifelberg, Germany: Springer International Publishing.

Boekaerts, M. (1993). Anger in relation to school learning. Learning and Instruction, 3(4), 269-280. doi:10.1016/0959-4752(93)90019

Bridgeland, J. M. (2010). The new dropout challenge: Bridging gaps among students, parents, and teachers. New Directions for Student Leadership, 2010(127), 101-110.

Bronfenbrenner, U., \& Morris, P. A. (1998). The ecology of developmental processes. In W. Damon (Series Ed.) \& R. M. Lerner (Vol. Ed.), Handbook of child psychology: Vol. 1: Theoretical models of human development (pp. 993 - 1028). New York: Wiley.

Brown, K., \& Fletcher, A. (2002). Disaffection or disruptive engagement? A collaborative inquiry into pupils' behaviour and their perceptions of their learning in modern language lessons. Pedagogy, Culture \& Society, 10(2), 169-192.

Chan, D. (2009). So why ask me? Are self-report data really that bad. In C.E. Lance \& R.J. Vandenberg (Eds.), Statistical and methodological myths and urban legends: Doctrine, verity and fable in the organizational and social sciences (pp. 309-336). New York: Routledge. 
Chang, M. (2009). An appraisal perspective of teacher burnout: Examining the emotional work of teachers. Educational Psychology Review, 21(3), 193-218. doi:10.1007/s10648-009-9106

Cheung, G. W., \& Rensvold, R. B. (2002). Evaluating goodness-of-fit indexes for testing measurement invariance. Structural Equation Modeling, 9(2), 233-255.

Coan, J. A., \& Gottman, J. M. (2007). The specific affect coding system (SPAFF). In J.A. Coan \& J.J.B. Allen (Eds.), Handbook of emotion elicitation and assessment (pp. 267-285). New York: Psychology Press.

Craig, S., Graesser, A., Sullins, J., \& Gholson, B. (2004). Affect and learning: an exploratory look into the role of affect in learning with AutoTutor. Journal of Educational Media, 29(3), 241-250.

Daschmann, E. C., Goetz, T., \& Stupnisky, R. H. (2011). Testing the predictors of boredom at school: Development and validation of the precursors to boredom scales. British Journal of Educational Psychology, 81(3), 421-440.

Dupéré, V., Leventhal, T., Dion, E., Crosnoe, R., Archambault, I., \& Janosz, M. (2015). Stressors and turning points in high school and dropout: A stress process, life course framework. Review of Educational Research, 85(4), 591-629.

Eccles, J. S. (1999). The development of children ages 6 to 14. The future of children, 3044.

Eccles, J. S., Wigfield, A., Midgley, C., Reuman, D., Iver, D. M., \& Feldlaufer, H. (1993). Negative effects of traditional middle schools on students' motivation. The Elementary School Journal, 93(5), 553-574. 
Engels, M. C., Colpin, H., Van Leeuwen, K., Bijttebier, P., Van Den Noortgate, W., Claes, S., ... \& Verschueren, K. (2017). School engagement trajectories in adolescence: The role of peer likeability and popularity. Journal of School Psychology, 64, 61-75.

Freudenberg, N., \& Ruglis, J. (2007). Peer reviewed: Reframing school dropout as a public health issue. Preventing Chronic Disease, 4(4), 1-11.

Fulmer, S. M., \& Frijters, J. C. (2009). A review of self-report and alternative approaches in the measurement of student motivation. Educational Psychology Review, 21(3), 219-246.

Galand, B., \& Hospel, V. (2013). Peer victimization and school disaffection: Exploring the moderation effect of social support and the mediation effect of depression. British Journal of Educational Psychology, 83(4), 569-590.

Gerstorf, D., Hoppmann, C. A., \& Ram, N. (2014). The promise and challenges of integrating multiple time-scales in adult developmental inquiry. Research in Human Development, 11(2), 75-90.

González, A., Garrido, J. M. F., Castro, Y. R., \& Rodríguez, M. V. C. (2015). Class Anxiety in Secondary Education: Exploring Structural Relations with Perceived Control, Engagement, Disaffection, and Performance. The Spanish Journal of Psychology, 18, 869-878.

González, A., \& Paoloni, P. V. (2014). Self-determination, behavioral engagement, disaffection, and academic performance: A mediational analysis. The Spanish Journal of Psychology, 17, 1-10. 
González, A., Paoloni, P., Donolo, D., \& Rinaudo, C. (2015). Behavioral engagement and disaffection in school activities: Exploring a model of motivational facilitators and performance outcomes. Anales De Psicología, 31(3), 869-878. doi:10.6018/analesps.31.3.176981

Gottfried, A. E., Fleming, J. S., \& Gottfried, A. W. (2001). Continuity of academic intrinsic motivation from childhood through late adolescence: A longitudinal study. Journal of Educational Psychology, 93(1), 3-13.

Gottfried, A. E., Marcoulides, G. A., Gottfried, A. W., \& Oliver, P. H. (2009). A latent curve model of parental motivational practices and developmental decline in math and science academic intrinsic motivation. Journal of Educational Psychology, 101(3), 729-739.

Green, J., Martin, A. J., \& Marsh, H. W. (2007). Motivation and engagement in English, mathematics and science high school subjects: Towards an understanding of multidimensional domain specificity. Learning and Individual Differences, 17(3), 269-279.

Guvenc, H. (2015). The Relationship between Teachers' Motivational Support and Engagement versus Disaffection. Educational Sciences: Theory and Practice, 15(3), 647-657.

Haerens, L., Aelterman, N., Vansteenkiste, M., Soenens, B., \& Van Petegem, S. (2015). Do perceived autonomy-supportive and controlling teaching relate to physical education students' motivational experiences through unique pathways? 
distinguishing between the bright and dark side of motivation. Psychology of Sport and Exercise, 16, 26-36. doi:10.1016/j.psychsport.2014.08.013

Hakanen, J. J., Bakker, A. B., \& Schaufeli, W. B. (2006). Burnout and work engagement among teachers. Journal of School Psychology, 43(6), 495-513.

Henry, K. L., Knight, K. E., \& Thornberry, T. P. (2012). School disengagement as a predictor of dropout, delinquency, and problem substance use during adolescence and early adulthood. Journal of Youth and Adolescence, 41(2), 156-166.

Hesse-Biber, N., Leavy, P. (2011). The practice of qualitative research. Los Angeles, CA: Sage.

Hu, L. \& Bentler, P.M. (1999). Cutoff Criteria for Fit Indexes in Covariance Structure Analysis: conventional criteria versus new alternatives. Structural Equation Modeling, 6(1), 1-55.

Jackson, P. W. (1990). Life in classrooms. New York, NY: Teachers College Press.

Jang, H., Kim, E. J., \& Reeve, J. (2012). Longitudinal test of self-determination theory's motivation mediation model in a naturally occurring classroom context. Journal of Educational Psychology, 104(4), 1175-1188. doi:10.1037/a0028089

Jang, H., Kim, E. J., \& Reeve, J. (2016). Why students become more engaged or more disengaged during the semester: A self-determination theory dual-process model. Learning and Instruction, 43, 27-38.

Jang, H., Reeve, J., \& Deci, E. L. (2010). Engaging students in learning activities: It is not autonomy support or structure but autonomy support and structure. Journal of Educational Psychology, 102(3), 588-600. 
Juvonen, J., Le, V. N., Kaganoff, T., Augustine, C. H., \& Constant, L. (2004). Focus on the wonder years: Challenges facing the American middle school. Santa Monica, CA: Rand Corporation.

Kerr, M. M., Zigmond, N., Schaeffer, A. L., \& Brown, G. M. (1986). An observational follow-up study of successful and unsuccessful high school students. The High School Journal, 70(1), 20-24.

King, R. B. (2015). Sense of relatedness boosts engagement, achievement, and wellbeing: A latent growth model study. Contemporary Educational Psychology, 42, 26-38.

Kline, R.B. (2011). Principles and practice of Structural Equation Modeling. New York, NY: The Guilford Press.

Kyriacou, C. (2001). Teacher stress: Directions for future research. Educational Review, 53(1), 27-35. doi:10.1080/00131910120033628

Larson, R. W., \& Richards, M. H. (1991). Boredom in the middle school years: Blaming schools versus blaming students. American Journal of Education, 99(4), 418-443.

Lazarus, R.S. (2006) Emotions and Interpersonal Relationships: Toward a PersonCentered Conceptualization of Emotions and Coping. Journal of Personality, 74(1), $9-46$.

Little, R. J. (1988). A test of missing completely at random for multivariate data with missing values. Journal of the American Statistical Association, 83(404), 11981202. 
Lee, W., \& Reeve, J. (2012). Teachers' estimates of their students' motivation and engagement: Being in synch with students. Educational Psychology, 32(6), 727747.

Lumby, J. (2012). Disengaged and disaffected young people: Surviving the system. British Educational Research Journal, 38(2), 261-279.

Mac Iver, D. J., Young, E. M., \& Washburn, B. (2002). Instructional practices and motivation during middle school (with special attention to science). In A. Wigfield, \& J. S. Eccles (Eds.), Development of achievement motivation; development of achievement motivation (pp. 333-351, Chapter xvii, 366 Pages) Academic Press, San Diego, CA.

Markow, D., Macia, L., Lee, H. (2013). MetLife Survey of the American Teacher: Challenges for School Leadership. Retrieved from https://www.metlife.com/metlife-foundation/about/survey-americanteacher.html?WT.mc_id=vu1101

Martin, A. J. (2011). The motivation and engagement scale (11 ed). Syndey, NSW: Lifelong Achievement Group.

Martin, A. J., Anderson, J., Bobis, J., Way, J., \& Vellar, R. (2012). Switching on and switching off in mathematics: An ecological study of future intent and disengagement among middle school students. Journal of Educational Psychology, 104(1), 1-18.

Martin, A. J., Papworth, B., Ginns, P., Malmberg, L., Collie, R. J., \& Calvo, R. A. (2015). Real-time motivation and engagement during a month at school: Every 
moment of every day for every student matters. Learning and Individual Differences, 38, 26-35.

Martin, D. P., \& Rimm-Kaufman, S. E. (2015). Do student self-efficacy and teacherstudent interaction quality contribute to emotional and social engagement in fifth grade math?. Journal of School Psychology, 53(5), 359-373.

Martin, A. J., Way, J., Bobis, J., \& Anderson, J. (2015). Exploring the ups and downs of mathematics engagement in the middle years of school. The Journal of Early Adolescence, 35(2), 199-244.

Maslach, C., Schaufeli, W.B., Leiter, M.P. (2001). Job Burnout. Annual Reviews in Psychology, 52, 397-422.

McArdle, J. J., \& Grimm, K. J. (2010). Five steps in latent curve and latent change score modeling with longitudinal data. In Longitudinal research with latent variables (pp. 245-273). Springer Berlin Heidelberg.

Merrick, E. (1999). An exploration of quality in qualitative research: Are reliability and validity relevant? In M. Kopala \& L.A. Suzuki (Eds.), Using qualitative methods in psychology (pp. 25-36). Thousand Oaks, CA: Sage.

Midgley, C., Maehr, M. L., Hruda, L. Z., Anderman, E., Anderman, L., Freeman, K. E., \& Urdan, T. (2000). Manual for the patterns of adaptive learning scales. Ann Arbor: University of Michigan.

Morgan, D.L. (1998). Practical strategies for combining qualitative and quantitative methods: Applications to health research. Qualitative Health Research, 8, 362-376. 
Nardi, E., \& Steward, S. (2003). Is mathematics TIRED? A profile of quiet disaffection in the secondary mathematics classroom. British Educational Research Journal, 29(3), 345-366.

Nett, U. E., Goetz, T., \& Hall, N. C. (2011). Coping with boredom in school: An experience sampling perspective. Contemporary Educational Psychology, 36(1), 49-59.

Nizielski, S., Hallum, S., Schütz, A., \& Lopes, P. N. (2013). A note on emotion appraisal and burnout: The mediating role of antecedent-focused coping strategies. Journal of Occupational Health Psychology, 18(3), 363-369.

doi:http://dx.doi.org/10.1037/a0033043

Noddings, N. (2012). The caring relation in teaching. Oxford Review of Education, 38(6), $771-781$

Peklaj, C., Kalin, J., Pecjak, S., Zuljan, M. V., \& Levpuscek, M. P. (2012). Perceptions of teachers' goals in classroom, students' motivation and their maladaptive behavior as predictors of high school math achievement. Studia Psychologica, 54(4), 329.

Pekrun, R. (2017). Emotion and Achievement During Adolescence. Child Development Perspectives, 11(3), 215-221.

Pekrun, R. \& Buhner, M.. (2014). Self-report Measures of Academic Emotions. In R. Pekrun \& L. Linnenbrick-Garcia (Eds.), International handbook of emotions in education (pp. 561-579). New York, NY: Routledge.

Pekrun, R., Goetz, T., \& Frenzel, A. C. (2005). Achievement Emotions Questionnaire-Mathematics (AEQ-M) user's manual. Munich, Germany: 
University of Munich, Department of Psychology.

Pekrun, R., Goetz, T., Titz, W., \& Perry, R. P. (2002). Academic emotions in students' self-regulated learning and achievement: A program of qualitative and quantitative research. Educational Psychologist, 37(2), 91-105.

Pekrun, R., Lichtenfeld, S., Marsh, H. W., Murayama, K., \& Goetz, T. (2017). Achievement emotions and academic performance: Longitudinal models of reciprocal effects. Child Development, 88(5), 1653-1670.

Pianta, R. C., Hamre, B. K., \& Allen, J. P. (2012). Teacher-student relationships and engagement: Conceptualizing, measuring, and improving the capacity of classroom interactions. In Handbook of research on student engagement (pp. 365-386). New York: Springer.

Plenty, S., \& Heubeck, B. G. (2013). A multidimensional analysis of changes in mathematics motivation and engagement during high school. Educational Psychology, 33(1), 14-30.

Podsakoff, P. M., MacKenzie, S. B., Lee, J. Y., \& Podsakoff, N. P. (2003). Common method biases in behavioral research: a critical review of the literature and recommended remedies. Journal of Applied Psychology, 88(5), 879-903.

Poorthuis, A. M., Juvonen, J., Thomaes, S., Denissen, J. J., Orobio de Castro, B., \& Van Aken, M. A. (2015). Do grades shape students' school engagement? The psychological consequences of report card grades at the beginning of secondary school. Journal of Educational Psychology, 107(3), 842-854. 
Ravet, J. (2007). Making sense of disengagement in the primary classroom: A study of pupil, teacher and parent perceptions. Research Papers in Education, 22(3), 333362.

Ream R. K., \& Rumberger R. W. (2008). Student engagement, peer social capital, and school drop-out among Mexican American and non-Latino White students. Sociology of Education, 81, 109-139. doi:10.1177/003804070808100201

Reeve, J. (2009). Why teachers adopt a controlling motivating style toward students and how they can become more autonomy supportive. Educational Psychologist, 44(3), $159-175$.

Reeve, J. (2013). How students create motivationally supportive learning environments for themselves: The concept of agentic engagement. Journal of Educational Psychology, 105(3), 579-595.

Reeve, J., \& Jang, H. (2006). What teachers say and do to support students' autonomy during a learning activity. Journal of Educational Psychology, 98(1), 209-218. doi:10.1037/0022-0663.98.1.209

Reeve, J., Jang, H., Carrell, D., Jeon, S., \& Barch, J. (2004). Enhancing students' engagement by increasing teachers' autonomy support. Motivation and Emotion, 28(2), 147-169. doi:10.1023/B:MOEM.0000032312.95499.6f

Reisenzein, R., Junge, M., Studtmann, M., \& Huber, O. (2014). Observational Approaches to the Measurement of Emotions. In R. Pekrun \& L. LinnenbrickGarcia (Eds.), International handbook of emotions in education (pp. 580-606). New York, NY: Routledge. 
Reschly, A. L., \& Christenson, S. L. (2012). Jingle, jangle, and conceptual haziness: Evolution and future directions of the engagement construct. In Handbook of Research on Student Engagement (pp. 3-19). New York: Springer.

Richards, J. (2012, July). Teacher stress and coping strategies: A national snapshot. In The Educational Forum(Vol. 76, No. 3, pp. 299-316). Taylor \& Francis Group.

Riley, K., \& Docking, J. (2004). Voices of disaffected pupils: Implications for policy and practice. British Journal of Educational Studies, 52(2), 166-179.

Roeser, R. W., Eccles, J. S., \& Strobel, K. R. (1998). Linking the study of schooling and mental health: Selected issues and empirical illustrations. Educational Psychologist, 33(4), 153-176.

Rogat, T. K., Witham, S. A., \& Chinn, C. A. (2014). Teachers' autonomy relevant practices within an inquiry-based science curricular context: Extending the range of academically significant autonomy supportive practices. Teachers College Record, 116(7), 1-46.

Rumberger, R. W., \& Lim, S. A. (2008). Why students drop out of school: A review of 25 years of research (Vol. 15, pp. 1-130). California Dropout Research Project Report. Senko, C., \& Miles, K. M. (2008). Pursuing their own learning agenda: How masteryoriented students jeopardize their class performance. Contemporary Educational Psychology, 33(4), 561-583.

Shim, S. S., Cho, Y., \& Wang, C. (2013). Classroom goal structures, social achievement goals, and adjustment in middle school. Learning and Instruction, 23, 69-77. 
Singer, J.D. \& Willett, J.B. (2003). Applied longitudinal data analysis: Modeling change and event occurrence. New York: Oxford University Press.

Skilling, K., Bobis, J., Martin, A. J., Anderson, J., \& Way, J. (2016). What secondary teachers think and do about student engagement in mathematics. Mathematics Education Research Journal, 28(4), 545-566.

Skinner, E. A., \& Belmont, M. J. (1993). Motivation in the classroom: Reciprocal effects of teacher behavior and student engagement across the school year. Journal of Educational Psychology, 85(4), 571-581.

Skinner, E., Furrer, C., Marchand, G., \& Kindermann, T. (2008). Engagement and disaffection in the classroom: Part of a larger motivational dynamic?. Journal of Educational Psychology, 100(4), 765-781.

Skinner, E. A., Kindermann, T. A., \& Furrer, C. J. (2009). A motivational perspective on engagement and disaffection: Conceptualization and assessment of children's behavioral and emotional participation in academic activities in the classroom. Educational and Psychological Measurement, 69, 493-525.

Skinner, E. A., Pitzer, J. R., \& Steele, J. S. (2016). Can student engagement serve as a motivational resource for academic coping, persistence, and learning during late elementary and early middle school?. Developmental Psychology, 52(12), 20992117. doi:10.1037/dev0000232

Skinner, E. A., \& Wellborn, J. G. (1997). Children's coping in the academic domain. Handbook of children's coping: Linking theory and intervention. (pp. 387422). Plenum Press, New York, NY. 
Stake, R. E. (2006). Multiple case study analysis. New York, NY: Guilford Press.

Stark, P., \& Noel, A.M. (2015). Trends in High School Dropout and Completion Rates in the United States: 1972-2012 (NCES 2015-015). U.S. Department of Education. Washington, DC: National Center for Education Statistics. Retrieved from http://nces.ed.gov/pubsearch.

Sutton, R. E. (2004). Emotional regulation goals and strategies of teachers. Social Psychology of Education, 7(4), 379-398.

Swanson, J. M., Schuck, S., Porter, M. M., Carlson, C., Hartman, C. A., Sergeant, J. A., ... Wigal, T. (2012). Categorical and Dimensional Definitions and Evaluations of Symptoms of ADHD: History of the SNAP and the SWAN Rating Scales. The International Journal of Educational and Psychological Assessment, 10(1), 51-70.

Toshalis, E. (2015). Make me! Understanding and engaging student resistance in school. Cambridge, MA: Harvard Educational Press.

Tulis, M., \& Ainley, M. (2011). Interest, enjoyment and pride after failure experiences? Predictors of students' state-emotions after success and failure during learning in mathematics. Educational Psychology, 31(7), 779-807.

Tulis, M., \& Fulmer, S. M. (2013). Students' motivational and emotional experiences and their relationship to persistence during academic challenge in mathematics and reading. Learning and Individual Differences, 27, 35-46.

Vansteenkiste, M., Soenens, B., Van Petegem, S., \& Duriez, B. (2014). Longitudinal associations between adolescent perceived degree and style of parental prohibition and internalization and defiance. Developmental Psychology, 50(1), 229. 
doi:10.1037/a0032972

Vogel-Walcutt, J. J., Fiorella, L., Carper, T., \& Schatz, S. (2012). The definition, assessment, and mitigation of state boredom within educational settings: A comprehensive review. Educational Psychology Review, 24(1), 89-111.

Wallace, T. L., \& Sung, H. C. (2016). Student Perceptions of Autonomy-Supportive Instructional Interactions in the Middle Grades. The Journal of Experimental Education, 1-25. doi:10.1080/00220973.2016.1182885

Wallace, T. L., Sung, H. C., \& Williams, J. D. (2014). The defining features of teacher talk within autonomy-supportive classroom management. Teaching and Teacher Education, 42, 34-46. doi:10.1016/j.tate.2014.04.005

Wang, M., Chow, A., Hofkens, T., \& Salmela-Aro, K. (2015). The trajectories of student emotional engagement and school burnout with academic and psychological development: Findings from Finnish adolescents. Learning and Instruction, 36, $57-$ 65.

Way, S. M. (2011). School discipline and disruptive classroom behavior: The moderating effects of student perceptions. The Sociological Quarterly, 52(3), 346-375. doi:10.1111/j.1533- 8525.2011.01210.x

Wentzel, K. (2009). Students' relationships with teachers as motivation contexts. In K. Wentzel \& A. Wigfield (Eds.), Handbook of motivation in school (pp. 301-322). Mahwah, NJ: Erlbaum.

Wigfield, A., Byrnes, J. P., \& Eccles, J. S. (2006). Development during early and middle adolescence. Handbook of Educational Psychology, 2, 87-113. 
Wigfield, A., Eccles, J. S., Fredricks, J. A., Simpkins, S., Roeser, R. W., \& Schiefele, U. (2015). Development of achievement motivation and engagement. In R.M. Lerner \& M. Lamb (Eds.). Handbook of Child Psychology and Developmental Science (pp.657-691). New York: Wiley.

Yin, R.K. (2003). Case study research: design and methods. Thousand Oaks, CA: Sage Publications.

Yoshikawa, H., Weisner, T. S., Kalil, A., \& Way, N. (2008). Mixing qualitative and quantitative research in developmental science: uses and methodological choices. Developmental Psychology, 44(2), 344-354.

doi: $10.1037 / 0012-1649.44 .2 .344$ 


\section{Appendix A: Study 1 - Item by Construct Tables.}

\section{Table A1}

Student-reported Selection Variables Student disaffection (SR).

\begin{tabular}{ll}
\hline Behavioral Disaffection & I can't wait for class to be over. \\
& I don't try very hard in this class. \\
& When I'm in class, I think about other things. \\
& When I don't understand something, I just give \\
& up. \\
Emotional Disaffection & I feel worried about how I'm doing in this class. \\
& The work in this class frustrates me. \\
& I don't see the point of anything we are learning \\
in this class.
\end{tabular}




\section{Appendix B: Study 2 Item by Construct Tables.}

Table B1

Student-report of student disaffection items

\section{Student Disaffection (SR)}

Behavioral Disaffection I don't try very hard in science.*

When a class is too much work, I just don't do it.*

When I get behind in my homework, I just give up.

In school, I don't work very hard.*

If a class is really hard, I'll probably do badly in it.

Emotional Disaffection When we work on science, I feel bored.

When we work on something in class, I feel bored.*

I can't stand doing school work.*

I really don't care about school

Note. Items marked with an * were included in the SR disaffection scale for the classroom dynamics model.

Table B2

Teacher-report of student disaffection items

\section{Student Disaffection (TR)}

Behavioral Disaffection In my class, this student refuses to do anything.

When faced with setbacks, this student gives up.

Emotional Disaffection In my class, this student does not really care.

When faced with setbacks, this student acts like school

doesn't matter.

Table B3

Student-report of student-teacher relationships items

\section{Student-teacher relationships (SR)}

Involvement/Withdrawal My teachers just don't understand me. (-)

I can't really count on my teachers. (-)

Autonomy support/

Controlling behavior
My teachers explain why the things I learn in school are important.

The rules at this school are so unfair. (-)

People here are always telling me what to do. (-) 